\title{
Frequency Response of Synthetic Vocal Fold Models with Linear and Nonlinear Material Properties
}

Stephanie M. Shaw

Brigham Young University - Provo

Follow this and additional works at: https://scholarsarchive.byu.edu/etd

Part of the Communication Sciences and Disorders Commons

\section{BYU ScholarsArchive Citation}

Shaw, Stephanie M., "Frequency Response of Synthetic Vocal Fold Models with Linear and Nonlinear Material Properties" (2010). Theses and Dissertations. 2433.

https://scholarsarchive.byu.edu/etd/2433

This Thesis is brought to you for free and open access by BYU ScholarsArchive. It has been accepted for inclusion in Theses and Dissertations by an authorized administrator of BYU ScholarsArchive. For more information, please contact scholarsarchive@byu.edu, ellen_amatangelo@byu.edu. 
Frequency Response of Synthetic Vocal Fold Models with

Linear and Nonlinear Material Properties

Stephanie M. Shaw

A thesis submitted to the faculty of

Brigham Young University

in partial fulfillment of the requirements for the degree of

Master of Science

Christopher Dromey, Chair

Scott L. Thomson

Shawn L. Nissen

Department of Communication Disorders

Brigham Young University

August 2010

Copyright (c) 2010 Stephanie Shaw

All Rights Reserved 


\author{
ABSTRACT \\ Frequency Response of Synthetic Vocal Fold Models with \\ Linear and Nonlinear Material Properties
}

Stephanie M. Shaw

Department of Communication Disorders

Master of Science

Previous studies have shown the importance of cricothyroid muscle activation in altering fundamental frequency in the human voice. Other studies have investigated the non-linear properties of vocal fold tissue and the impact of this non-linearity on frequency response. Several physical models of the vocal folds have been made for research purposes. However, all have been isotropic in nature with linear stress-strain properties. The purpose of this study was to create a physical model with non-linear stress-strain properties to investigate the frequency response of the model as cricothyroid muscle activation was simulated (in other words, as the vocal folds were stretched in an anterior-posterior dimension).

In this study the physical models of the vocal folds were stretched in $1 \mathrm{~mm}$ increments and the fundamental frequency $\left(\mathrm{F}_{0}\right)$ was recorded at each position. Subglottal pressure was also monitored and phonation threshold pressures were recorded for each adjustment in length and vocal fold tension, because this can influence $\mathrm{F}_{0}$. Results were obtained for models with and without non-linear properties for comparison. Tensile tests were also conducted for the linear and non-linear synthetic vocal folds.

Results indicate that non-linear models demonstrated a more substantial frequency response than linear vocal fold models and a more predictable $\mathrm{F}_{0}$ increase with respect to increasing vocal fold length. Phonation threshold pressures also increased with increasing vocal fold length for non-linear vocal fold models. This trend was reversed for linear vocal fold models, with phonation threshold pressures decreasing with increasing vocal fold length. These results indicate that the non-linear vocal fold models more accurately represent the human vocal folds than do linear models. This study serves as the foundation for future research to quantify the impact of non-linear tissue properties versus active tensioning (through antagonistic thyroarytenoid muscle activation) on $\mathrm{F}_{0}$ response and phonation threshold pressure.

Keywords: vocal folds, nonlinear, linear, voice, synthetic 


\section{ACKNOWLEDGMENTS}

There are countless individuals who have helped and supported me while I have worked to complete this research and thesis write-up. First and foremost, I must thank my thesis chair, Dr. Dromey, for all of the time and effort he has put into helping me edit my thesis and for his encouragement, support, and patience throughout this process. I would also like to thank Dr. Thomson for all of his support throughout the research stages of this project and for allowing me to become a part of his research team. I also express my gratitude to Dr. Nissen for his willingness to serve as a committee member and for his input, especially during the editing stages of this process.

I would be remiss if I did not specifically thank Simeon Smith for the innumerable hours he has dedicated to helping me with my research and for encouraging me to find joy in the journey, even in the face of what seemed like insurmountable obstacles.

I express my gratitude as well to my friends and family who have always been behind me and who have provided me with much-needed encouragement. I especially thank my parents. I know I would not be where I am today without their wisdom, love, and continued support. 


\section{Table of Contents}

Page

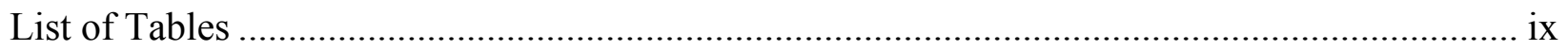

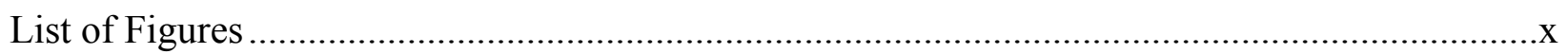

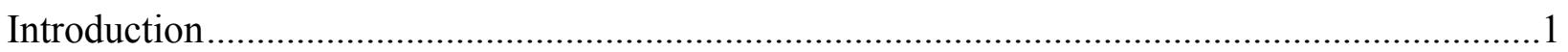

Definition of Acoustical Parameters …...................................................................... 1

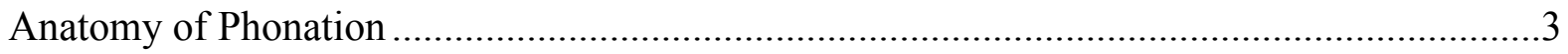

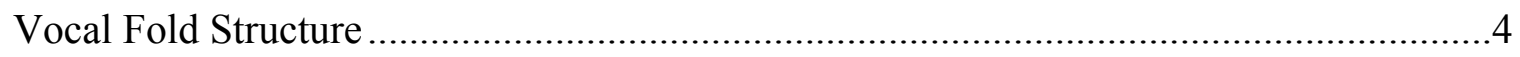

Stress-Strain Properties of the Vocal Folds ..........................................................

Mechanics of Phonation.......................................................................................... 12

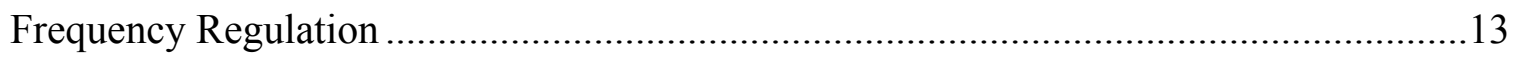

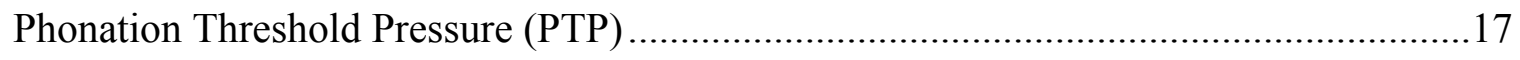

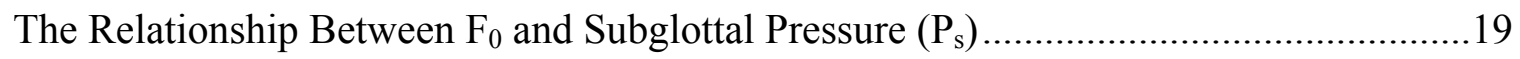

History of Modeling Human Vocal Physiology .................................................................24

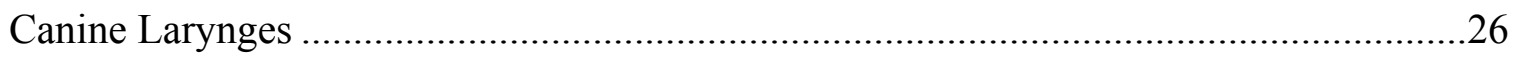

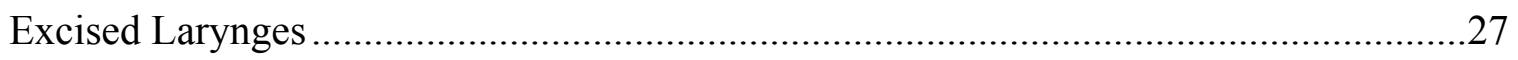

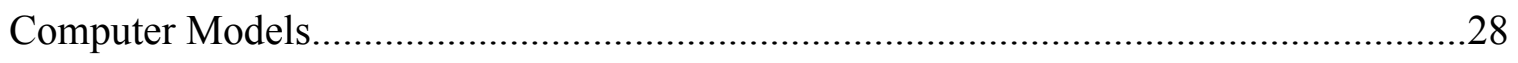

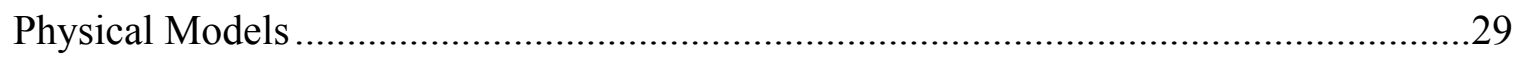

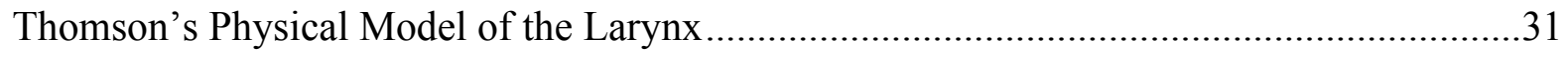

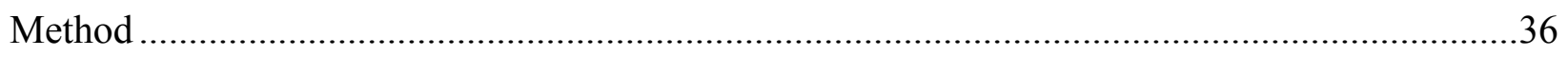

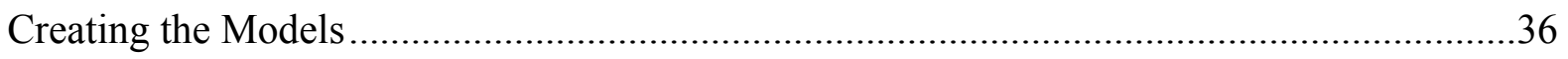

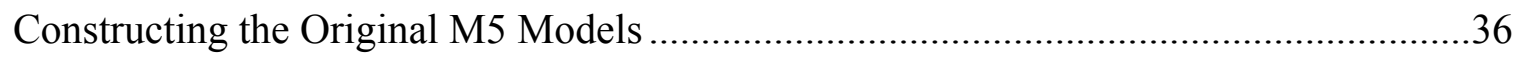

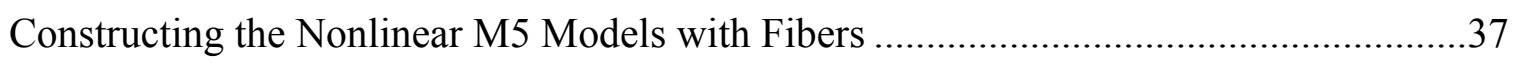

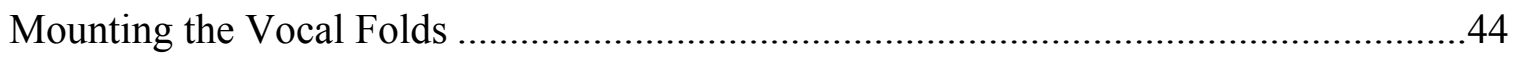


viii

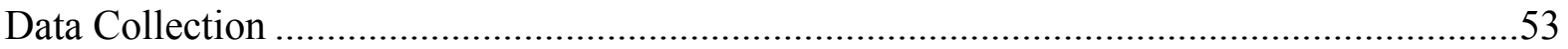

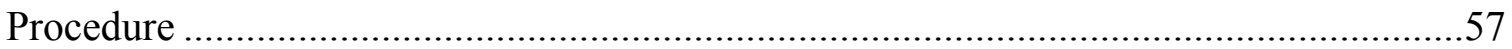

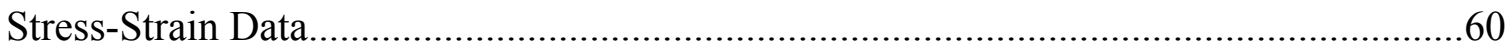

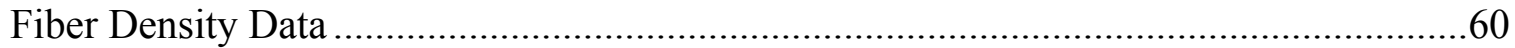

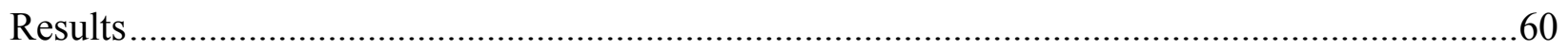

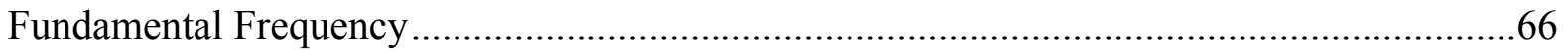

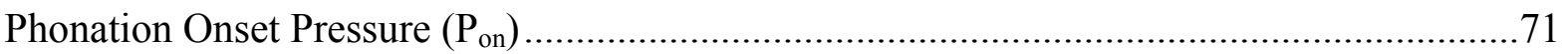

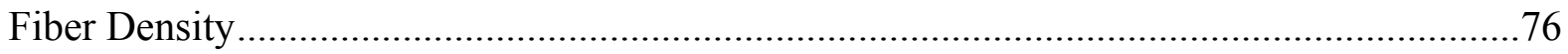

Changes in Frequency as a Result of Slight Changes in Subglottal Pressure...........................78

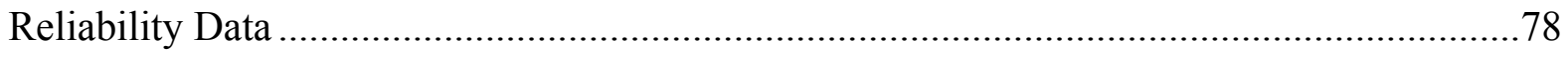

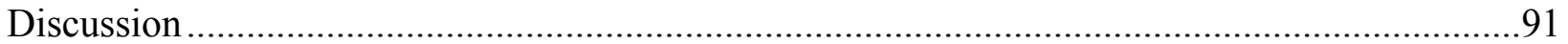

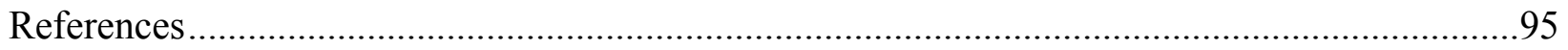




\section{List of Tables}

Table

Page

1. Fundamental Frequency $\left(\mathrm{F}_{0}\right)$ at Onset Pressure $\left(\mathrm{P}_{\text {on }}\right)$ and $\mathrm{P}_{\text {on }}+0.20 \mathrm{kPa}$ for Normal Models \#1, 2, and 3

2. Fundamental Frequency $\left(\mathrm{F}_{0}\right)$ at Onset Pressure $\left(\mathrm{P}_{\text {on }}\right)$ and $\mathrm{P}_{\text {on }}+0.20 \mathrm{kPa}$ for Fiber Models \#1, 2, and 3

3. Onset Pressures $\left(\mathrm{P}_{\text {on }}\right)$ for Normal Models \#1, 2, and 3 .....

4. Onset Pressures $\left(\mathrm{P}_{\text {on }}\right)$ for Fiber Models \#1, 2, and 3...............................................74

5. Number of acrylic fibers present in each Fiber model...... 


\section{List of Figures}

Figure $\quad$ Page

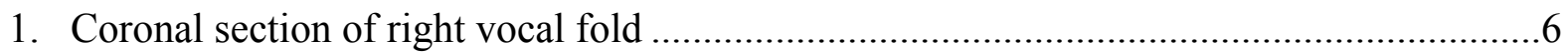

2. Layers of vocal fold tissue showing varying densities of elastin and collagen fibers .........7

3. Stress-strain curves for the human vocal folds ............................................................. 10

4. PTP values as a function of pitch.........................................................................2

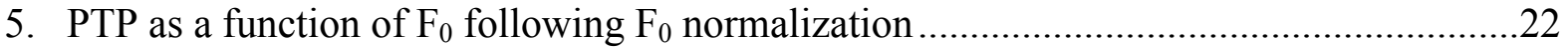

6. Fundamental frequency vs. subglottal pressure for excised canine larynges .................23

7. The relationship between $\mathrm{F}_{0}$ and PTP across four separate studies ............................25

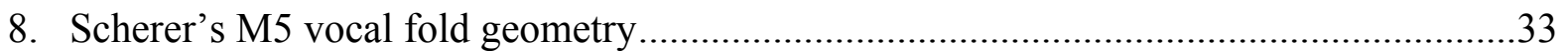

9. Molds used to create two-layered physical model of the vocal folds .............................34

10. Layout for microscope slides used to construct fiber layers .........................................38

11. Double-sided tape placement for fiber layer construction............................................39

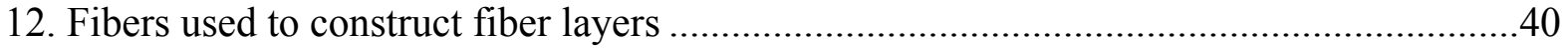

13. Actual construction of fiber layers..................................................................... 41

14. Constructed fiber layers still housed within the microscope slides .............................42

15. Fiber layers divided and prepared for construction ..................................................45

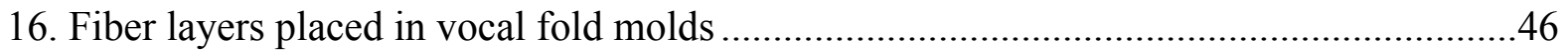

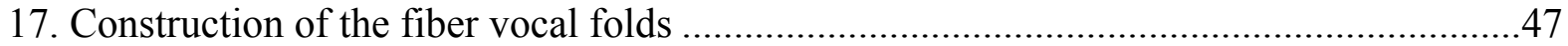

18. Design and layout for two-plate tensioning system ..................................................48

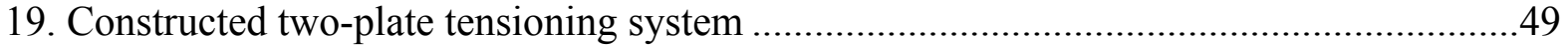

20. Diagram of each corner plate used in the four-plate tensioning system ..........................50

21. Constructed four-plate tensioning system............................................................

22. Fiber vocal folds mounted in four-plate tensioning system .......................................52 
23. Schematic showing set-up of air supply .54

24. Four-plate tensioning system mounted to air supply .55

25. Set-up and positioning for high speed and digital video cameras . .56

26. High-speed images taken during testing from a normal vocal fold model . .58

27. High-speed images taken during testing from a fiber vocal fold model.........................59

28. Stress-strain properties for normal silicone vocal fold models...................................61

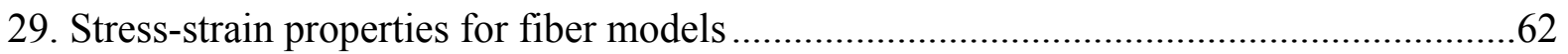

30. Set-up used to count acrylic fibers in each nonlinear fiber model................................63

31. Medial surfaces of an individual fiber vocal fold after being sliced..............................64

32. Magnified image showing individual acrylic fibers ..............................................65

33. Fundamental frequency $\left(\mathrm{F}_{0}\right)$ vs. extension for normal vocal fold models .......................68

34. Fundamental frequency $\left(\mathrm{F}_{0}\right)$ vs. extension for nonlinear vocal fold models ...................70

35. Onset pressure vs. extension for normal models ................................................... 73

36. Onset pressure vs. extension for fiber models ..................................................... 75

37. $\mathrm{F}_{0}$ response with respect to subglottal pressure for Normal Model \#1 ...........................79

38. $\mathrm{F}_{0}$ response with respect to subglottal pressure for Normal Model \#2 ...........................80

39. $\mathrm{F}_{0}$ response with respect to subglottal pressure for Normal Model \#3 ...........................81

40. $\mathrm{F}_{0}$ response with respect to subglottal pressure for Fiber Model \#1 ..............................82

41. $\mathrm{F}_{0}$ response with respect to subglottal pressure for Fiber Model \#2 ...............................83

42. $\mathrm{F}_{0}$ response with respect to subglottal pressure for Fiber Model \#3 ...............................84

43. Retest Reliability - Normal Model \#1 ............................................................. 85

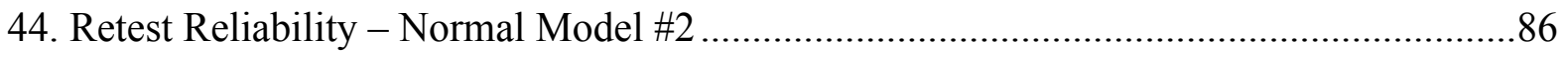

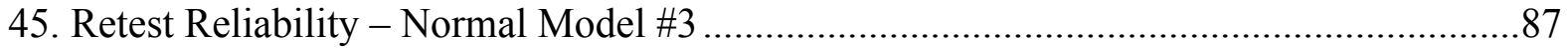


xii

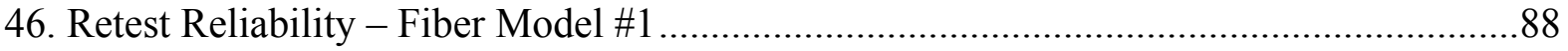

47. Retest Reliability - Fiber Model \#2 _...........................................................................89

48. Retest Reliability - Fiber Model \#3 .....................................................................90 


\section{Introduction}

Even after decades of research into the human voice, there are still significant gaps in our understanding of the physiology of phonation. The purpose of this study is to help fill in some of those gaps by investigating and quantifying the relationship between changes in vocal fold length, fundamental frequency, and phonation threshold pressure using a physical model of the human vocal folds. The role of collagen and elastin fibers within the deeper layers of the lamina propria, especially with regard to increasing fundamental frequency, has only recently received attention within the field of vocal fold research. The results of the present study will add to the existing research by giving us important, quantitative information which can increase our understanding of the physiology of phonation, particularly with respect to fundamental frequency adjustment and phonation threshold pressure. In addition, this research will assist in the development of more realistic synthetic vocal fold models which can then, in turn, be used to further research in this area.

\section{Definition of Acoustical Parameters}

In studies involving phonation, it is important to first have a basic understanding of acoustics and how sound is created, analyzed, perceived, and understood. In the most basic sense, sounds are the result of some form of mechanical vibration. When any object is set in motion, air molecules surrounding the object are in turn set in motion. This movement of air molecules results in a wave of air molecule vibration, or in other words a sound wave, which travels outward from the source. To better analyze and describe sound waves, various terms and parameters are used to define their properties. Each of these properties determines how the sound is perceived by a human listener (Martin, 2006; Strong \& Plitnik, 1992; Zemlin, 1998).

One such parameter used in analyzing and describing sound waves is frequency, which denotes how many vibrations occur per second and is measured in Hertz $(1 \mathrm{Hertz}=1$ 
cycle/second). Frequency is perceived by the human ear as pitch. Sounds with higher frequencies are perceived as having a higher pitch while lower frequency sounds are perceived as having a lower pitch. Some sound waves contain only one frequency (a sinusoidal wave); however, most sounds we hear are made up of multiple frequencies in combination, which together form a complex sound wave. Some complex sounds are periodic in nature, meaning that the frequency pattern repeats itself in a predictable way over a certain time interval (period). Others are non-periodic or aperiodic, meaning there is no predictable or discernable pattern of repetition (Martin, 2006; Strong \& Plitnik, 1992; Zemlin, 1998).

Several terms are used in literature to describe the frequency components that make up complex sound waves. One of these terms is partial, which refers to each sinusoid or frequency component that makes up a complex sound wave. The lowest-frequency sinusoid or partial is referred to as the fundamental frequency. All additional partials fall into two categories: harmonic and inharmonic. Harmonic partials are integer multiples of the fundamental frequency. Any partials that do not fit this category are considered inharmonic. Periodic (or nearly periodic) sound waves generally contain harmonic partials, whereas nonperiodic or aperiodic sounds contain many inharmonic partials (Martin, 2006; Strong \& Plitnik, 1992; Zemlin, 1998).

A second parameter that is essential in describing and analyzing sound waves is amplitude or intensity. Intensity is determined by the amount of sound energy per unit of area and is largely related to pressure. The human ear perceives changes in intensity or pressure as changes in loudness. As sound waves travel and spread outward from the source, the pressure of the wave decreases, as does the intensity of the sound and therefore the perceived loudness of that sound to a human listener. Intensity of sound is most often expressed in decibels (dB), a 
logarithmic scale created for the purpose of expressing intensity of sound in manageable units (Martin, 2006; Strong \& Plitnik, 1992; Zemlin, 1998).

In order to create sound waves, energy is required — at least enough energy to set a given object or vibrator in motion. In some instances, a vibrator is supplied with a short burst of energy which initiates motion or oscillation. The vibrator is then left alone and the amplitude of vibration gradually decays or dies out at whatever rate naturally occurs (based on the object's physical properties). This is considered a free vibration. An example of free vibration would be plucking a guitar string. In other instances, a vibrator is continuously supplied with energy and the oscillation of the object is maintained. This is what is referred to as driven vibration, or selfsustained vibration. The human voice, being continuously supplied with energy in the form of a steady flow of air from the lungs, would be classified as a self- sustained vibrator. In either case, with both free and driven vibrators, a certain amount of force is required, dependent upon the properties of the vibrator, to set the object in motion and to initiate vibration. For the human voice, this minimum force is referred to as the phonation threshold pressure and occurs when lung pressure is sufficient to initiate vocal fold vibration (Martin, 2006; Strong \& Plitnik, 1992; Zemlin, 1998). Each of these acoustic and aerodynamic concepts-frequency, intensity, periodicity, and threshold pressure - will allow us to better understand the human larynx and phonation.

\section{Anatomy of Phonation}

In the human larynx, many muscles and other anatomic structures must work together to create sound. The vocal folds are the structures that vibrate and modulate airflow from the lungs, thereby producing the sound source for speech. Muscles within the larynx, pharynx, neck, and face provide a speaker with the ability to alter the position and tension of the vocal folds and to 
shape the vocal tract, thus allowing a speaker to adjust voicing and resonance. This degree of flexibility gives the human voice a wide range of possible frequencies, amplitudes, and qualities. Some of the most notable structures of the larynx include the thyroid cartilage, the cricoid cartilage, the epiglottis, the paired arytenoid cartilages, the paired corniculate cartilages, and the paired cuneiform cartilages. Several intrinsic laryngeal muscles are used to control phonation by positioning and shaping the vocal folds. In this study, the structure of the vocal folds themselves and the impact of cricothyroid (CT) muscle activation are of primary interest because they are involved in the regulation of the fundamental frequency of the voice (Case, 2002; Zemlin, 1998). Therefore, the anatomical review that follows will focus on these structures.

Vocal fold structure. In studying the human voice, it is important to start with a solid understanding of the vocal folds themselves. There are two true vocal folds made up of several different non-contractile tissue layers and muscles. The most superficial layers of each of these folds are made up of the epithelium and lamina propria, which will be described in more detail below.

The thyroarytenoid (TA) muscles. Just deep to the lamina propria tissues are the TA muscles - so named because of their points of attachment to both the thyroid and arytenoid cartilages. These muscles constitute the main mass of the vocal folds. Each TA muscle can be subdivided into two separate halves: the thyrovocalis and the thyromuscularis. The vocalis muscle fibers run superficial to those of the thyromuscularis, which is located just inferior and lateral to the vocalis muscle. Together, the thyrovocalis and thyromuscularis are responsible for regulating longitudinal tension within the vocal folds. When acting alone with no other intrinsic muscles activated, the TA muscle shortens and relaxes the vocal folds. This shortening of the 
vocal folds can result in some vocal fold bulging, and can actually alter the shape of the vocal folds themselves (Case, 2002; Zemlin, 1998).

The cricothyroid (CT) muscle. The CT muscle links the thyroid and cricoid cartilages anteriorly and is responsible for adjusting the position of the thyroid cartilage relative to the cricoid cartilage. This cartilage movement causes the vocal folds to lengthen, thereby increasing their tension and thus, fundamental frequency. Because of this role in controlling the length of the vocal folds, the CT muscle is considered the primary pitch-changer of the human voice (Case, 2002; Zemlin, 1998). Therefore, the CT muscle and its effect on human phonation will be of most interest in the present study. However, to say that CT muscle is the only muscle that contributes to pitch changes would be an oversimplification. To be more precise, contraction of the CT muscle is generally opposed by the TA muscles (described above). This antagonistic relationship results in an even greater and more significant increase in the longitudinal tension within the vocal folds than could be achieved by the CT muscle acting alone (Case, 2002; Titze, 1994; Zemlin, 1998).

The tissue layers. Aside from this underlying muscle structure, the vocal folds are made up of four additional tissue layers, for a total of five layers in each vocal fold (See Figure 1). The most superficial of the tissue layers is the epithelium. This layer is made up of squamous epithelial cells and acts as a capsule, helping to maintain the shape of the vocal folds by containing the softer, more fluid-like tissue below. It is between 0.05 and $0.10 \mathrm{~mm}$ thick (Case, 2002; Titze, 1994; Zemlin, 1998).

Just deep to the epithelial layer are the three layers of the lamina propria, which are nonmuscular (see Figure 2). The first of these is the superficial layer of the lamina propria, which is made of loose elastin fibers interspersed with a few collagen fibers and surrounded by 


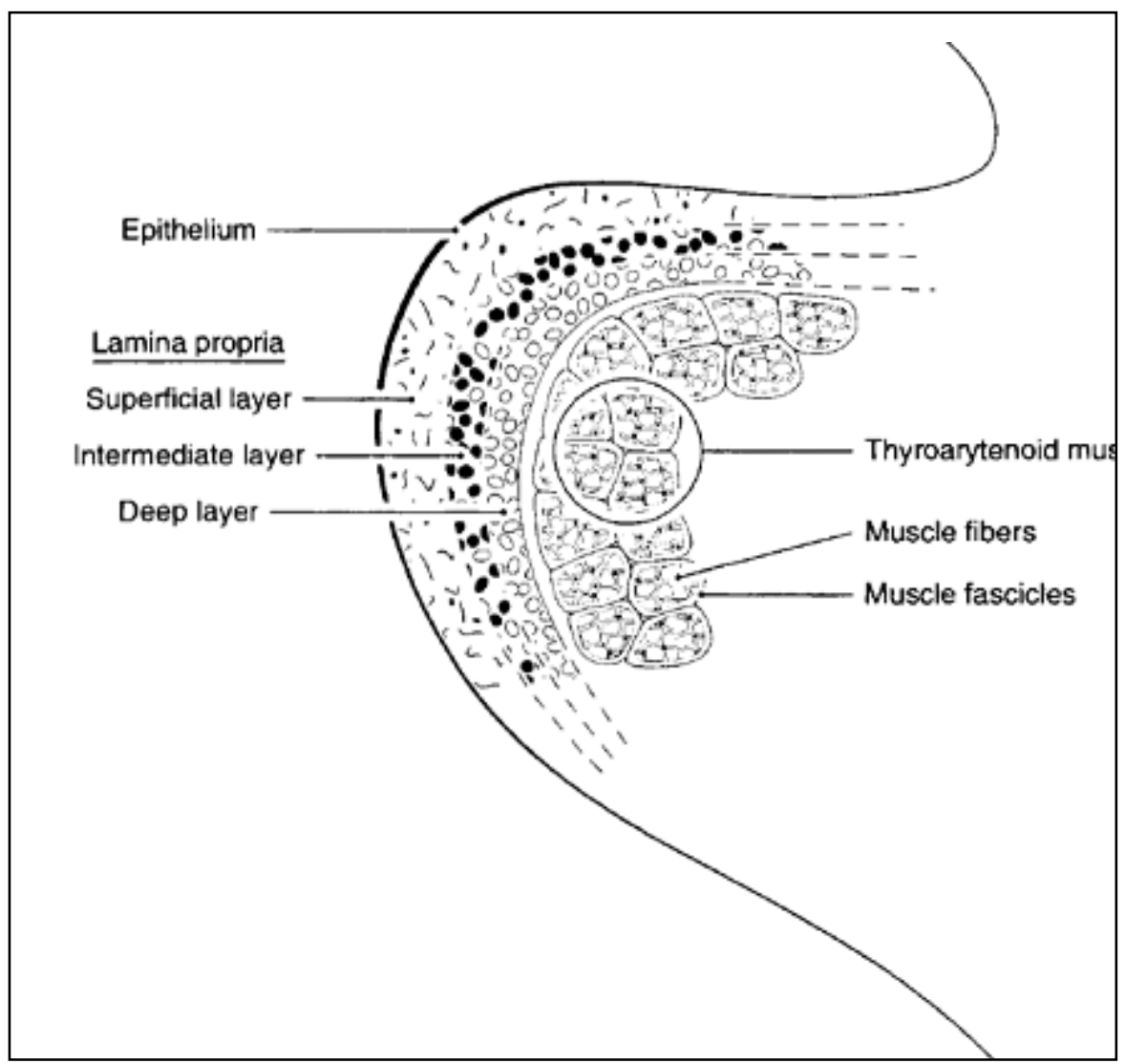

Figure 1. Coronal section through the right vocal fold, showing the five tissue layers. From Titze, I. R. (1994). Principles of voice production. Englewood Cliffs, N.J.: Prentice Hall, p. 17. Used with permission of the author. 


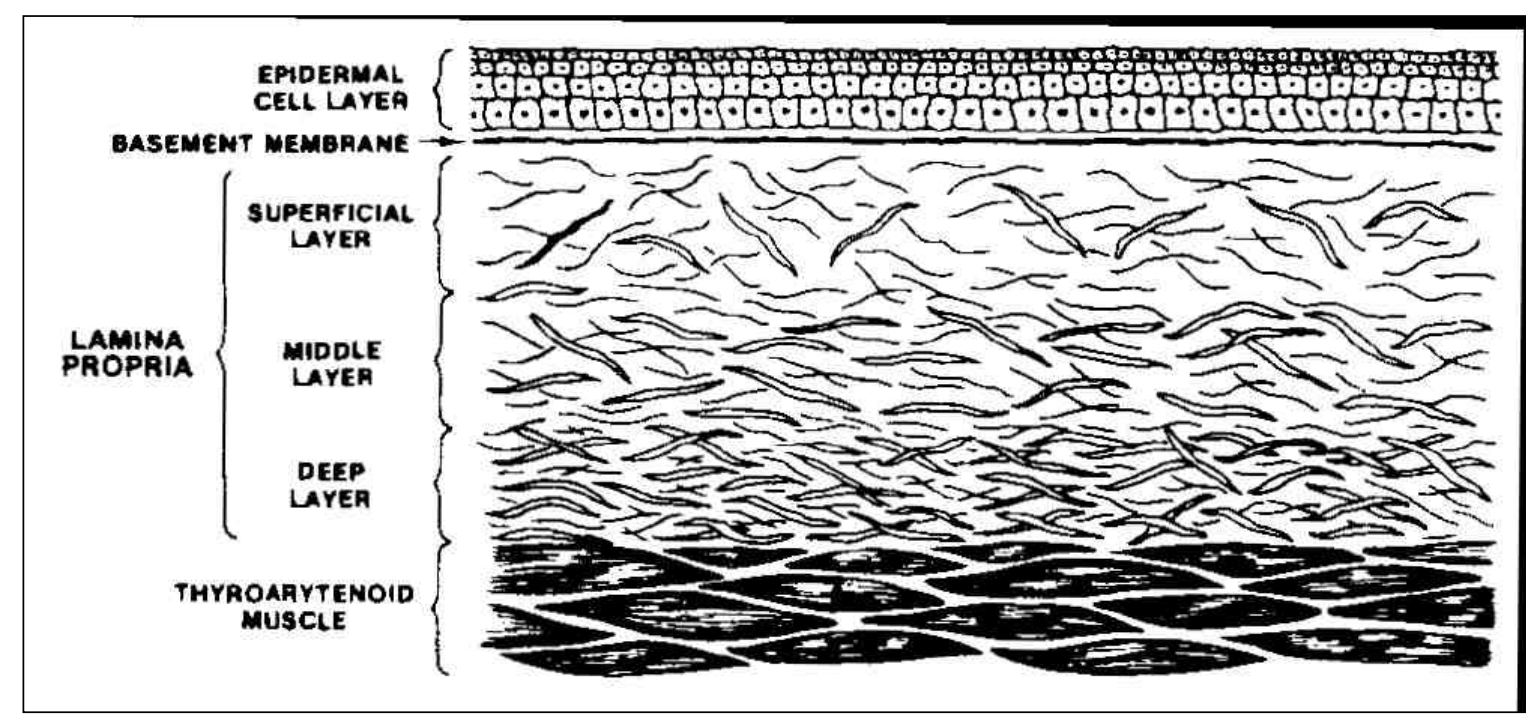

Figure 2. Layers of vocal fold tissue showing varying densities of elastin and collagen fibers. Note the prevalence of elastin fibers (shown as a thin, wavy line) in the middle/intermediate layer of the lamina propria and the increased density of collagen fibers in the deep layer. From Gray, S. D., Alipour, F., Titze, I. R., \& Hammond, T. H. (2000). Biomechanical and histologic observations of vocal fold fibrous proteins. Annals of Otology, Rhinology, \& Laryngology, 109(1), p. 77. Used with permission of the publisher. 
interstitial fluids. A special type of protein structure found within the elastin fibers gives it the ability to stretch and elongate. This soft tissue layer, similar to gelatin in consistency, is approximately 0.5 mm thick (Case, 2002; Gray, Alipour, Titze, \& Hammond, 2000; Titze, 1994; Zemlin, 1998).

Next is the intermediate layer of the lamina propria, which consists of elastin fibers arranged in an anterior-posterior direction. These elastin fibers are interspersed with collagen fibers, giving this layer a consistency similar to a "bundle of soft rubber bands" (Zemlin, 1998, p. 129). Just deep to this layer is the deep layer of the lamina propria which is made up of mainly collagenous fibers. These collagen fibers contain protein structures which, unlike elastin fibers, limit elongation. They are therefore similar in consistency to a bundle of cotton thread (and about as inextensible). Together, the intermediate and deep layers of the lamina propria measure about 1 to $2 \mathrm{~mm}$ in thickness (Case, 2002; Gray et al., 2000; Titze, 1994; Zemlin, 1998).

The last layer, just deep to the lamina propria, is the TA muscle. This muscle tissue, as noted above, makes up the main mass of the vocal folds and has the consistency of a stiff bundle of rubber bands. It measures approximately 7 to $8 \mathrm{~mm}$ in thickness (Case, 2002; Titze, 1994; Zemlin, 1998).

Cover-body classification. From a mechanical standpoint, Hirano reclassified the tissue layers into three categories: cover, transition (also known as the vocal ligament), and body. The cover, according to this classification, consists of the epithelium and superficial layer of the lamina propria; the transition consists of the intermediate and deep layers of the lamina propria; and the body consists of the vocalis muscle. The cover and transition (in other words, the four most superficial layers) are controlled passively, while the body is controlled passively and actively. Looking at the vocal folds from this standpoint allows one to divide the layers by 
mechanical rather than biological or histological properties. This is helpful because mechanical properties are more easily observed than histological properties. For example, the structural integrity of an individual's vocal folds can be assessed by observing individual cycles of vocal fold vibration (using an endoscope with stroboscopic lighting). The vocal folds should demonstrate a marked mucosal wave during voicing which travels across the upper surface of the vocal folds and dissipates just before it reaches the thyroid cartilage. This mucosal wave is a mechanical property unique to the human vocal folds and is clinically relevant because it is one indicator that the vocal fold tissue is healthy. In addition, the mucosal wave gives a unique sound quality to the human voice (Jiang et al., 2000). If the vocal fold tissue is damaged, this mucosal wave may be affected or in some cases even be absent (Hirano \& Kakita, 1985; Zemlin, 1998).

Stress-strain properties of the vocal folds. Two other mechanical properties that are representative of structural or histological properties of vocal fold tissues are stress and strain. Before discussing the relevance of these properties, it is first important to understand the concepts of stress and strain. Stress is a term used to describe how much force must be applied to a substance to produce a physical change (e.g., a change in length). Strain is used to describe the extent of the deformation that results from the application of the stressing force, or how much the length has changed. For some homogeneous materials (having the same mechanical properties throughout), stress-strain curves are linear, or nearly linear, in nature due to the uniformity and consistency of properties throughout the object or model. However, for the human vocal folds, the stress-strain curve is far from linear, even if TA muscle activation is removed from the equation (See Figure 3). The reason for this can be found by looking more closely at the histological and mechanical differences between the five tissue layers of the human 


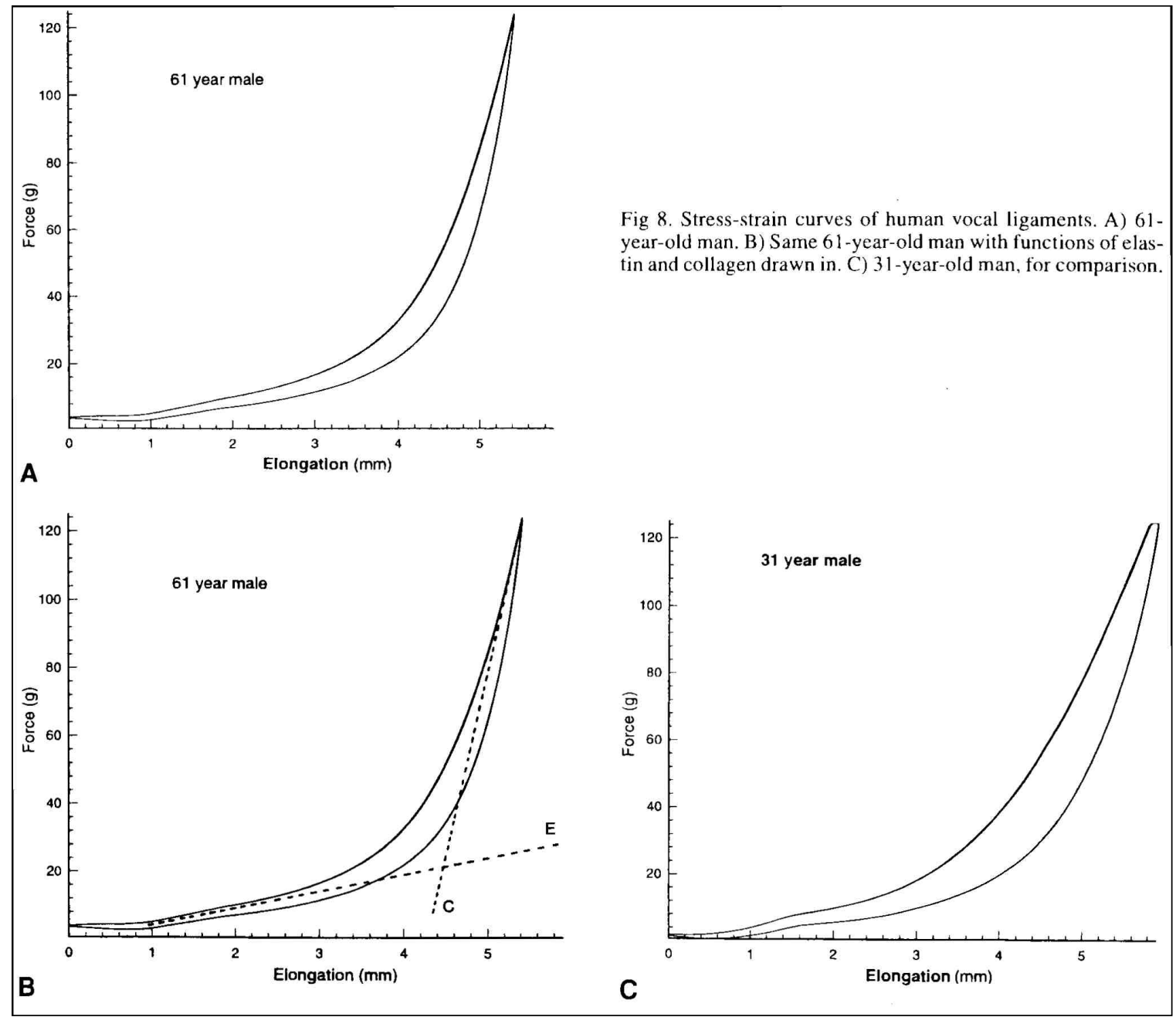

Figure 3. Stress-strain curves for the human vocal folds with functions of elastin (E) and collagen (C) drawn in for comparison. From Gray, S. D., Alipour, F., Titze, I. R., \& Hammond, T. H. (2000). Biomechanical and histologic observations of vocal fold fibrous proteins. Annals of Otology, Rhinology, \& Laryngology, 109(1), p. 83. Used with permission of the publisher. 
vocal folds, especially the three layers of the lamina propria (Gray et al., 2000; Hirano \& Kakita, 1985)

As previously described, each of the layers of the lamina propria consists of different proteins, some fibrous and some interstitial. Interstitial proteins are important in controlling water content and tissue viscosity. Fibrous proteins on the other hand, namely elastin and collagen, are designed to handle stress and help control the vocal fold's shape (Gray et al., 2000; Gray, Hirano, \& Sato, 1993; Hirano \& Kakita, 1985).

The superficial layer of the lamina propria consists mostly of loose tissue with few collagen and elastin fibers, giving it a high viscosity and allowing for a higher strain, or change in length, for a given amount of stress. The intermediate layer contains a greater proportion of elastin fibers, giving this layer more structure than the superficial layer while still retaining a high level of elasticity or strain. Gray quantified this elasticity further, indicating that elastin fibers can be stretched approximately two times their length and return back to their original length after the stress is removed (Gray et al., 2000; Gray et al., 1993; Hirano \& Kakita, 1985). The deep layer of the lamina propria, like the intermediate layer, contains some elastin fibers. However, it also contains a higher proportion of collagen fibers. Unlike elastin fibers, collagen fibers have little elasticity. Instead, they provide the vocal folds with strength and bear increasing levels of stress with less deformation than elastin fibers (Gray et al., 2000; Gray et al., 1993; Hirano \& Kakita, 1985)

In examining the stress-strain curve for the human vocal fold (Figure 3), one can see that the early part of the curve resembles closely the performance of elastin fibers. After approximately $30 \%$ of strain has occurred, the curve takes a notable slope upwards. Following 
this transition, or break-point, the curve closely resembles the stress-strain curve for collagen fibers (Gray et al., 2000; Gray et al., 1993; Hirano \& Kakita, 1985).

This stress-strain curve is very important for understanding how frequency changes occur in the human voice. For normal, everyday speaking, the more easily deformed elastin fibers dominate the majority of pitch changes which occur in the human voice. However, the contribution of the collagen fibers is essential for achieving higher pitches (used most often in singing) as they allow for large increases in stiffness for even the slightest adjustments in vocal fold length (Gray et al., 2000; Gray et al., 1993; Hirano \& Kakita, 1985). In the words of Steven Gray, "Now it is apparent why the stress-strain curve is so relevant to vocal production. It is critical that we easily generate high levels of tissue stress without much increase in length. This ability to easily generate high levels of tissue stress is a product of the collagenous part of the vocal ligament and is the main mechanism of providing humans with a large dynamic pitch range" $(2000$, p. 84$)$.

\section{Mechanics of Phonation}

Since the mid $20^{\text {th }}$ century, two main theories have been proposed to explain the physiology of phonation. The first of these is called the neurochronaxic theory. Introduced in the 1950s by a French physiologist by the name of Husson, this theory states that vibration of the vocal folds during voicing is the result of individual neural firings or impulses, which cause rapid and repeated adductions and abductions of the vocal folds. These impulses are sent from the cerebrum to the TA muscles via the recurrent laryngeal nerve, a branch of Cranial Nerve $\mathrm{X}$. The TA muscles then respond to these impulses with rhythmic medial contractions. According to Husson's theory, the air column passing through the glottis acts solely as an amplifier for these 
active vibrations of the vocal folds. Frequency, he believed, is controlled by the frequency or rate of neural firings originating from the cerebrum (Case, 2002; Rubin, 1960a, 1960b).

While Husson did find some initial success in supporting his claims with scientific evidence, numerous studies conducted in the 1960s disproved his neurochronaxic theory in support of the myoelastic-aerodynamic theory of phonation (Rubin, 1960b). This theory, which has been extensively supported by research evidence, is accepted today as the most accurate explanation of vocal fold vibration. Initially proposed by Mueller in 1848, Van den Berg helped bring the theory back into favor in 1958 (following the short-lived success of the neurochronaxic theory) through his extensive research on the nature of vocal fold vibration.

According to the myoelastic-aerodynamic theory, vocal fold vibration is passive in nature, occurring in response to airflow from the lungs and subglottic pressure built up below the vocal folds. The vocal folds are adducted through contraction of intrinsic laryngeal muscles, namely the lateral cricoarytenoid (LCA) and transverse arytenoid muscles. Subglottic pressure builds up below the folds until it reaches a pressure great enough to overcome their stiffness and inertia, at which point the vocal folds are blown apart. Elastic forces within the folds help pull them back together, closing off the airway and beginning the process over again. In addition to elastic forces, pressure in the constricted portion of the glottis is lowered due to Bernoulli effect as the air rushes past the folds. This pressure may become negative and assist in pulling the vocal folds back to midline. Once the vocal folds return to their closed position, this process starts over again, resulting in repetitive pattern of vibration, which continues as long as there is airflow from the lungs (Case, 2002; Lieberman, 1968; Rubin, 1960b; Titze, 1980).

Frequency regulation. According to the myoelastic-aerodynamic theory of phonation, several factors come into play in determining the fundamental frequency of the voice. These 
include the length, mass, and tension of the folds. In general, as length and/or mass increase, fundamental frequency decreases. On the other hand, as tension within the folds increases, fundamental frequency increases (Case, 2002; Strong \& Plitnik, 1992; Titze, 1994).

The length of the human vocal folds changes significantly during childhood and adolescence. At birth, human vocal folds measure about 2.5 to $3 \mathrm{~mm}$ in length. By 1 year of age, the vocal folds have increased in length to about $5.5 \mathrm{~mm}$. Vocal fold length continues to increase at a steady, comparable rate for males and females until about age ten, at which time the male vocal folds go through rapid growth, increasing to approximately 17 to $20 \mathrm{~mm}$ in length after puberty. Female vocal folds also grow during puberty but continue at about the same rate as they did during childhood. Postpubertal length for female vocal folds is about 12.5 to $17 \mathrm{~mm}$, which corresponds to an increase of about $4 \mathrm{~mm}$ during puberty (Case, 2002; Hirano, Kurita, \& Nakashima, 1981; Zemlin, 1998).

These changes in vocal fold length have a significant impact on voice fundamental frequency. A baby's first cry can range in frequency from about $400 \mathrm{~Hz}$ to $800 \mathrm{~Hz}$ (typically averaging closer to $400 \mathrm{~Hz}$ ). As the child grows and the vocal folds begin to lengthen, the fundamental frequency begins to decrease. Wilson's 1979 book entitled, Voice Disorders in Children (as cited in Zemlin, 1998), reported average fundamental frequencies for both males and females between the ages of 7 and 11. Both genders had an average fundamental frequency of about $295 \mathrm{~Hz}$ at the age of 7 . By the ages of ten and eleven, a gap had begun to develop, with an average fundamental frequency of $265 \mathrm{~Hz}$ for females (age 11) and $235 \mathrm{~Hz}$ for males (age 10). This finding would be consistent with the pubertal changes in vocal fold length described above. Additional studies have investigated average total growth of male and female vocal folds. These studies have found that the vocal folds increase in length by $11.57 \mathrm{~mm}$ in males over a 
lifetime (a 63\% growth rate) and only by about $4.16 \mathrm{~mm}$ (a 34\% growth rate) in females (Case, 2002). These differences in length for adult female and adult male vocal folds underlie a significant difference in fundamental frequency, with adult males averaging $125 \mathrm{~Hz}$ and adult females averaging $210 \mathrm{~Hz}$ (Case, 2002; Zemlin, 1998).

These changes in vocal fold length for both males and females are also accompanied by changes in total mass of the vocal folds. This is especially noticeable in the male larynx because the rapid increase in vocal fold length, which occurs during puberty on the scale of about $10 \mathrm{~mm}$, co-occurs with a significant thickening of the vocal folds and therefore an increase in mass. These increases in mass and length of the male vocal folds during puberty result in a fundamental frequency drop equal to about one full octave (Case, 2002; Seikel, King, \& Drumright, 2005; Zemlin, 1998).

A third factor that significantly influences the fundamental frequency of vibration is vocal fold tension. As with a guitar or a piano string, increasing tension within the string results in an increase in frequency. Similarly, an increase in tension within the vocal folds results in an increase in the fundamental frequency of vibration. The CT muscle links the thyroid and cricoid cartilages and is responsible for adjusting the position of the thyroid cartilage relative to the cricoid cartilage. When the CT muscle contracts, the thyroid cartilage to which the vocal folds are attached tilts anteriorly, causing the vocal folds to stretch, increasing the tension within the folds (Case, 2002; Lofqvist, Baer, McGarr, \& Story, 1989; Titze, 1994; Zemlin, 1998). Often this CT muscle contraction is accompanied by TA activation. Simultaneous contraction of the $\mathrm{CT}$ and TA muscles generates isometric tension, giving even more control and range to adjustments in fundamental frequency (Case, 2002). 
The differing concentrations of elastin and collagen fibers throughout the three layers of the lamina propria have a significant impact on the level of tension within the vocal folds when stress is applied. For initial alterations in vocal fold length, high amounts of strain, or changes in vocal fold length which result from the stress being applied, occur for a given amount of stress, and tension increases little by little. However, after the level of strain passes the break-point (at approximately $30 \%$ strain), even slight adjustments in vocal fold length result in significant increases in tension within the vocal folds. This is due to the presence of collagen fibers which are more involved beyond this break-point and help resist further strain (Gray et al., 2000; Gray et al., 1993; Hirano \& Kakita, 1985).

It is easier to understand the effects of changing length, mass, and tension when each occurs independently. However, it is more difficult when they occur simultaneously, which is most often the case. For instance, CT muscle activation results in a stretching of the vocal folds. In isolation, increasing the length of a vibrator is associated with a decrease in fundamental frequency. However, this stretching of the vocal folds also increases tension, which is associated with an increase in frequency. The cumulative result is an increase in fundamental frequency, because the increase in tension is more influential than the increase in length.

Another factor to consider is that the effective mass of the vocal folds, or the portion that is actually vibrating, changes as length increases. While the actual mass of an object cannot change without adding or removing material, the mass of the vocal folds can be rearranged as the vocal folds are lengthened. As the vocal folds are stretched, the cross-sectional mass, or linear mass density, decreases, resulting in an increase in fundamental frequency. This principle is especially noticeable when a male singer uses a falsetto voice. During this process, tension within the vocal folds is so high that the lateral portions of the vocal folds are immobilized. This 
reduces the effective mass to just the free edges of the vocal folds, or the vocal ligament. Since the effective mass in this example has been significantly reduced, the fundamental frequency increases in accordance with the laws of physics, in this case by as much as a few octaves (Case, 2002; Lieberman, 1968; Seikel et al., 2005; Titze, 1994). The opposite is also true. As the vocal folds are shortened and relaxed through posterior tilting of the thyroid cartilage, the effective mass or linear mass density of the vocal folds increases, resulting in a decrease in fundamental frequency (Titze, 1994; Zemlin, 1998).

Phonation threshold pressure (PTP). Closely connected to the frequency of vibration of human vocal folds is what is referred to as phonation threshold pressure or PTP. PTP has been defined as "the minimum lung pressure required to initiate phonation" (Titze, 1992, p. 2926). Another article defined this term from a more practical viewpoint, indicating that is was a "measure of the 'ease' of phonation" and suggesting that it could be diagnostically useful in determining vocal health (Titze, Schmidt, \& Titze, 1995, p. 3080). Some research studies have also used the terms $\mathrm{P}_{\text {on }}$ and $\mathrm{P}_{\text {off. }}$. These terms are often preferred when studying PTP, especially with excised larynges or models where parameters can be more closely controlled, since the pressure required to initiate phonation is often higher than the pressure required to sustain phonation once it has been initiated (Plant, Freed, \& Plant, 2004; Titze et al., 1995). Subglottal pressure $\left(\mathrm{P}_{\mathrm{s}}\right)$ is another term frequently used. This refers to the pressure used during phonation in a more general sense (not necessarily the pressure required to initiate or maintain phonation).

Studies have been conducted to determine the impact of various physiologic parameters on PTP. In two separate studies, vocal fold hydration, and therefore, tissue viscosity, were found to have a significant impact on PTP, with decreased hydration resulting in higher PTP and increased hydration in lower PTP (Finkelhor, Titze, \& Durham, 1988; Verdolini-Marston, Titze, 
\& Druker, 1990). Another study found that vocal fold thickness had a significant impact, with thinner vocal folds always requiring a higher PTP (Chan, Titze, \& Titze, 1997). Zhang (2009) also found that PTP increased with increasing stiffness in either the body or cover layers. Because fundamental frequency is so closely related to vocal fold thickness and stiffness of the body and cover layers, additional studies have been done to investigate the relationship between fundamental frequency and PTP. It was found that changes in fundamental frequency had the most significant impact on PTP out of all of the parameters tested (most likely due to the factors previously mentioned), which also included intensity, closure speed of the vocal folds, and laryngeal airway resistance (Plant et al., 2004).

The reason for the association between fundamental frequency and PTP is that both are closely related to the tension within the vocal folds. Increasing fundamental frequency requires an increase in the tension of the vocal folds, which in turn increases the glottal resistance to airflow. In order for airflow to continue when there is increased tension, the pressure below the vocal folds must increase. In this way, the increase in $\mathrm{P}_{\mathrm{s}}$ could be considered a response to the increase in tension and fundamental frequency (Seikel et al., 2005; Zemlin, 1998). However, an increase in $\mathrm{P}_{\mathrm{s}}$ can also result in slight increases in $\mathrm{F}_{0}$, as has been evidenced in a number of previous research studies (Hsiao, Liu, Luschei, \& Titze, 2001; Titze, 1989)

Direct measurements of PTP and $\mathrm{P}_{\text {on }}$ are currently limited due to several research-related challenges. One such challenge is that the human vocal folds are relatively small and inaccessible while in vivo, making them difficult to view directly (Dollinger \& Berry, 2006). Also individual parameters which affect PTP and regular phonation are difficult to control. This is especially true with studies involving human speakers because muscles cannot be isolated or controlled individually (Chan et al., 1997). 
However, some studies have succeeded in computing estimates of PTP to use as a reference for typical vocal function. In 1992 Titze measured PTP for excised canine larynges and found the values to vary from $0.3-0.8 \mathrm{kPa}$ (or kilopascal, a unit used to measure pressure), depending on tissue freshness. In another study, $\mathrm{P}_{\text {on }}$ in particular was estimated from a physical model of the vocal folds and found to be in the range of 0.13 to $0.34 \mathrm{kPa}$, depending on the fluid viscosity of the mucosa (Chan et al., 1997). A study conducted on excised human larynges found the minimum pressure at which phonation could be initiated $\left(\mathrm{P}_{\text {on }}\right)$ to be $3 \mathrm{~cm} \mathrm{H}_{2} \mathrm{O}$, which is equivalent to $0.29 \mathrm{kPa}$; phonation could, however, be sustained as pressure was reduced to approximately $2 \mathrm{~cm} \mathrm{H}_{2} \mathrm{O}$, which is equivalent to $0.2 \mathrm{kPa}$ (Baer, 1981). A study conducted on in vivo canine larynges reported $\mathrm{P}_{\mathrm{s}}$ to vary from approximately 0.55 to $3.72 \mathrm{kPa}$, a range which the researchers suggest, "is quite typical for human phonation under soft and very loud conditions" (Hsiao et al., 2001).

The relationship between $F_{0}$ and subglottal pressure $\left(\mathbf{P}_{\mathbf{s}}\right)$. Several studies have been undertaken to try to quantify the relationship between subglottal pressure $\left(\mathrm{P}_{\mathrm{s}}\right)$ and fundamental frequency. One such study, conducted by Solomon, Ramanathan, and Makashay (2007) focused specifically on quantifying PTP as a function of fundamental frequency. This research was conducted using 8 speakers, all with untrained voices. Participants were instructed to produce their quietest phonation at 10 different pitches by repeating the syllable /pi/ seven times. Pitches were presented in random order. Pressure was measured using a transducer attached to a facemask. Measurements were estimates of PTP, rather than direct measurements, and were based on the intraoral air pressure recorded during /p/ occlusion. Results were charted and compared with previously published theoretical models (see Figure 4 and 5 for charted results from this study). Results indicated that, on the whole, PTP increased exponentially with 
fundamental frequency. However, a few speakers demonstrated the lowest PTPs at a comfortable pitch (still relatively low), and slightly higher PTPs at frequencies below that pitch (Solomon et al., 2007).

Another study conducted in 1989 by Ingo Titze used excised human larynges to investigate the relationship between fundamental frequency changes resulting from increased vocal fold length and slight adjustments in fundamental frequency resulting from $P_{s}$ changes. In this study, Titze altered vocal fold length in 1-mm increments using micromanipulators attached to an aluminum framework. A stroboscopic light source was used to illuminate vocal fold motion and the images were recorded and analyzed. Fundamental frequency was measured by direct digital recording on the strobe light and was verified through an electroglottographic signal. The relationships between $\mathrm{P}_{\mathrm{s}}$, fundamental frequency changes, and vocal fold length changes were then calculated and graphed (see Figure 6). For changes in vocal fold length $(\Delta \mathrm{L})$ of $-3 \mathrm{~mm}$, the change in fundamental frequency with respect to the change in $\mathrm{P}_{\mathrm{s}}\left(\Delta \mathrm{F}_{0} / \Delta \mathrm{P}_{\mathrm{s}}\right)$ was calculated to be $5.28 \mathrm{~Hz} / \mathrm{cm} \mathrm{H}_{2} 0$. For $\Delta \mathrm{L}=+3 \mathrm{~mm}, \Delta \mathrm{F}_{0} / \Delta \mathrm{P}_{\mathrm{s}}$ was calculated to be 0.54 $\mathrm{Hz} / \mathrm{cm} \mathrm{H}_{2} 0$. As is evidenced by this study, $\mathrm{P}_{\mathrm{s}}$ changes can in fact influence fundamental frequency of vibration, especially as vocal fold length decreases.

In 2001, Hsiao, Liu, Luschei and Titze conducted a study that used in vivo canine larynges to investigate the relationship between fundamental frequency changes (through activation of the $\mathrm{CT}$ muscle) and $\mathrm{P}_{\mathrm{s}}$ changes. In this study, TA muscle activation remained constant using deep brain stimulation to keep the muscle activated. The CT muscle was then stimulated directly using probes and varying amounts of electric current. For three separate 


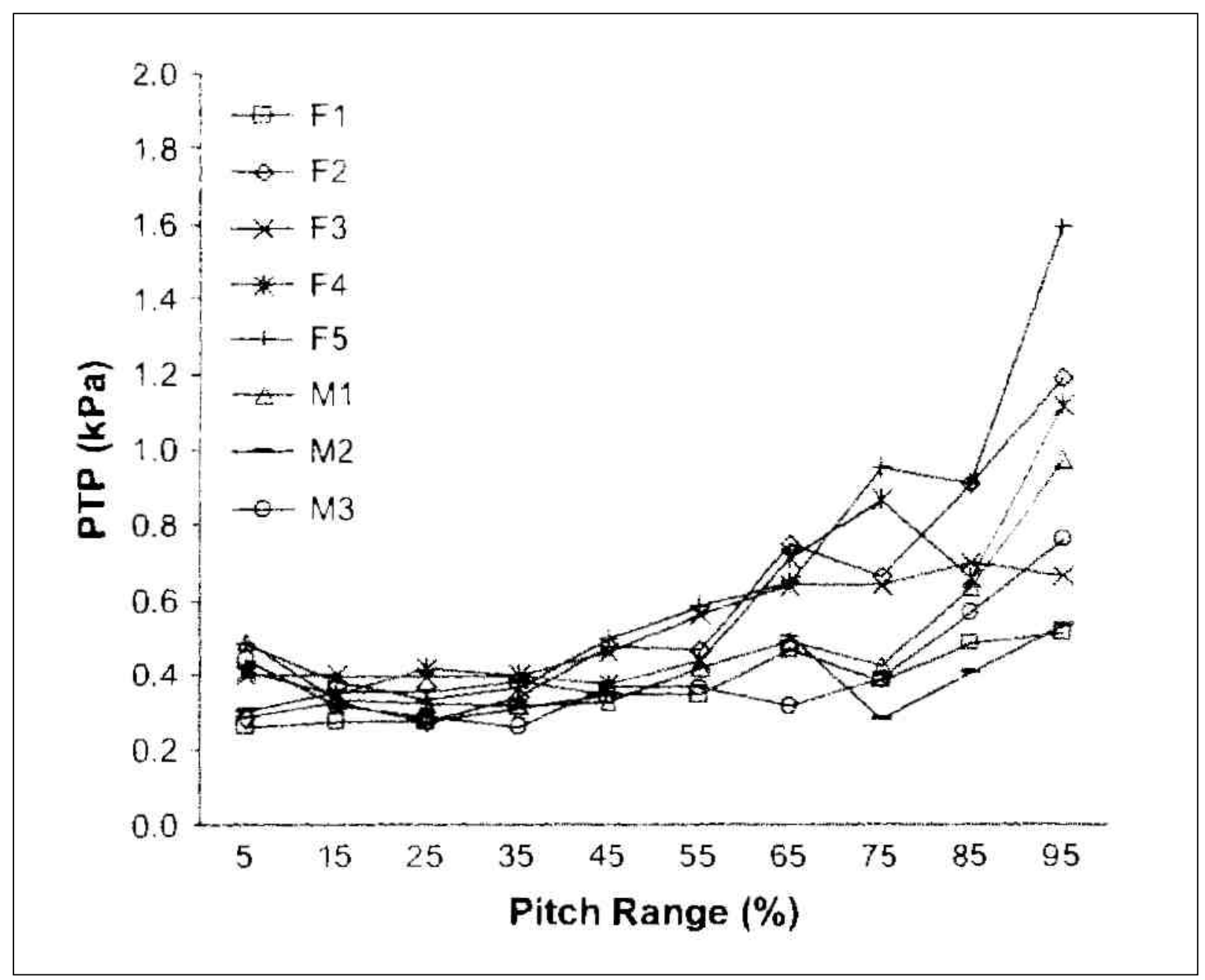

Figure 4. Chart representing PTP values as a function of pitch for each subject used in research study at targeted pitch levels. Reprinted from Journal of Voice, Vol. 21(5), Solomon, N. P., Ramanathan, P., \& Makashay, M. J., Phonation threshold pressure across pitch and range: Preliminary test of a model, p. 545, Copyright 2007, with permission from Elsevier. 


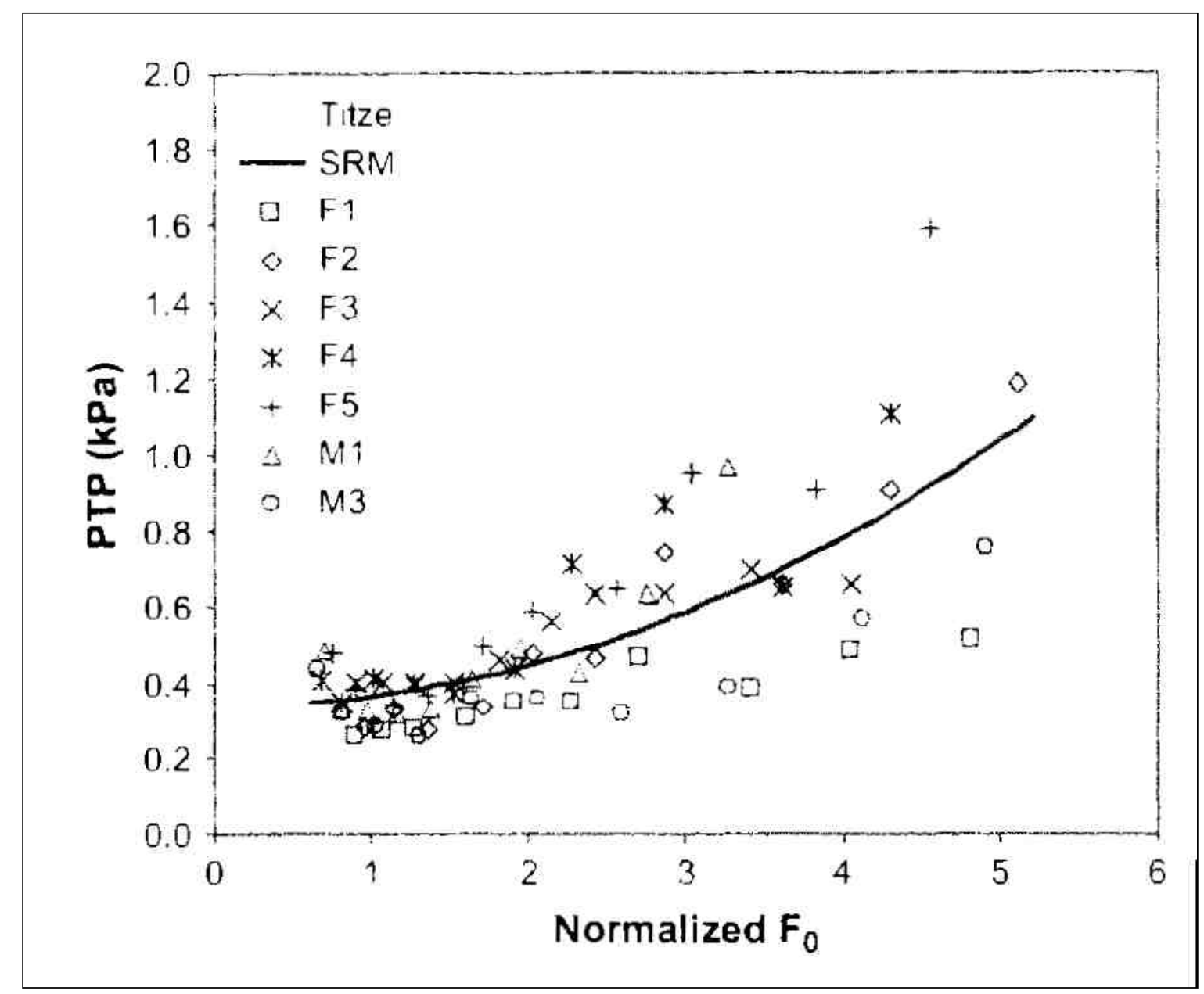

Figure 5. Graph representing PTP as a function of $\mathrm{F}_{0}$ following $\mathrm{F}_{0}$ normalization. Data points were normalized by dividing by $120 \mathrm{~Hz}$ for men (average $\mathrm{F}_{0}$ for men) and $205 \mathrm{~Hz}$ for women (average $\mathrm{F}_{0}$ for women). Notice the slight rise in PTP with the lowest $\mathrm{F}_{0}$ data points. Also notice the general rise in PTP with increasing $\mathrm{F}_{0}$. Reprinted from Journal of Voice, Vol. 21(5), Solomon, N. P., Ramanathan, P., \& Makashay, M. J., Phonation threshold pressure across pitch and range: Preliminary test of a model, p. 545, Copyright 2007, with permission from Elsevier. 


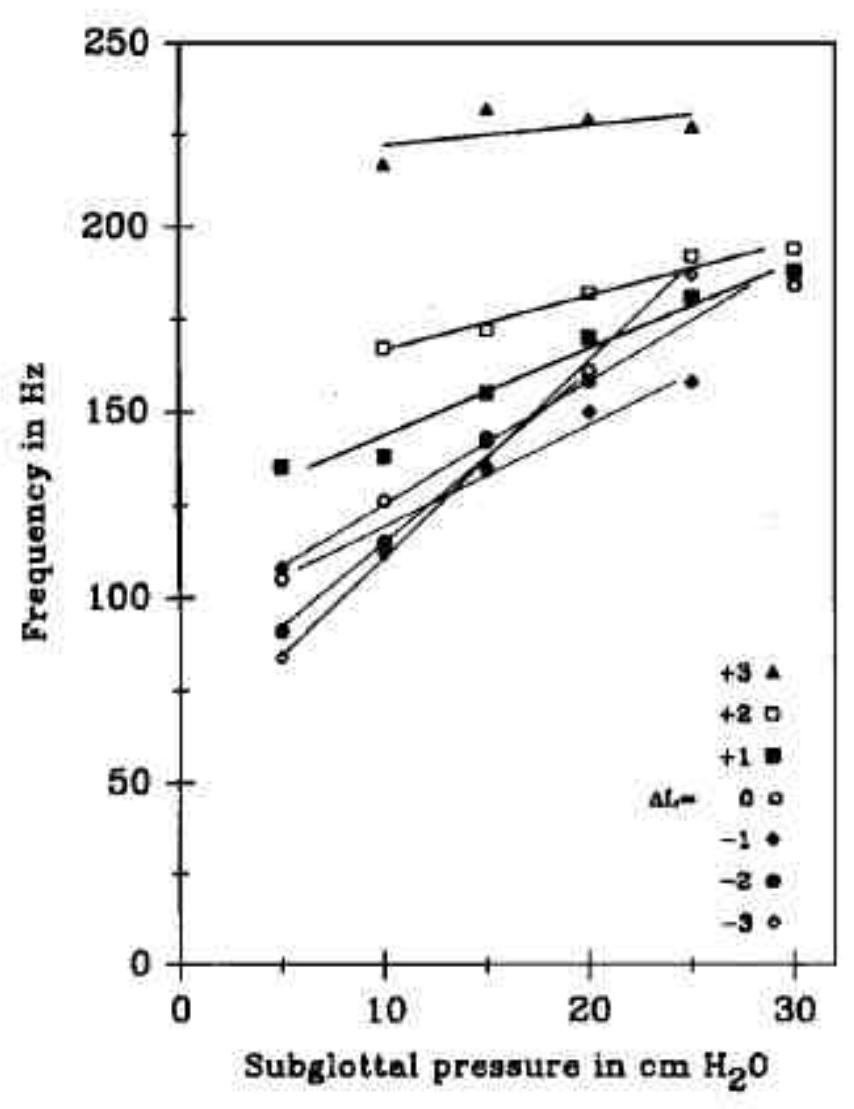

FIG. 6. Fundumental frequency as a function of subglottal pressure for sev. en elongations. Measurements were obtained from excised canine larynges and represent averages over no less than 4 larynges and no more than 11 larynges; $\Delta L$ is in $\mathrm{mm}$.

Figure 6. Graph representing the relationship between fundamental frequency and subglottal pressure for several vocal fold lengths using excised canine larynges. Reprinted with permission from Titze, I. R., On the relation between subglottal pressure and fundamental frequency in phonation. Journal of the Acoustical Society of America, 85(2),p. 905. Copyright 1989, Acoustical Society of America. 
degrees of current and muscle activation, pressure was increased in $0.1 \mathrm{kPa}$ increments from the lowest and highest pressures which could sustain phonation. Frequency data was also obtained. The relationship between the driving pressure $\left(\mathrm{P}_{\mathrm{s}}\right)$ and fundamental frequency $\left(\mathrm{F}_{0}\right)$ was then determined by generating $\mathrm{P}_{\mathrm{s}}-\mathrm{F}_{0}$ slopes. Results from this study indicated that the fundamental frequency of vibration depended less on the amplitude of vibration (and therefore, $\mathrm{P}_{\mathrm{s}}$ ) as the vocal folds increased in length and tension.

In Titze (1992), research was conducted to determine the relationship between PTP and F0. Titze used data from four previous studies (Cleveland \& Sundberg, 1988; Finkelhor et al., 1988; Gramming, 1988; Verdolini-Marston et al., 1990) involving human subjects and excised canine larynges. These studies found similar trends, with PTP increasing for increasing F0 (see Figure 7).

\section{History of Modeling Human Vocal Physiology}

Researchers in many disciplines have recognized the value of using models in studying a variety of phenomena. In the field of vocal physiology, the use of models is particularly important because of the inaccessibility of live human vocal folds for experimentation and direct measurement, and because of the inability of human speakers to voluntarily control individual muscles and muscle groups, thus making it nearly impossible to experimentally control all of the relevant variables (van den Berg, 1968). The use of models in vocal fold research can be advantageous in that they allow researchers to control and evaluate the specific contribution of each parameter to the final output of the system. In the study of voice, canine larynges, excised human larynges, computer models, and physical models have allowed important insights into the physiology of phonation. 


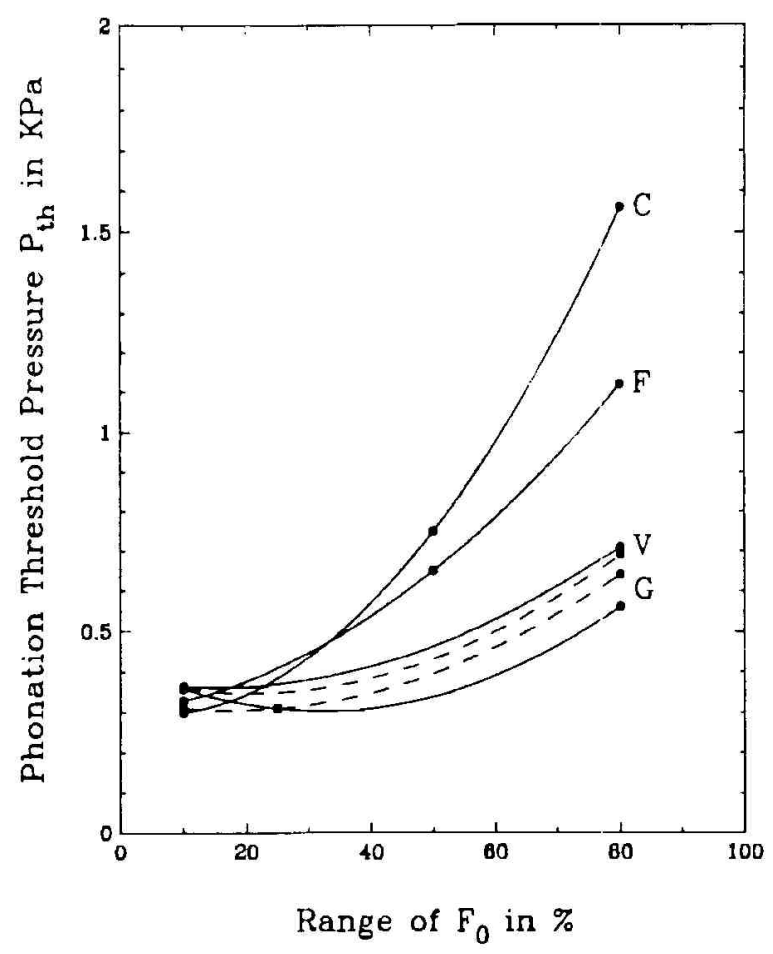

FIG. 1. Change of phonation threshold pressure with fundamental frequency. Data set $G$ is from Grarnming (1988), F is from Finkelhor et al. (1988), $V$ is from Verdolini-Marston et al. (1990), and C is from Cleveland and Sundberg (1985). Solid lines are for males and dashed lines are for females.

Figure 7. The relationship between fundamental frequency and PTP across four separate studies involving both human subjects and excised canine larynges. Reprinted with permission from Titze, I. R., Phonation threshold pressure: A missing link in glottal aerodynamics. Journal of the Acoustical Society of America, 91(5),p. 2927. Copyright 1992, Acoustical Society of America. 
Canine larynges. The first person to report using models of the larynx to study phonation was a researcher by the name of Ferrein. In 1741, he used isolated canine larynges to investigate whether vocal folds should be classified as a string or wind instrument (van den Berg, 1968). Using canine larynges in vocal fold research has several advantages. For one, canine larynges generally share the same shape as human larynges and therefore exhibit similar patterns of vibration, making them fairly accurate models. Additionally, studies that would not be possible with human volunteers can be conducted using live vocal folds (in vivo) while dogs are sedated. In vivo studies can provide a wealth of information that isolated models cannot, such as how the vocal tract and other structures of the head and neck affect phonation (Titze, 1980, 1994).

There are, however, some disadvantages to the use of canine larynges in research on human phonation. While there are definite similarities between human and canine larynges, there are also some significant structural differences. For instance, the canine vocal fold consists of three layers rather than five-an epithelial layer, a superficial layer that is thicker than the human's (about 2 to $3 \mathrm{~mm}$ ), and a muscle layer-lacking intermediate and deep layers of the lamina propria. As with the human infant vocal folds, canine vocal folds lack a well-defined vocal ligament and have a relatively thick mucosa. These structural differences are thought to result in a reduced ability to sustain phonation, especially high-pitched phonation (Saito, Fukuda, Isogai, \& Ono, 1981; Titze, 1980, 1994). Because of these differences, generalization of results from research involving canine larynges to human phonation is limited. "However," as Baer stated, "it is still a useful exercise to develop a model for the excised canine larynx, since very comprehensive data can be obtained on the anatomy, the mechanical properties, and the vibratory patterns in these preparations" (Saito et al., 1981, p. 106). 
Excised larynges. Isolated human larynges were also used in early studies of phonation. This practice began as early as 1840 with research conducted by Johannes Müller. Other researchers have used excised human larynges in their research as well, including Trendelenburg in 1937 and van den Berg in the 1960s. Using human larynges in the study of phonation has the advantage of being more anatomically and physiologically accurate than canine larynges. Using excised larynges rather than intact human larynges has benefits as well. Isolated larynges allow researchers to take more direct measurements, even within the vocal folds themselves. It also gives them greater control over parameters such as subglottal pressure and muscle tension and contraction (Thomson, Mongeau, \& Frankel, 2005; van den Berg, 1968). Baer noted one other advantage to using human larynges in isolation. He said, "a particular advantage is that vibrations can be observed from the inferior aspect or the medial aspect, as well as from the normal superior aspect" (Saito et al., 1981, p. 119).

However, research can be made more challenging in that consistency across larynges is limited in parameters such as tissue thickness, because of anatomical variability. Also the life of these models is limited because of the difficulty in maintaining the self-oscillation viability of the tissues. Excised human larynges require very careful freezing and hydration techniques to maintain tissue freshness. Mechanical properties may also be altered because the action of the vocalis muscle cannot be adequately simulated in these larynges, and death of the tissue, which is unavoidable, may affect vibratory patterns (Saito et al., 1981; Thomson et al., 2005; van den Berg, 1968).

Van den Berg conducted an experiment in the 1960s to determine whether or not isolated larynges are even an accurate representation of live human larynges. He questioned whether removal from the supra- and sub-glottal structures as well as the gradual death and deterioration 
of the tissue, especially muscle tissue, would affect the integrity of such models. Through his research, van den Berg found that excised human larynges performed remarkably well in comparison to in vivo human larynges for up to one month or even more as long as proper precautions were taken to preserve the specimens. This involved storing them in diluted physiological salt solution in a refrigerator (van den Berg, 1968). Therefore, as can be inferred from these studies, while there are some definite limitations to using human larynges in isolation in studying human phonation, important knowledge can be gained by the use of such models.

Computer models. In recent decades, many advances have come about because of computers. This has been the case in the study of phonation, which has in recent years relied on computer modeling to increase our understanding of vocal fold vibration. Using computer simulations requires first that mathematical models of the larynx be created. These mathematical models are then input into computer programs, which digitally simulate the motion of the vocal folds. Computer models have many advantages over other forms of modeling. One of these is that researchers are able to vary many different parameters one at a time, or even several at the same time. This allows them to determine the impact of these adjustments individually and collectively on the acoustic output. Also, modifications can be made to computer simulations with more speed and ease than with, for instance, physical models, in which a brand new model must be made for each adjustment to a physical parameter (Zemlin, 1998).

Computer simulations have been used to study phonation since as early as 1968 , at which time Flanagan and Landgraf were able to construct a one-mass computer model to study frequency changes in the human voice (Titze, 1980). Computer models have gone from onemass models, as in Flanagan and Landgraf's study, to two-mass models, to sixteen-mass models, and even to a continuum of discrete masses. Ingo Titze has been a prominent researcher in the 
field of human phonation and has used many computer simulations in his research. Through this research we have made impressive progress in our understanding of vocal fold motion and vibration patterns. It was in large part his research conducted in 1979—which used computer models that took into account the curved boundaries of the vocal folds as well as the viscoelastic properties of the various layers of vocal fold tissue - that shed light on the effect of longitudinal stress on fundamental frequency changes in the human voice. This study also helped prove that subglottal pressure does not directly control fundamental frequency (Zemlin, 1998).

Physical models. Another type of model that has been used frequently in studying the vocal folds is the physical model. When physical models are carefully constructed with "welldefined geometry and biomechanical features" (Chan et al., 1997, p. 3722), they allow researchers more control over variables and parameters than can be achieved with real vocal folds. For example, vocal fold thickness, and even the thickness of each layer of the vocal folds, varies across the population. In a physical model, these parameters can be controlled, kept constant, and even replicated for further research. Also, fabrication is relatively straightforward and inexpensive. There is no need to freeze the model or worry about dehydration, as with excised human or canine larynges. There is relatively little wear and tear over time. Models can be used for several hours uninterrupted and reused even after several months with reasonable reliability (Thomson et al., 2005). Models can also be replicated for further experimentation or if damage should occur. Lastly, physical models have an advantage over computer models in that vocal fold motion can be observed directly and recorded using stroboscopic cameras for further, more in-depth analysis (Chan et al., 1997; Thomson et al., 2005; Zemlin, 1998).

Unfortunately, physical models also have a number of disadvantages. One difficulty with physical modeling is that any slight adjustment to a physical parameter, such as vocal fold 
thickness or stiffness, requires the creation of a new model using altered materials. Even more importantly, "to be completely successful a model should manifest all the known properties of the structure or system it represents" (Zemlin, 1998, p. 183). This can be particularly challenging when it comes to physically modeling the vocal folds due to structural complexity and multiple layers of tissue. Also, to date, it has not been possible to replicate the contractile nature of muscle tissue. Because the TA muscle makes up a large portion of the vocal fold's mass, this makes a truly accurate physical replication of the vocal folds impossible, at least for the time being (Zemlin, 1998).

Despite these difficulties and setbacks, countless attempts have been made to create and study physical models of the vocal folds. As early as 1930, Sir Richard Paget created a model using rubberlike vocal folds with a complex resonating cavity above them. After much trial and error, Paget was able to use this model to create seemingly humanlike sounds, indicating that his model incorporated at least some of the properties of the human larynx and vocal tract (Zemlin, 1998).

More recently, attempts have been made to model the vocal folds using synthetic materials. The majority of these studies have been conducted using a single-layered, isotropic (having the same properties and values throughout) model of the vocal folds. Some of the previous studies conducted using these models have looked at the vibratory patterns of the synthetic vocal folds in comparison to human vocal folds and the influence of subglottal acoustics on these vibratory patterns (Thomson et al., 2005; Zhang, Neubauer, \& Berry, 2006a, 2006b). Others have examined the influence of subglottal structures and subglottal resonance on the acoustical output of these models (Zhang et al., 2006b). In many previous experiments involving physical modeling of the vocal folds a length of PVC pipe has been the only subglottal 
structure present, used to represent the trachea. These various models have been useful in helping to further research and increase knowledge in the area of phonation. However, humanlike phonation has been difficult to replicate with these models. This may be related to a lack of vocal tract presence or may be due the fact that they have not taken into account the multi-layered nature and nonlinear tissue properties of the human vocal folds.

As early as 1983, researchers began to create physical models of the vocal folds with multiple layers (Scherer, Titze, \& Curtis, 1983). In 1995, Titze, Schmidt, and Titze created a two-layered model consisting of fluid encapsulated in a silicone membrane, which represented the epithelium and superficial layer of the lamina propria. Titze and his team then used this model to study PTP based on glottal diameter and tissue viscosity (Titze et al., 1995). In another study conducted in 1997, Chan et al. used a two-layered physical model of the vocal folds to investigate the influence of vocal fold thickness and epithelial thickness on PTP in a two-layered model of the vocal folds. Each two-layered model included an epithelial capsule with varying thicknesses and a fluid layer of varying viscosities, representing the superficial layer of the lamina propria. While these two-layered models are more representative of human vocal folds than previous physical models have been, they still lack many important properties and characteristics, considering that the human vocal folds have five, rather than two, distinct layers of tissue. This undoubtedly limits the generalization of information gained from such models to the human voice.

\section{Thomson's Physical Model of the Larynx}

One researcher in the area of human phonation who has been involved with physical modeling of the vocal folds is Dr. Scott Thomson. In 2005, Thomson created a single-layered synthetic model, which was reasonably similar to human vocal folds with respect to vibratory 
onset pressure (the equivalent of PTP in humans, or $\mathrm{P}_{\mathrm{on}}$ ), size and shape, material properties, and oscillation frequency. This model measured $1.7 \mathrm{~cm}$ in length in the anterior-posterior dimension, which is a close approximation to the length of the vibrating portion of an average adult male's vocal folds. The model was made using a liquid polymer solution consisting of Evergreen ${ }^{\mathrm{TM}} 10$, a two-part addition cure polymer, mixed with Everflex ${ }^{\mathrm{TM}}$ to increase flexibility. The response of this model was similar to the human vocal folds with respect to subglottal pressure, frequency of oscillation, and amplitude of oscillation (Thomson et al., 2005). Onset pressure for this model averaged $1.15 \mathrm{kPa}$, which is comparable to threshold pressures measured in previous studies involving excised canine larynges, which averaged $0.9 \mathrm{kPa}$ (Jiang \& Titze, 1993). Self-sustained oscillations were achieved at $120 \mathrm{~Hz}$, which is within the normal range of average fundamental frequency for adult males (Thomson et al., 2005).

More recently, Thomson has succeeded in building a two-layered version of this singlelayered silicone model. The two-layered model was $1.7 \mathrm{~cm}$ in length, similar to the previous model. However, this new model consisted of a cover layer approximately $2 \mathrm{~mm}$ thick and a stiffer body layer beneath. The model was created using two separate molds and utilized Scherer's M5 vocal fold geometry (see Figure 8), which has been a standard in vocal fold research involving physical models since 2001 (Scherer et al., 2001). Rather than using a liquid polymer material, as was used with the previous single-layer model, this model was created using a silicone compound called Ecoflex 0030. The first mold, Mold A (see Figure 9), was the same mold used in Thomson's single-layered model (2005). The second mold, Mold B, was a replica of Mold A with $2 \mathrm{~mm}$ removed from the vocal fold surface. First, the body was created using Mold B. After the body was completely cured, the cover was added to the model using Mold A. Cover and body portions of this model differed in consistency to mimic more closely 


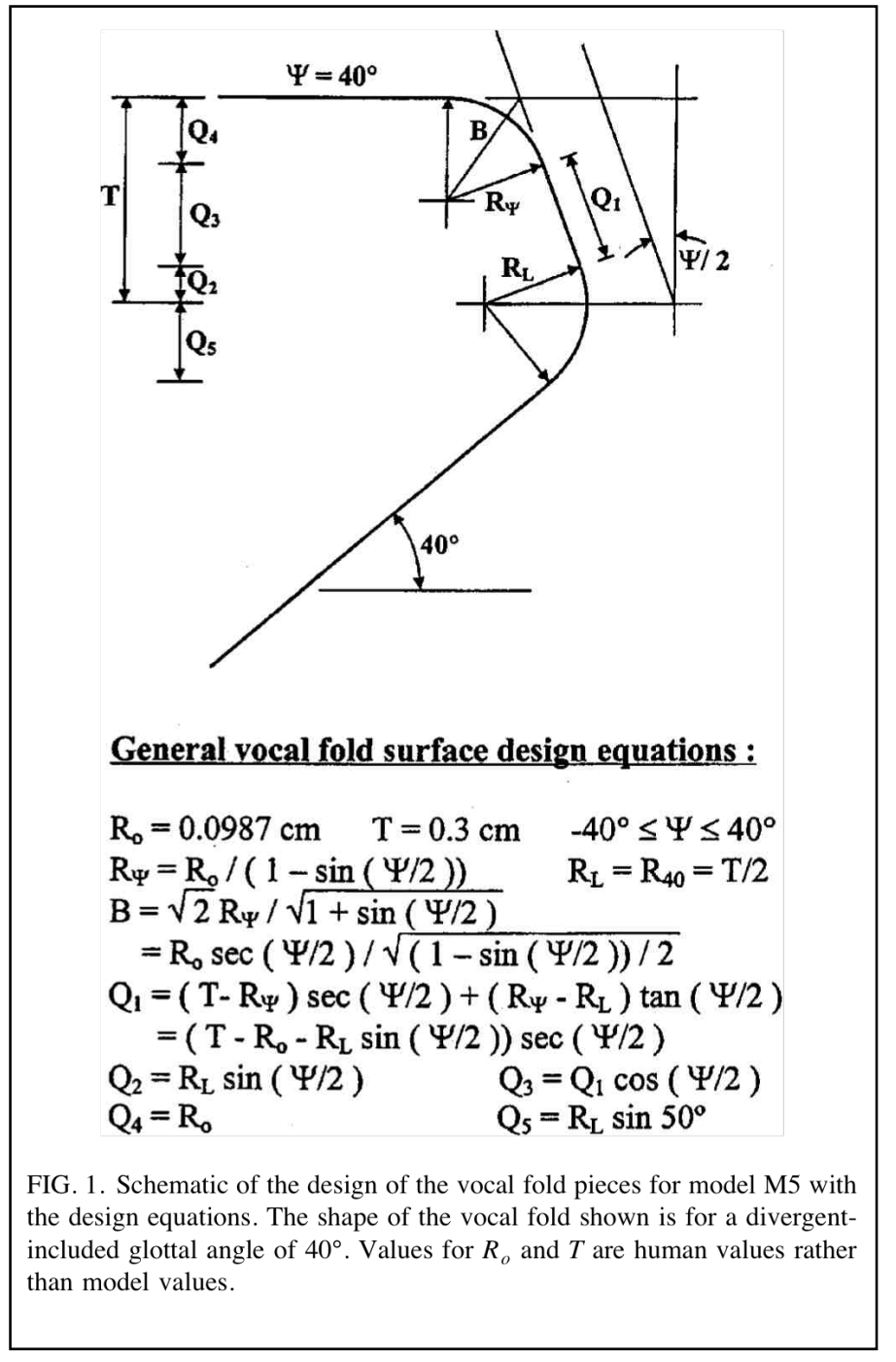

Figure 8. Scherer's M5 vocal fold geometry. From Scherer, R. C., Shinwari, D., De Witt, K. J., Zhang, C., Kucinschi, B. R., \& Afjeh, A. A. (2001). Intraglottal pressure profiles for a symmetric and oblique glottis with a divergence angle of 10 degrees. The Journal of the Acoustical Society of America, 109(4), 1616-1630. Used with permission of the publisher. 


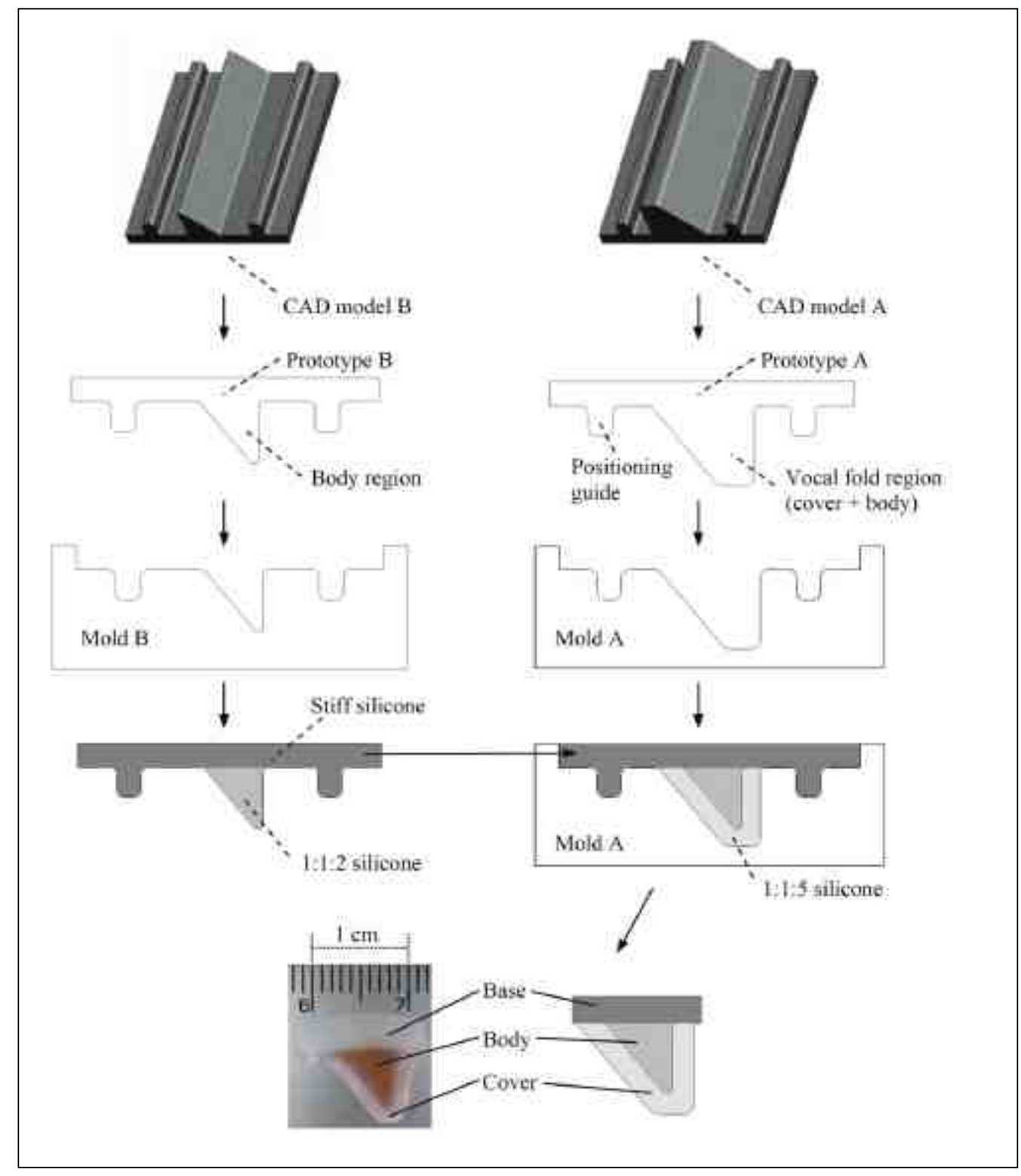

Figure 9. Molds used to create a two-layered physical model of the vocal folds. Mold B was used to create the body layer and Mold A was then used to add a $2 \mathrm{~mm}$ thick cover layer to the body. Reprinted with permission from Riede, T., Tokuda, I. T., Munger, J. B., \& Thomson, S. L., Mammalian laryngeal air sacs add variability to the vocal tract impedance: Physical and computational modeling, Journal of the Acoustical Society of America, 124(1), p. 637. Copyright 2008, Acoustical Society of America. 
human vocal fold tissue (Drechsel \& Thomson, 2008; Riede, Tokuda, Munger, \& Thomson, 2008). Further details on the fabrication process are available in Drechsel \& Thomson (2008) and Riede et al. (2008).

This two-layered model was tested and compared to human vocal folds. The model was similar to human vocal folds with respect to frequency of oscillation, amplitude of vibration, and flow rate. However, some differences were noted as well. For instance, the mucosal wave seen in typical human vocal folds was not significantly manifest in this two-layered model. Also, some adhesion of the surfaces was present in this model and resulted in changes in the patterns of vibration. While a mucus bridge is sometimes present between the vibrating human vocal folds, they typically do not adhere to the extent seen in this model (Drechsel \& Thomson, 2008).

As discussed previously, physical models, such as this two-layer vocal fold model, can provide benefits in vocal fold research as specific variables and parameters can be controlled. While many studies have been done to investigate the factors that influence fundamental frequency changes in the human voice and their effects on phonation threshold pressure, few of these studies have utilized physical models. The purpose of the current study was to help fill in some of the gaps in our understanding of the voice, particularly with regard to frequency regulation, using Thomson's two-layer silicone model. More specifically, this study sought to investigate the effect of increasing length and tension in models with linear and nonlinear stressstrain properties on fundamental frequency and $\mathrm{P}_{\text {on }}$. This research is designed to increase our understanding of the influence of the nonlinear nature of vocal fold tissue and CT muscle activation on frequency regulation in the human voice. In addition, this research sought to contribute a more realistic physical model of the vocal folds which could be used in further voice research. 


\section{Method}

\section{Constructing the Models}

Two different types of physical models, both based on Thomson's two-layer silicone model, were used in this study. Three models of each type were created and results from each were compared. The first model was a two-layered body-cover model made using a silicone compound called Ecoflex ${ }^{\mathrm{TM}}$ 0030, which has been used in several previous research studies (Drechsel \& Thomson, 2008; Riede et al., 2008; Thomson et al., 2005). A second physical model was created using a similar procedure and using the same M5 design (as described below and illustrated in Figures 8 and 9). However, this second model contained curled fibers embedded into the cover portion of the vocal folds to mimic the functional role of collagen fibers and their contribution to the nonlinear nature of the human vocal fold tissue.

Constructing the Original M5 Models. The three original, linear M5 physical models of the vocal folds were constructed according to the procedures outlined in Riede et al. (2008). In short, the models were created using two separate molds-Mold A and Mold B (See Figure 9) and a material called Ecoflex ${ }^{\mathrm{TM}}$ 0030, a two-part addition-cure silicone compound. An additional material called Dragon Skin ${ }^{\mathrm{TM}} \mathrm{Q}$ was used as the base for each model.

First, the body layer for each model was created using Mold B and a 1:1:2 ratio of Part A: Ecoflex $^{\mathrm{TM}}$ 0030, Part B: Ecoflex ${ }^{\mathrm{TM}}$ 0030, and Smooth-On's Silicone Thinner ${ }^{\circledR}$. This mixture gave the body layer a $10.5 \mathrm{kPa}$ cured modulus, giving it a consistency slightly stiffer than gelatin and a nearly linear stress-strain curve (Riede et al., 2008). After the body was completely cured, a layer of Dragon Skin ${ }^{\mathrm{TM}} \mathrm{Q}$, with a mixture ratio of 1:1:1 of Part A: Dragon Skin ${ }^{\mathrm{TM}} \mathrm{Q}$, Part B: Dragon Skin ${ }^{\mathrm{TM}} \mathrm{Q}$, and Silicone Thinner, measuring about $2.5 \mathrm{~mm}$ thick, was poured over the Ecoflex ${ }^{\mathrm{TM}} 0030$ in Mold B. 
Next, the body was removed from Mold B so a $2 \mathrm{~mm}$ thick cover layer could be added to the model using Mold A. This cover layer was also created using Ecoflex ${ }^{\mathrm{TM}}$ silicone compound. It was mixed with a 1:1:4 ratio of Part A: Ecoflex ${ }^{\text {TM }}$ 0030, Part B: Ecoflex ${ }^{\text {TM }}$ 0030, and Silicone Thinner. This ratio gave the cover layer a cured modulus of approximately $3.3 \mathrm{kPa}$ and a consistency slightly softer than gelatin (Drechsel \& Thomson, 2008; Riede et al., 2008). This differed from the 1:1:5 ratio used previously in Riede et al. Once mixed, the 1:1:4 silicone mixture was poured into Mold A. Immediately after, the cured body model was carefully inserted into Mold A, ensuring that no visible air bubbles remained underneath.

Constructing the Nonlinear M5 Models with Fibers. The three nonlinear models were created using a similar procedure and using the same M5 design. However, these nonlinear models contained curled fibers embedded into the cover portion of the vocal folds to mimic the performance and contribution of collagen fibers in human vocal folds. First, the body layer for each model was created exactly as outlined above for the original, linear model. Separate silicone layers were created which contained curled polyester fibers unwoven from a sample of polyester fabric and curled acrylic fibers unwoven from strands of knitting yarn. These fiber silicone layers were approximately $1 \mathrm{~mm}$ thick and were created using the following procedure (as illustrated in Figures 10-14).

First, a mold for each fiber layer was created using microscope slides, which measured 1 $\mathrm{mm}$ in thickness. These slides were laid flat and formed into a rectangular box measuring $4 \mathrm{~cm} \mathrm{x}$ $4.5 \mathrm{~cm} \times 1 \mathrm{~mm}$ thick, which was the thickness of the slides themselves. These slides were then glued together using Super Glue ${ }^{\mathrm{TM}}$ (see Figure 10). Next, a similar two-dimensional $4 \mathrm{~cm} \times 4.5$ cm box was drawn onto an overhead transparency sheet with an additional line was drawn perpendicular to the $4.5 \mathrm{~cm}$ sides, dividing the box into two equal halves (see Figure 10). 


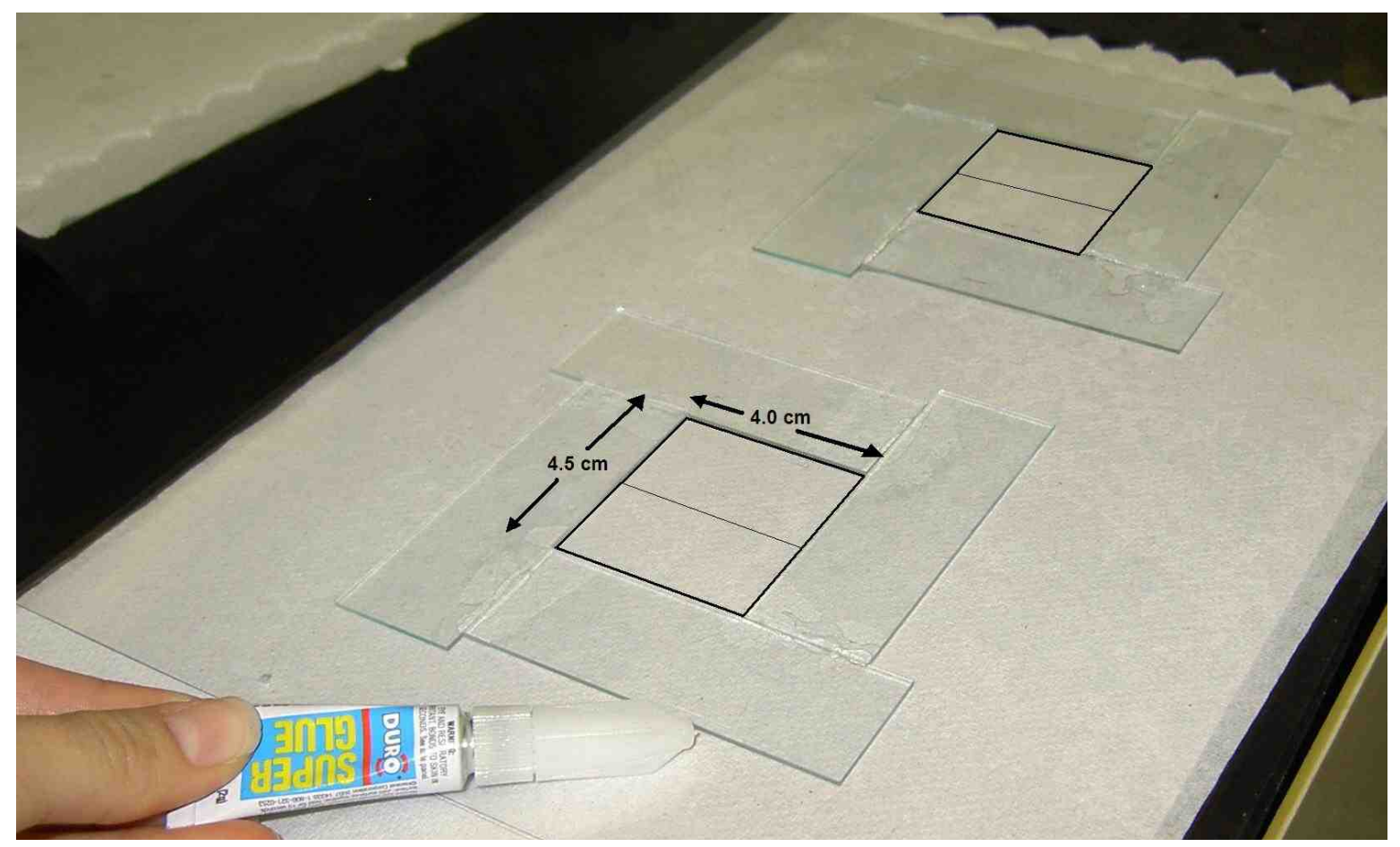

Figure 10. Layout for the microscope slides used to construct the fiber layers. The slides were laid flat to form a rectangular box measuring $4.5 \mathrm{~cm} \mathrm{x} 4.0 \mathrm{~cm}$. They were then glued together using Super Glue ${ }^{\mathrm{TM}}$. 

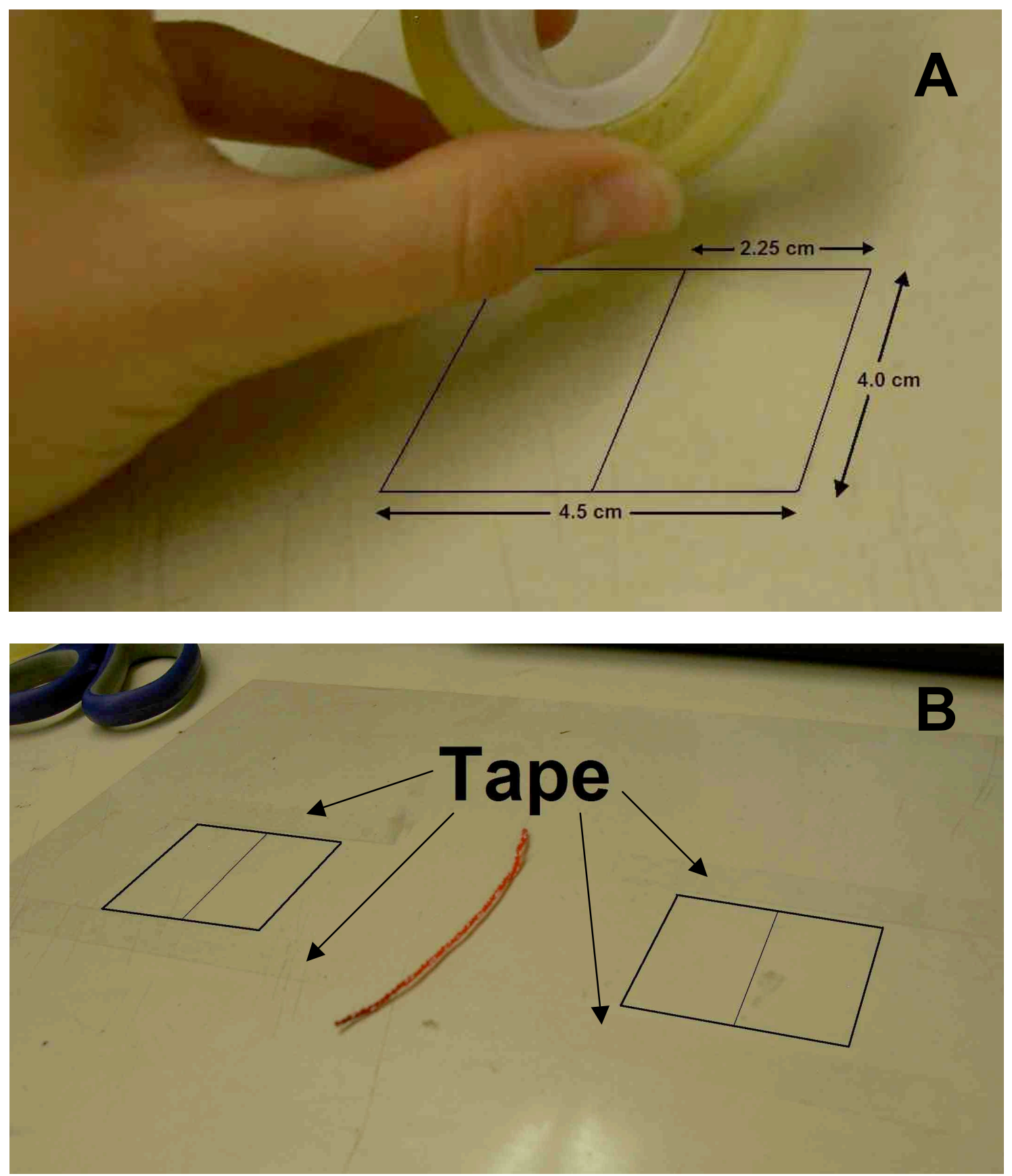

Figure 11. Photos illustrates the where the double-sided tape was placed during fiber layer construction. Overhead transparency sheets were used, and tape was placed directly on these transparency sheets. Note that the tape was placed parallel to the divided $4.5 \mathrm{~cm}$ side of the box used to construct the fiber layers. 

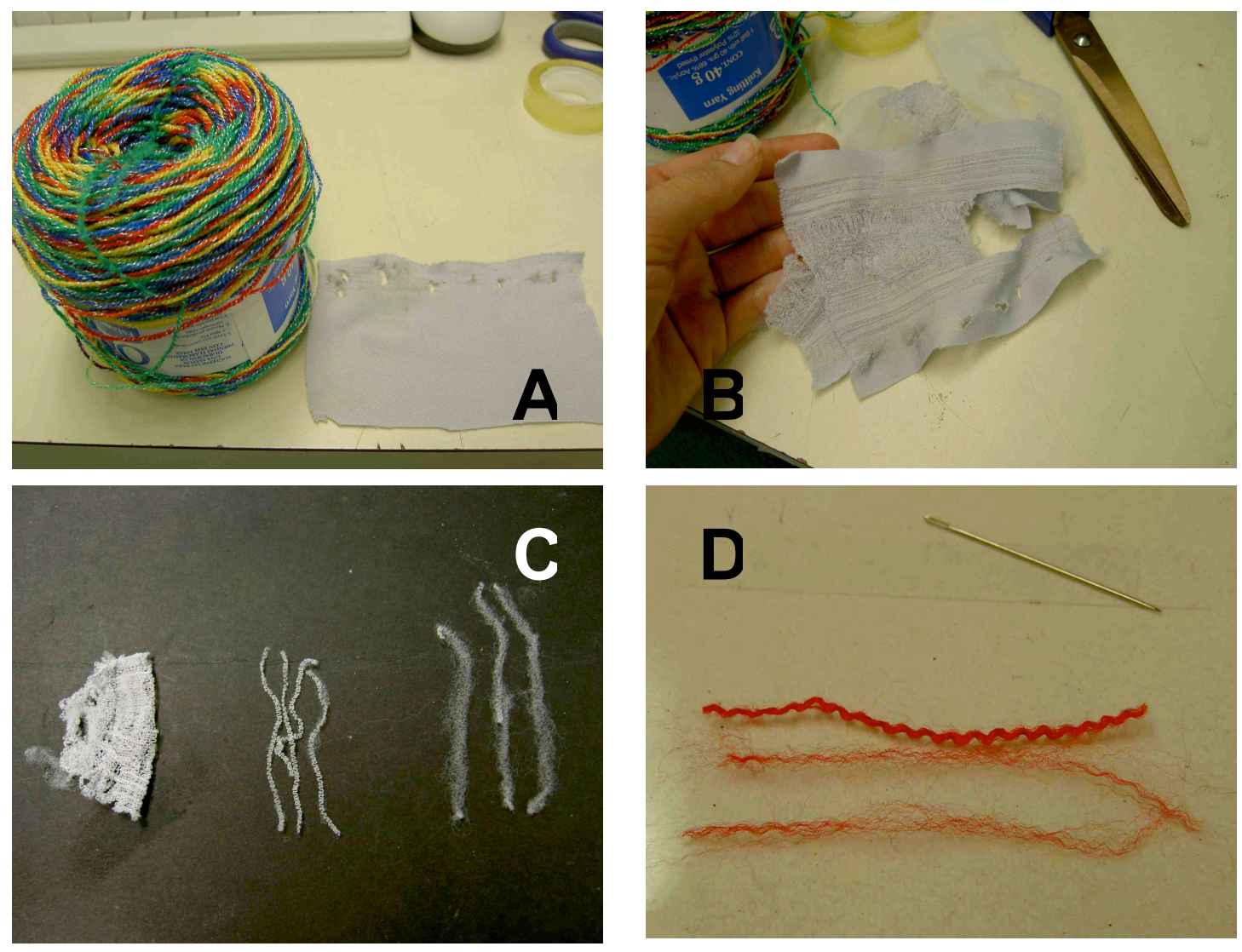

Figure 12. Photos illustrate the fibers that were used to construct the fiber layers used in this experiment. (A) Fibers were selected from the acrylic knitting yarn and polyester fabric illustrated. (B) Polyester fabric was separated into individual threads. (C) Since these threads were taken from woven fabric, they maintained a curled or coiled shape, as illustrated above. Threads were then stretched until individual strands began to separate into a more "matted" layout. (D) Each length of knitting yarn was divided into two halves (with each half containing a white portion of thread and a colored portion). The white portion of the thread was not used for this experiment and was therefore discarded. Each colored portion was separated into smaller sections. These smaller sections were used in constructing the fiber layers. 

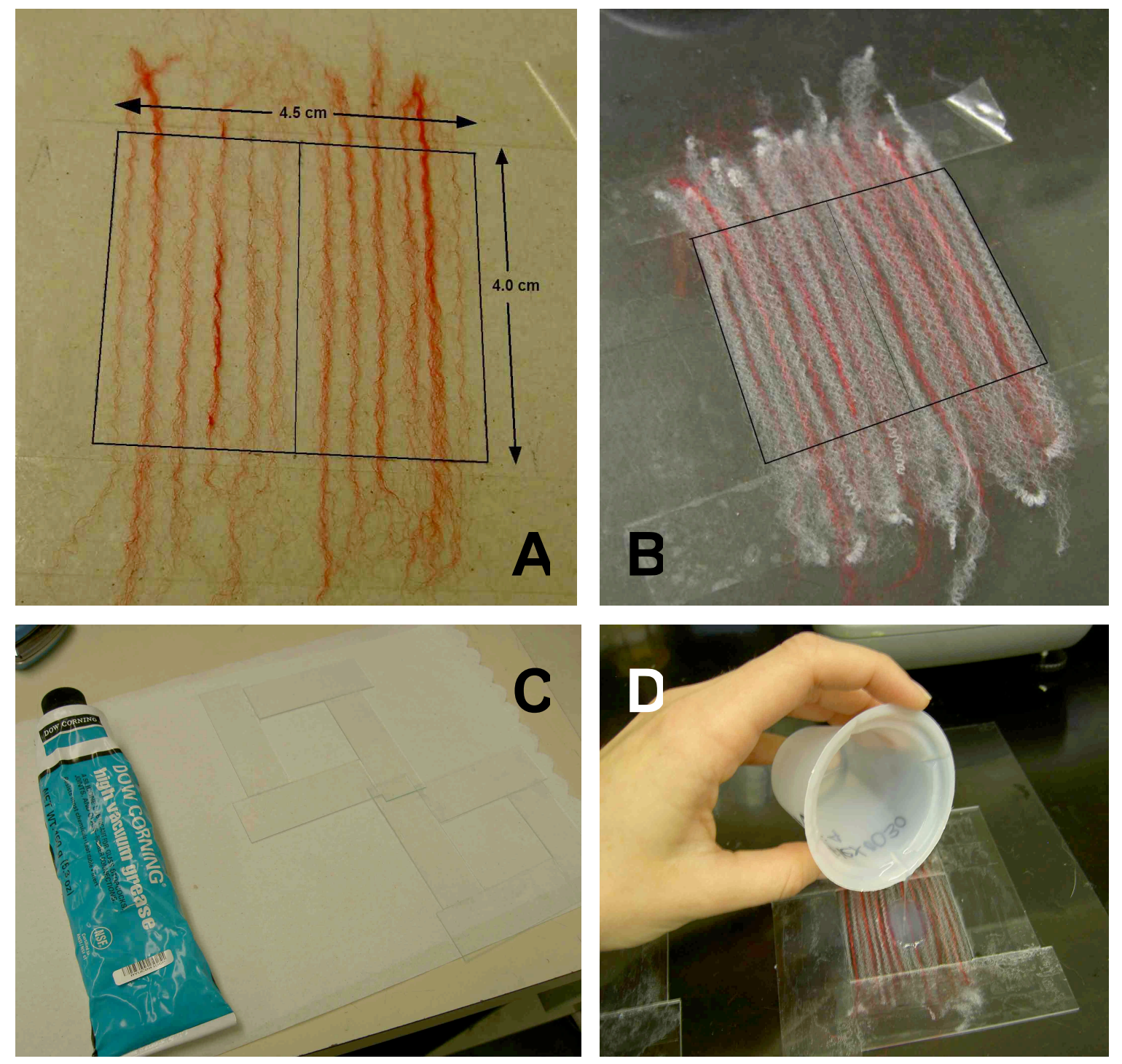

Figure 13. Photos illustrates the actual construction of fiber layers. (A) First, six acrylic strands were laid out in each half of the divided box, running parallel to the $4.0 \mathrm{~cm}$ side of the box. These strands were stuck down to the double sided tape that was placed earlier. (B) Seven polyester strands were then placed in each half of the box, between and beside each acrylic fiber. These polyester fibers were also stuck down to the double sided tape. (C) Vacuum grease was then spread onto one side of the glued microscope slides, also shown in Figure 10. (D) These glued slides were then laid onto the overhead transparency, around the fibers. Each set of slides and the transparency sheet were pressed together to ensure an airtight seal. Last, a 1:1:4 mixture of Ecoflex ${ }^{\mathrm{TM}} 0030$ was poured over the fibers up to the level of the microscope slides measuring $1 \mathrm{~mm}$ in thickness. 


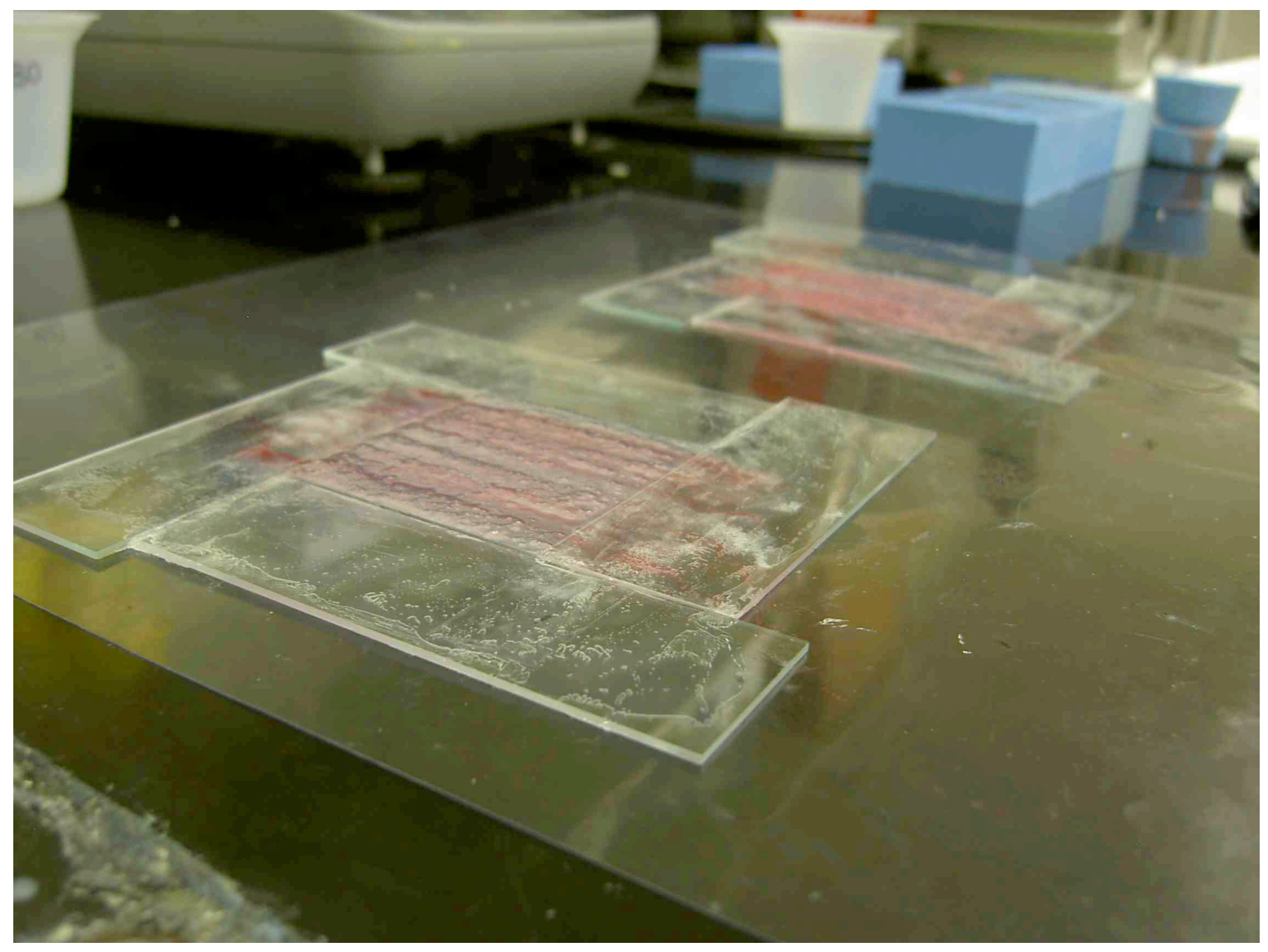

Figure 14. Photo illustrates the constructed fiber layers still housed within the microscope slides that were used to create $1 \mathrm{~mm}$ thick layers of silicone. 
Double-sided tape was placed parallel to both $4 \mathrm{~cm}$ sides, outside of the rectangular box (see Figure 11). Bundled strands of curled polyester fibers and curled acrylic knitting yarn fibers were then placed running parallel to the $4.5 \mathrm{~cm}$ sides and were anchored to the double-sided tape, alternating acrylic and polyester fibers. A total of 6 acrylic fiber bundles and 7 polyester fiber bundles were placed in each half of the box, totaling 12 acrylic fiber bundles and 14 polyester fiber bundles per layer or per slide (see Figures 12-14).

After all fibers were placed and secured to the double-sided tape, Dow Corning ${ }^{\circledR}$ High Vacuum Grease was spread onto one side of each set of glued microscope slides (see Figure 13). These glued slides were then laid onto the overhead transparency, with the vacuum grease down, around the matching rectangular boxes and secured fibers. Each set of slides was pressed tightly to the overhead transparency sheet to ensure an airtight seal. Last, a 1:1:4 mixture of Ecoflex ${ }^{\mathrm{TM}}$ 0030 was poured over the fibers and filled level with the microscope slides, making each fiber layer approximately $1 \mathrm{~mm}$ in thickness. They were then left to cure for at least 8 hours.

Once the fiber layers were completely cured, the microscope slides were removed and the silicone fiber layers were cut away from the transparency sheets along the drawn rectangular 4.5 $\mathrm{cm} \times 4.0 \mathrm{~cm}$ box. Each layer was then divided into two equal halves, parallel to the direction of the fibers, using a pair of scissors (see Figure 15). One half of each constructed silicone fiber layer was used to create each fiber vocal fold model.

To create a fiber vocal fold model, one of these silicone fiber layer halves was placed carefully into Mold A (the cover mold), ensuring that that no visible air bubbles were present between the mold and fiber layer (see Figure 16). Additional 1:1:4 mixture of Ecoflex ${ }^{\mathrm{TM}} 0300$ was poured into the molds over the fiber layers so that the cover layer would total $2 \mathrm{~mm}$ in thickness as was the case with the linear models. The body was then placed over that and 
secured in place, again ensuring that no air bubbles remained under the surface (see Figure 17). Three original M5 models and three M5 models with fibers were created for use in the current study.

Mounting the Vocal Folds. Following construction, each of the six vocal fold models were divided in half and cut to the proper dimensions (17 mm long x $13 \mathrm{~mm}$ wide; each model was used to create a pair of vocal folds). Individual folds were mounted to cured blocks of 1:1:1 ratio Dragon Skin $^{\mathrm{TM}} \mathrm{Q}$, a denser silicone compound, measuring $17 \mathrm{~mm}$ x $17 \mathrm{~mm}$ x $13 \mathrm{~mm}$. This was done using Sil-Poxy $\odot$ Silicone Rubber Adhesive with each vocal fold's Dragon $\operatorname{Skin}^{\mathrm{TM}}$ base layer (2.5 mm thick) glued directly to a Dragon $\mathrm{Skin}^{\mathrm{TM}}$ block.

Originally, a two-plate tensioning system was designed on which to mount the vocal fold models being tested. During preliminary testing, it was discovered that as the vocal folds were stretched in the anterior-posterior direction, the cross-sectional area of each vocal fold decreased (in other words, each vocal fold got thinner) and resulted in an inability to maintain glottal closure with only two solid plates (see Figures 18-19 for original two-plate setup design).

Therefore, a four-plate tensioning system was designed which utilized four aluminum blocks (see Figures 20-21), labeled $a, b, c$, and $d$. To begin, blocks $a$ and $b$ and blocks $c$ and $d$ were connected using 10-32 UNF x $13 / 4$ in (31 mm) screws. Two layers of weather-stripping were placed between these blocks prior to screw insertion. This weather-stripping allowed for an airtight seal to be maintained while ensuring that the vocal folds could be adducted following each length adjustment for adequate glottal closure. Holes were cut in both layers weatherstripping to allow for the screws to pass through. Blocks $a$ and $b$ and blocks $c$ and $d$ were then screwed together, leaving the weather-stripping in its uncompressed state (see Figure 22). 

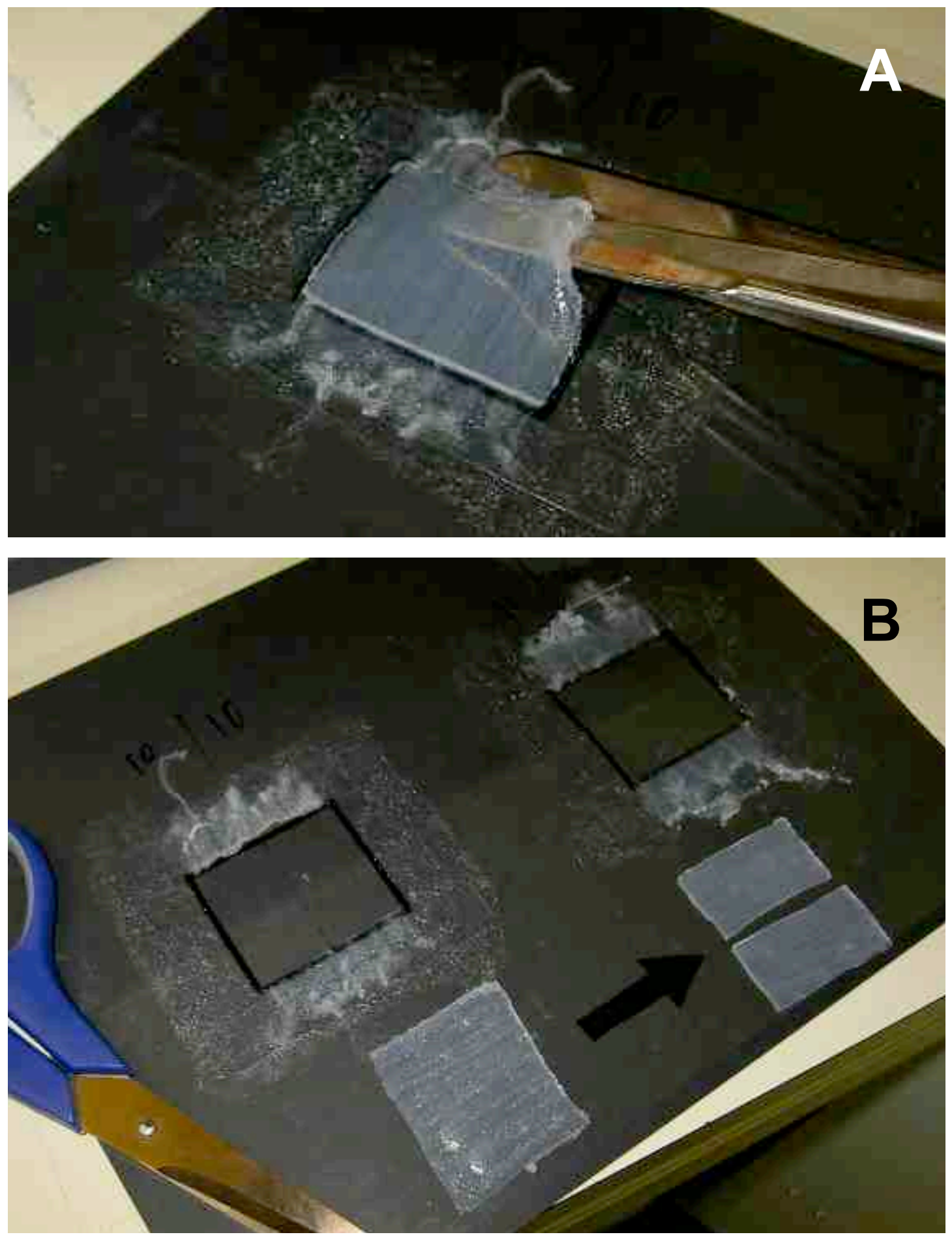

Figure 15. Photo shows how fiber layers were divided and prepared for construction. (A) After microscope slides were removed, fiber layers were cut along black template. (B) Each layer was then divided into two equal halves, parallel to the direction of the fibers. 

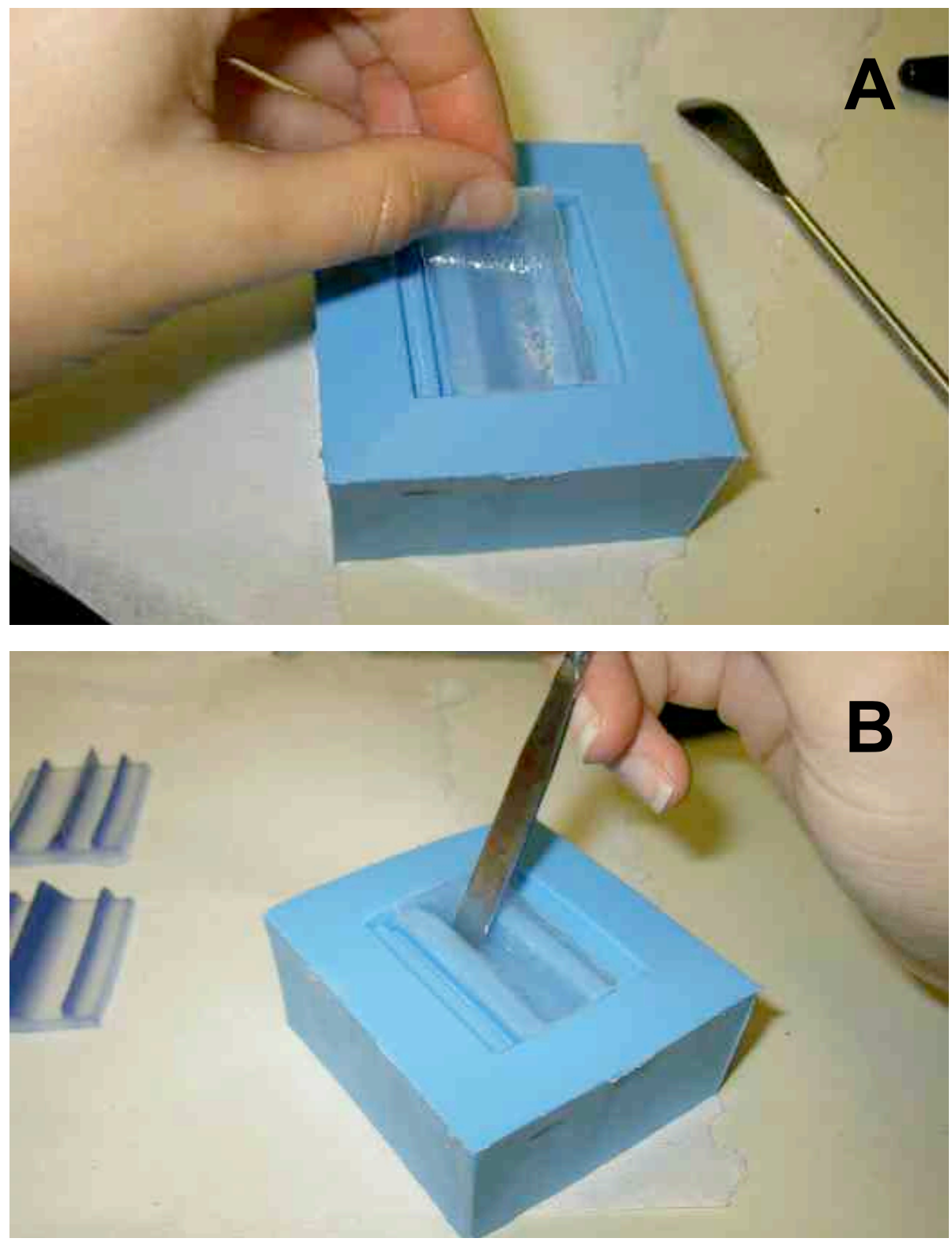

Figure 16. Photo shows how fiber layers were placed in vocal fold molds. (A) Fiber layers were placed in mold. (B) A spoonula was used to press each fiber layer into a cover mold. All air bubbles were carefully eliminated between mold surface and fiber layers using this spoonula. 

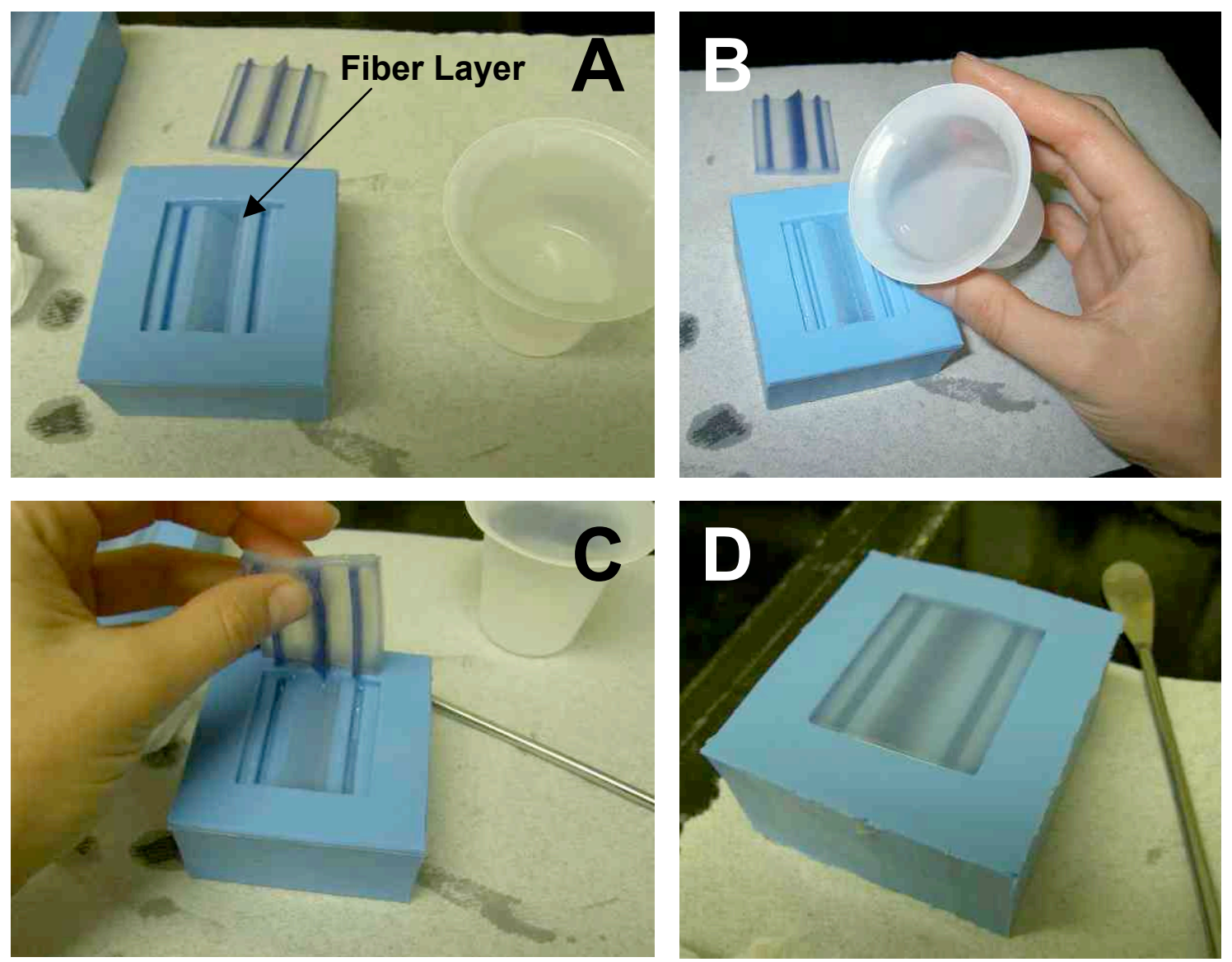

Figure 17. Photos illustrate the construction of the fiber vocal folds. (A) After each fiber layer was placed in the cover mold and all visible air bubbles were removed, a 1:1:4 mixture of Ecoflex $^{\mathrm{TM}} 0300$ was made to pour into the mold. (B) 1:1:4 mixture of Ecoflex ${ }^{\mathrm{TM}} 0300$ was then poured into the mold over the fiber layer. (C) The cured body model was carefully placed in the mold, ensuring that no air bubbles entered in. (D) Illustration of how fiber models look after placement of cured body model. Note that no air bubbles can be seen below the surface of this body model. 

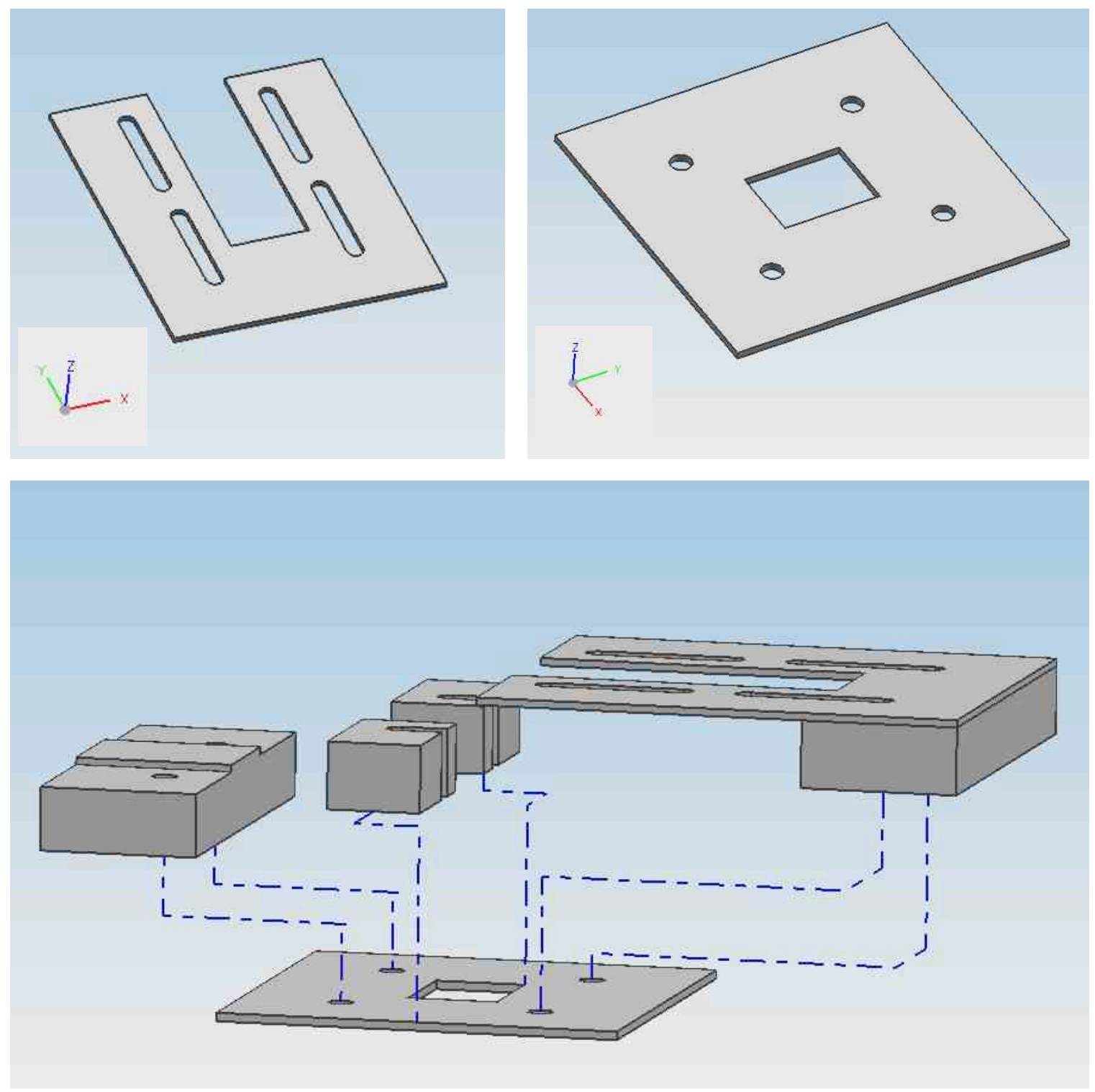

Figure 18. Diagram illustrating the design and layout for the two-plate tensioning system. This tensioning system was not used in the final testing due to the fact that glottal closure could not be achieved for higher extensions. 


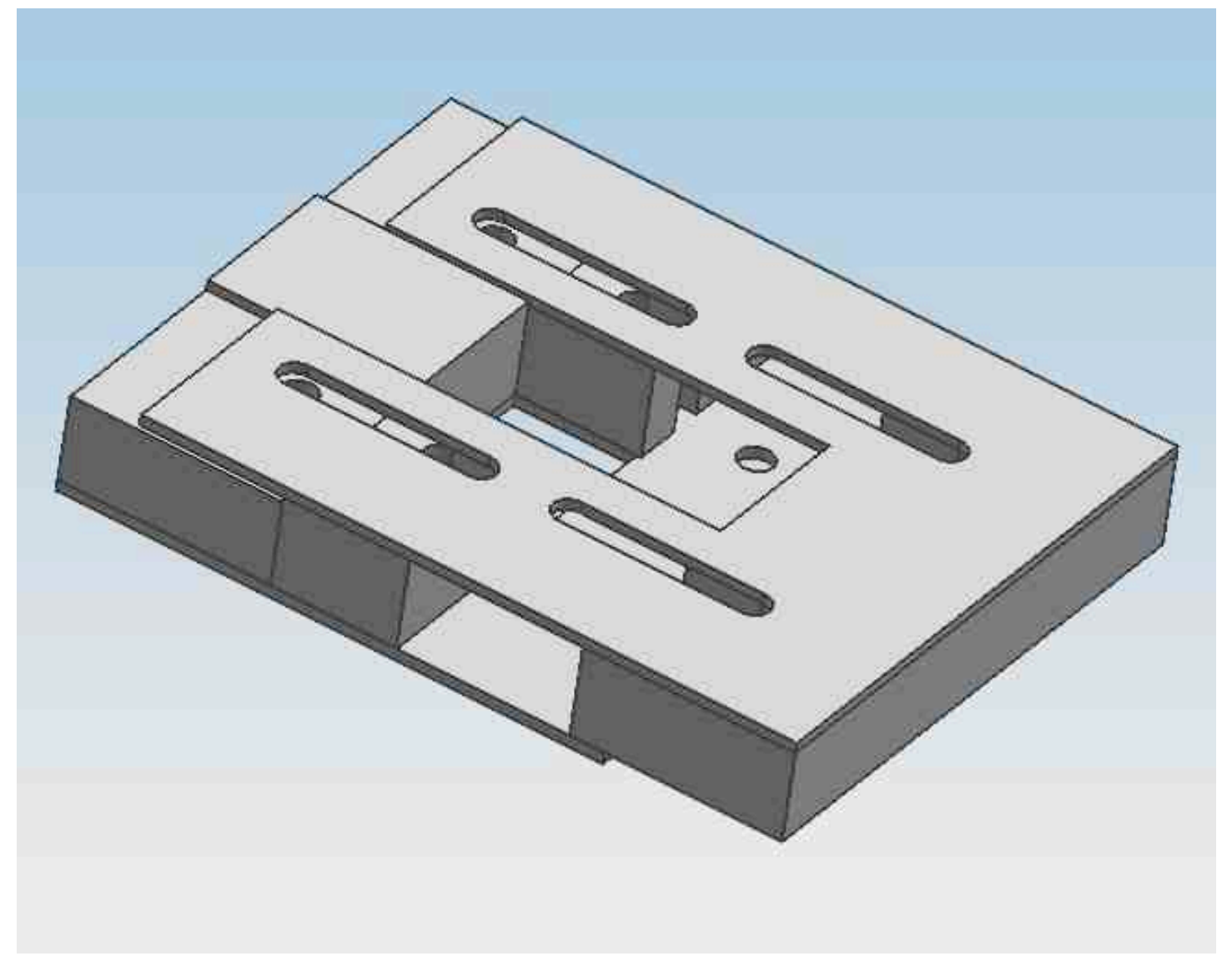

Figure 19. Diagram illustrating the constructed two-plate tensioning system. The previous figure illustrates each component of the system and how it was constructed. 


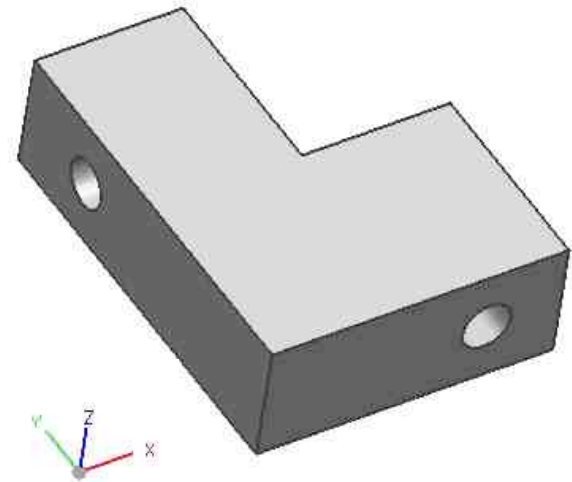

Figure 20. Diagram of each corner plate used in the four-plate tensioning system. 

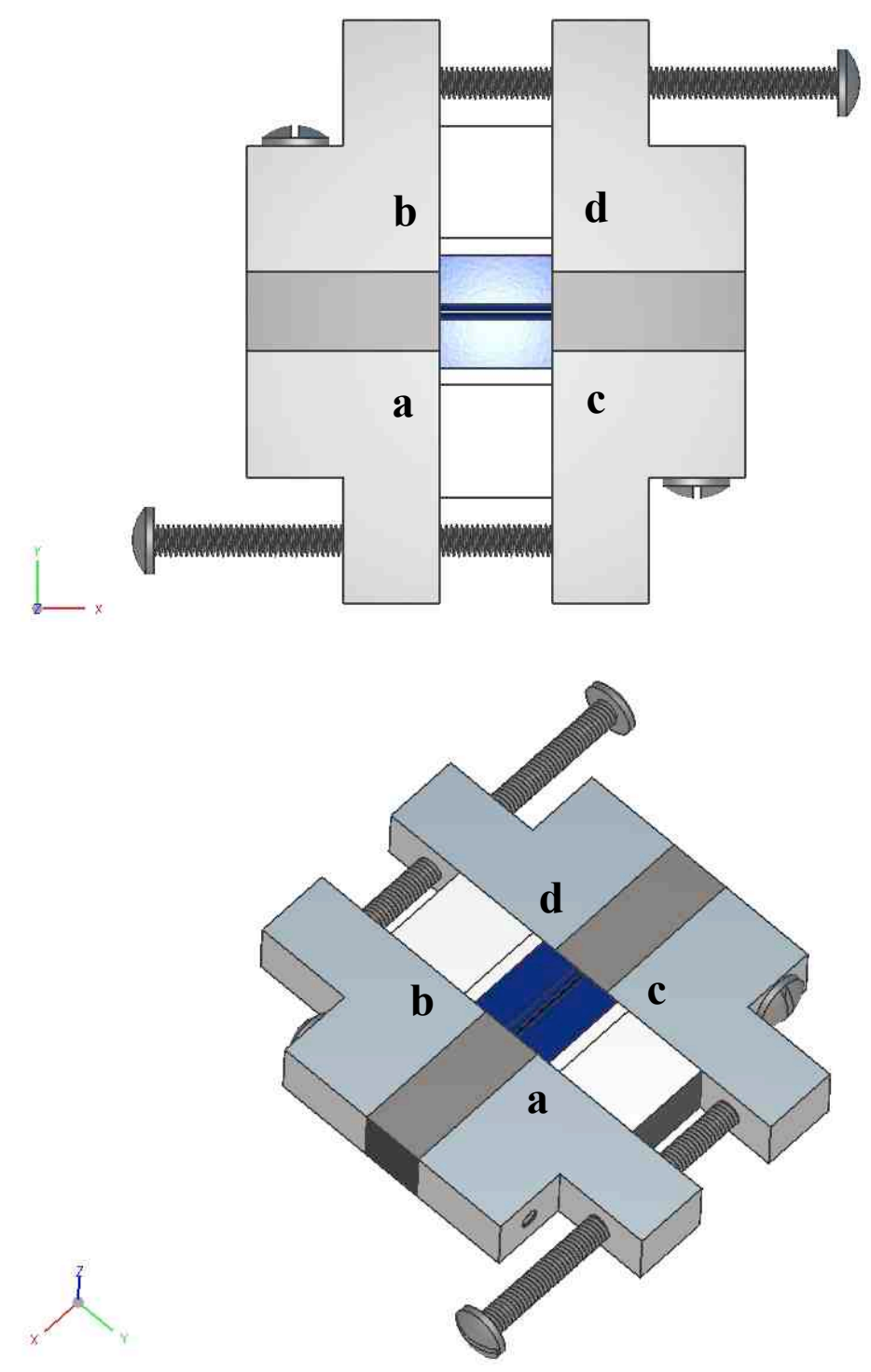

Figure 21. Diagram illustrating the constructed four-plate tensioning system used for this study. 

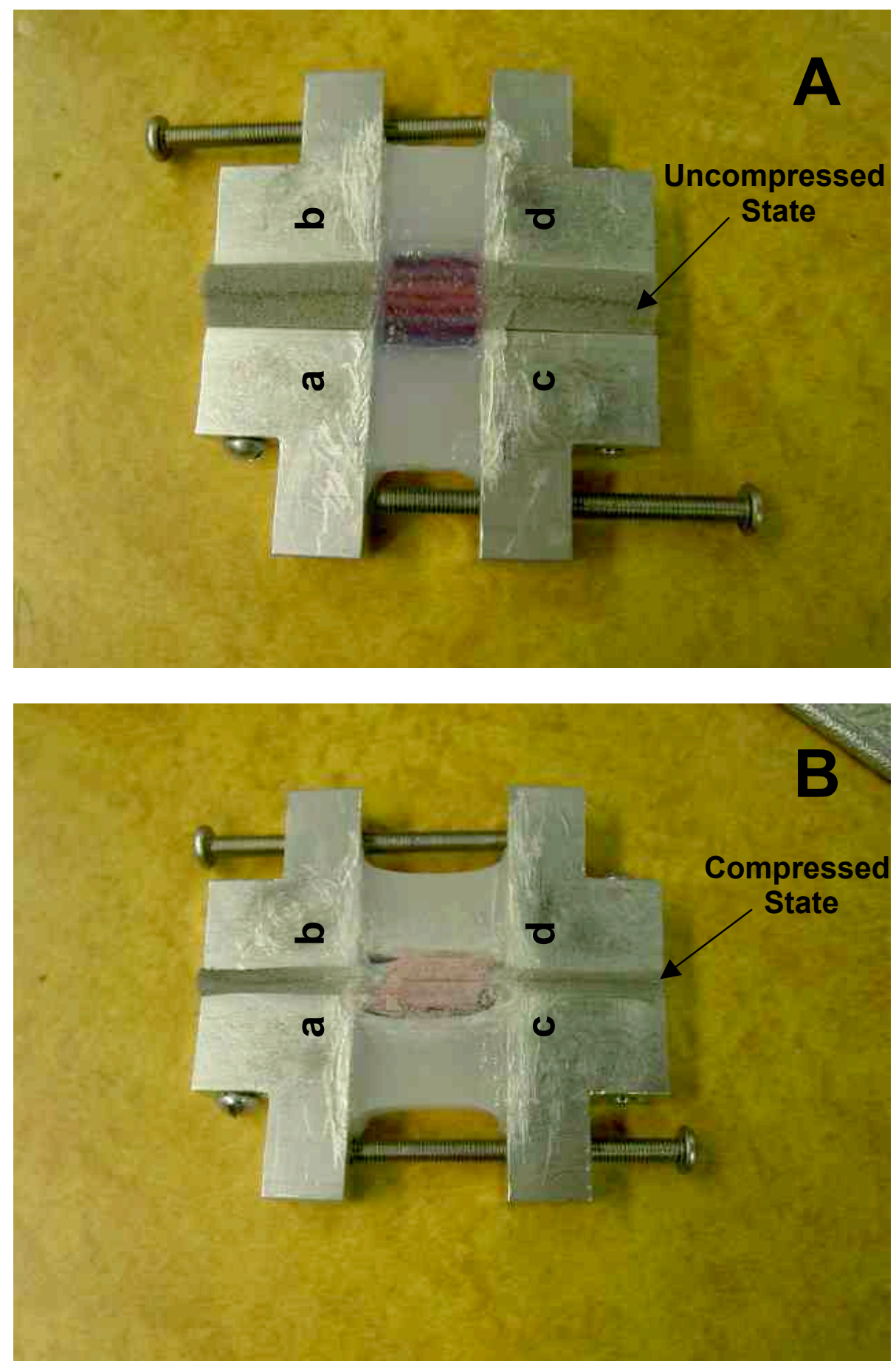

Figure 22. Fiber vocal folds mounted in four-plate tensioning system. (A) Illustrating uncompressed state prior to stretching. (B) Illustrating compressed state at $10 \mathrm{~mm}$ extension. 
A set of vocal folds with Dragon Skin ${ }^{\mathrm{TM}}$ blocks attached was then glued in place using Elmer's Stix-AllTM glue. One vocal fold was glued to block $c$ the other to block $d$, ensuring that medial edges of the vocal folds were touching and that superior aspects of the vocal folds were facing the same direction. Medial portions of the vocal folds were actually glued to the weatherstripping rather than the aluminum blocks to ensure that glottal closure could be attained throughout testing (see Figure 22A). Once the glue had set up enough to hold the vocal folds in place, plates $a$ and $b$ were glued to the opposing edges of the vocal folds (orientation shown in Figure 21). This setup was left to cure for a full twenty-four hours before testing to allow for the glue to fully set up. Once the glue was fully cured, additional screws were inserted into plates $a$ and $d$. Screws were then tightened until they contacted the opposing plates $c$ and $b$, which were not threaded. This design allowed the screws to push against the opposing plates, thereby lengthening the vocal folds.

\section{Data Collection}

During testing this four-plate system was mounted to an air supply using clamps (see Figures 23-25). Dow Corning ${ }^{\circledR}$ High Vacuum Grease was used between the air supply and tensioning plates to ensure that an airtight seal was obtained and to prevent any air leakage during testing. Air flow was then supplied to the system using an air compressor and clear plastic tubing (see Figure 23). Subglottal pressure was monitored using a pressure transducer placed inside the tubing directly below the level of the vocal folds. To calculate the frequency response of the physical model, a 1/4-inch microphone manufactured by Larson-Davis was also mounted inside the tubing just below the vocal folds, and fundamental frequency was measured using a National Instruments data acquisition system. 


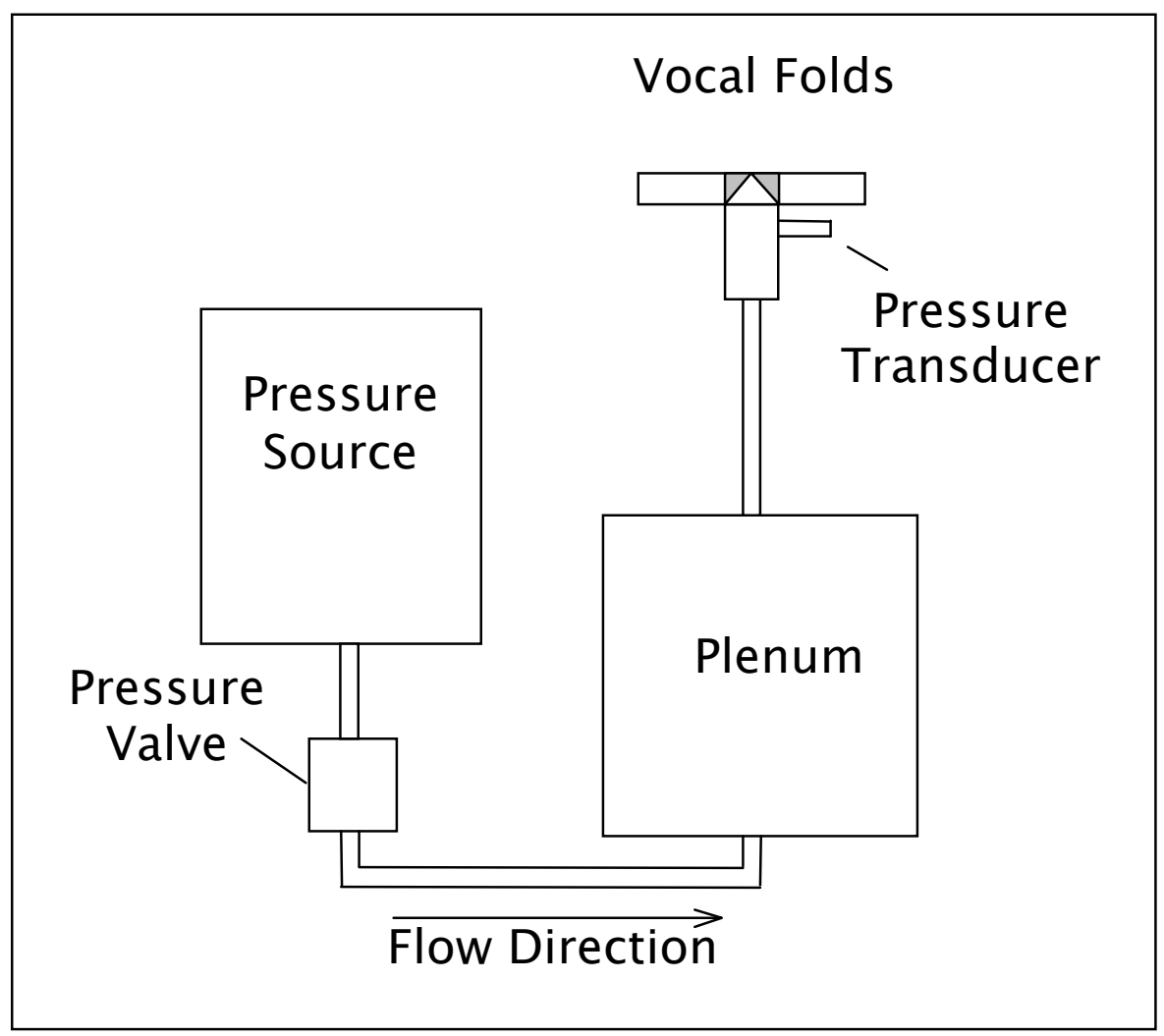

Figure 23. Schematic showing set-up of air supply. Reprinted from Journal of Biomechanics, Vol. 42, Pickup, B.A., Thomson, S.L., Influence of asymmetric stiffness on the structural and aerodynamic response of synthetic vocal fold models, p. 2220, Copyright 2009, with permission from Elsevier. 


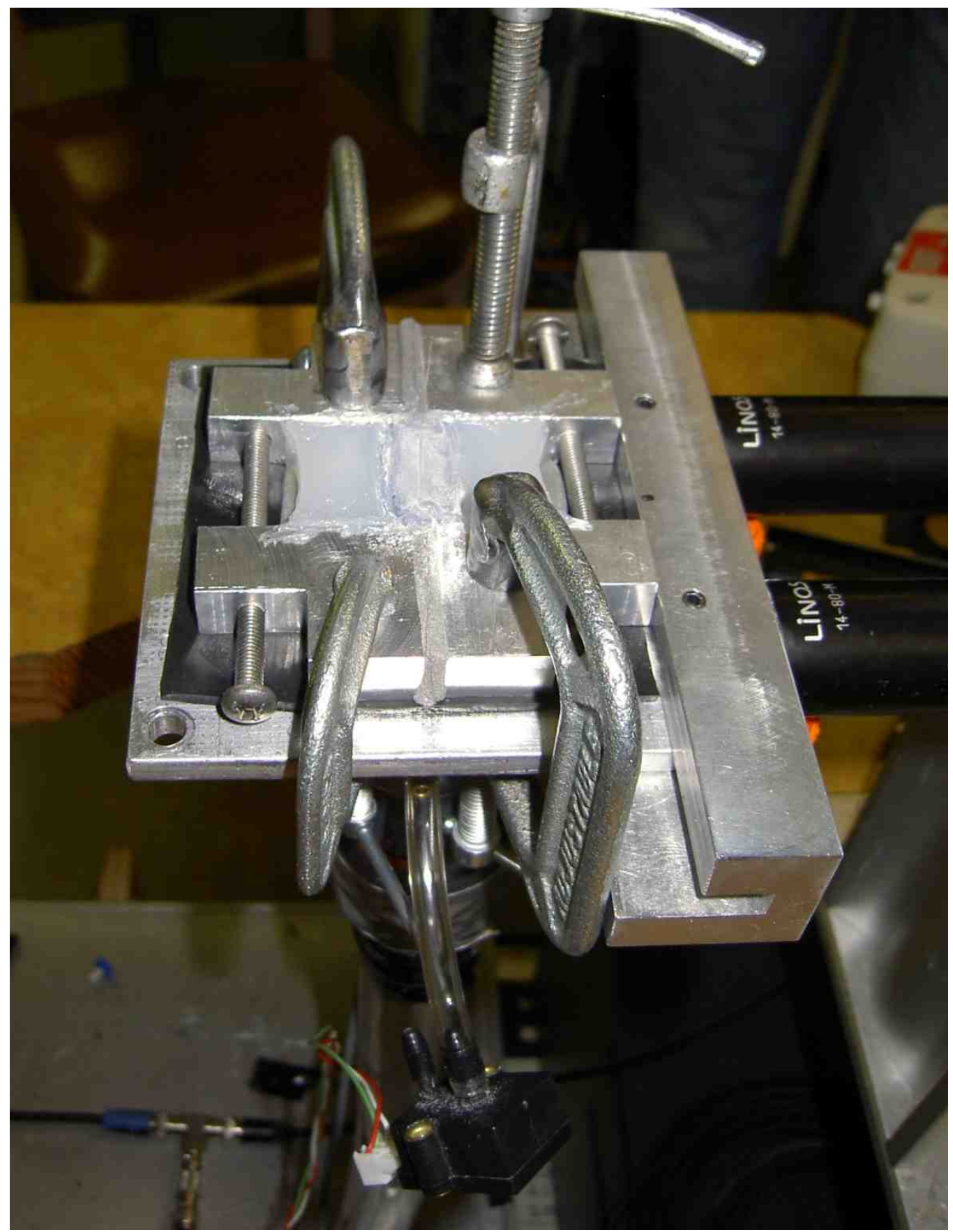

Figure 24. Photo showing the actual air-supply set-up used in testing. The four-plate tensioning system is shown, mounted to the air supply with clamps as described. 

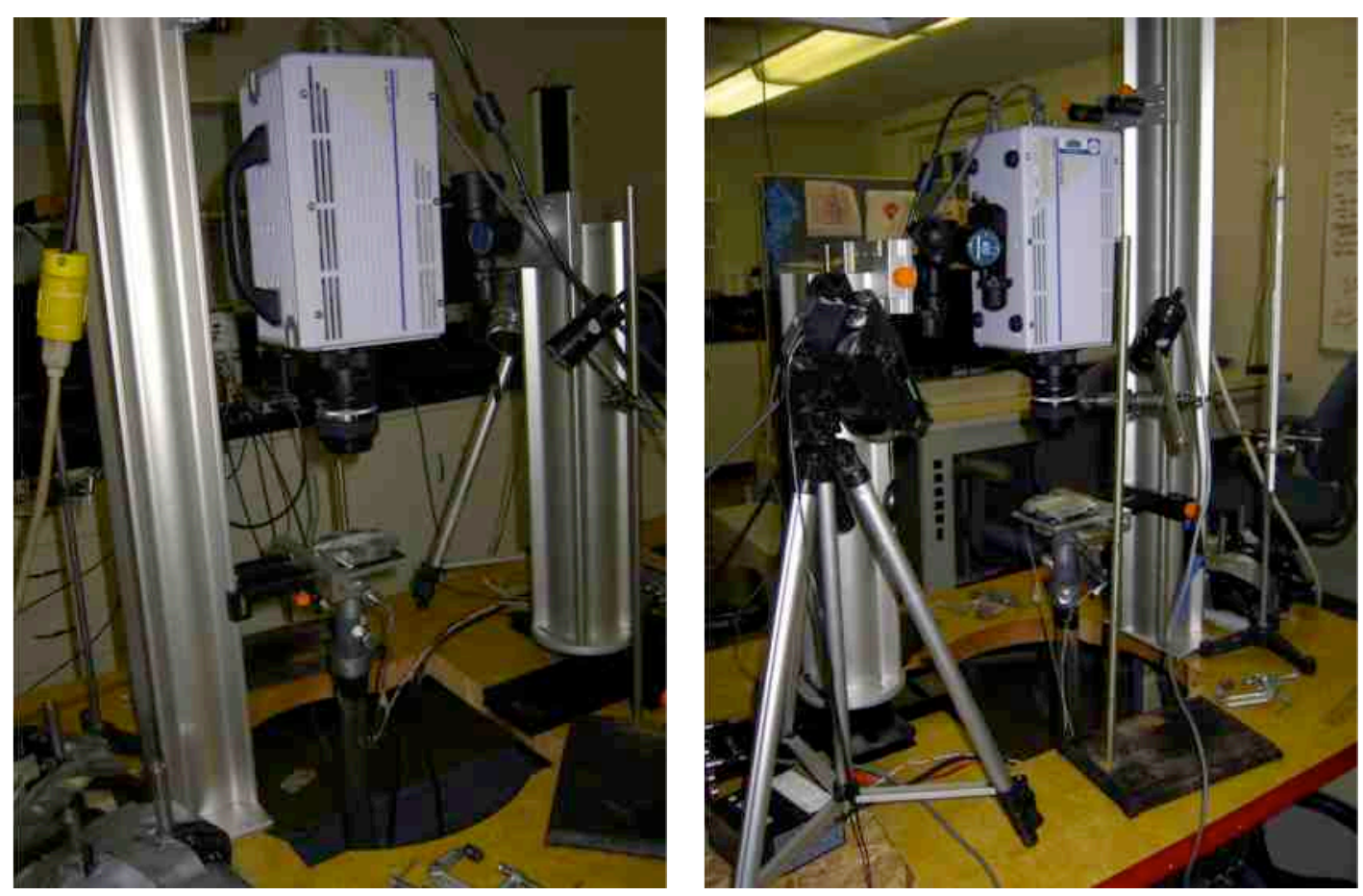

Figure 25. Photos showing the set-up and positioning for the high speed and digital video cameras used to record testing. 
To stretch the vocal folds and simulate CT muscle activation, screws running from blocks $a$ to $c$ and from blocks $b$ to $d$ were tightened gradually, pushing away the opposing plates. The length of the vocal folds was measured using a metric ruler for each increment of extension. Testing was performed at no extension and in $1 \mathrm{~mm}$ increments of extension up to $+10 \mathrm{~mm}$. For each vocal fold length the following procedure was followed.

Procedure. The setup was removed from the air supply. Screws running from plates $a$ to $c$ and $b$ to $d$ were tightened and vocal fold length measured until the desired length of extension was reached. The glottal gap was then closed after each extension by tightening screws running from plates $a$ to $b$ and $c$ to $d$, and the system was remounted to the air supply with clamps. Vocal fold length was re-measured after mounting was complete to ensure that the plates did not slide the vocal folds apart during the clamping process. Air flow was supplied to the system, and the subglottal pressure was monitored and gradually increased in increments of $0.1 \mathrm{kPa}$ until oscillation of the vocal folds occurred. This measure was recorded as the phonation threshold pressure for the given vocal fold extension. Subglottal pressure was then increased to $0.20 \mathrm{kPa}$ above the phonation threshold pressure, and the fundamental frequency was recorded again. The same process was repeated, relaxing the vocal folds from $+9 \mathrm{~mm}$ extension back to no extension. This procedure, including extension and relaxation measures, was repeated again twenty-four hours later to check for retest reliability of the silicone vocal folds.

All testing procedures were recorded using a Panasonic PV-GS400 digital video camera and an Omega HHT41B portable digital industrial stroboscope. High speed images were taken at $+0 \mathrm{~mm},+5 \mathrm{~mm}$, and $+10 \mathrm{~mm}$ extensions for one normal and one fibered model using a Photron APX-RS high speed camera at a rate of 10,000 frames per second with a 512 x 512 pixel resolution (see Figures 25-27). 


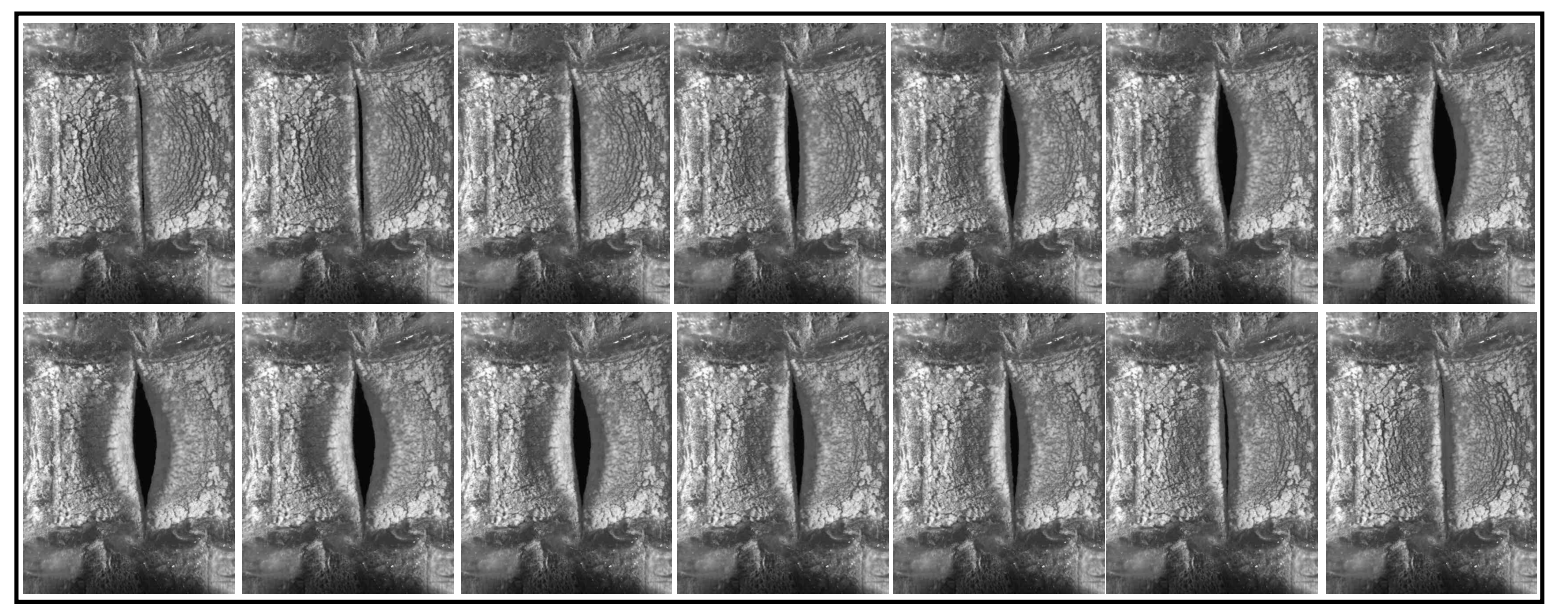

Figure 26. High-speed images taken during testing from a normal vocal fold model at $0 \mathrm{~mm}$ extension. 

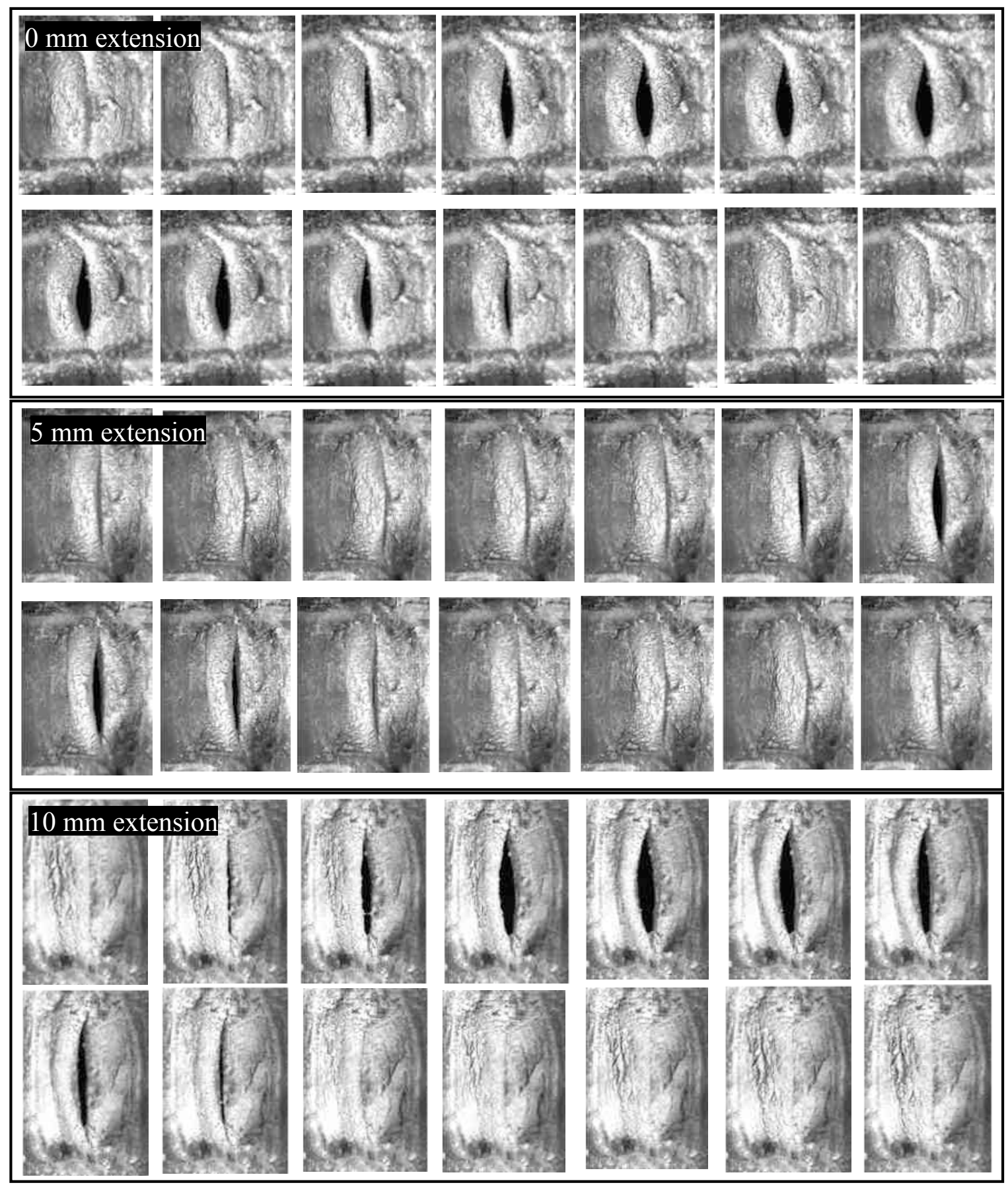

Figure 27. High-speed images taken during testing from a fiber vocal fold model at 0, 5, and 10 mm extensions. 
Stress-strain data. To obtain stress-strain curves for each model, samples of Ecoflex 0030 were created into cylindrical tubes—one representing the body layer with a 1:1:2 mixture ratio and one representing the cover layer with a 1:1:4 mixture ratio. Three normal and three fibered vocal fold models, distinct from those used in frequency testing, were also mounted to aluminum blocks using Elmer's Stix-All ${ }^{\mathrm{TM}}$ glue to obtain stress-strain curves for the constructed vocal folds. An Instron ${ }^{\circledR}$ tensile tester was then used to plot stress and strain of each material and of the linear and nonlinear vocal folds (see Figures 28 and 29).

Fiber density data. During an initial review of the findings, it was reasoned that fiber density could be impacting the results obtained during this testing. Therefore, fiber density readings were obtained using the following procedure.

Each of the three nonlinear fiber models tested in this study was removed from the dragon skin blocks used to attach the vocal folds to the tensioning plates during testing. Each model contained two individual vocal folds taken from the same original mold. Individual vocal folds were cut in half using a razor blade, making six individual folds in total for the three models. Scissors were then used to remove a 1-2 mm sample of cover layer from the medial portion of each vocal fold. Using a 10x magnification Selsi Loupe (model No. 415), acrylic yarn fibers were carefully removed from each 1-2 mm cover sample and counted (see Figures 30-32).

\section{Results}

The analysis of the data from these testing procedures focused on several key variables. These included fundamental frequency, phonation threshold pressure, fluctuations in frequency as a result of a slight increase in subglottal pressure, and retest reliability of each model type. Each variable will be addressed individually. 


\section{Stress vs. Strain for Linear Model}

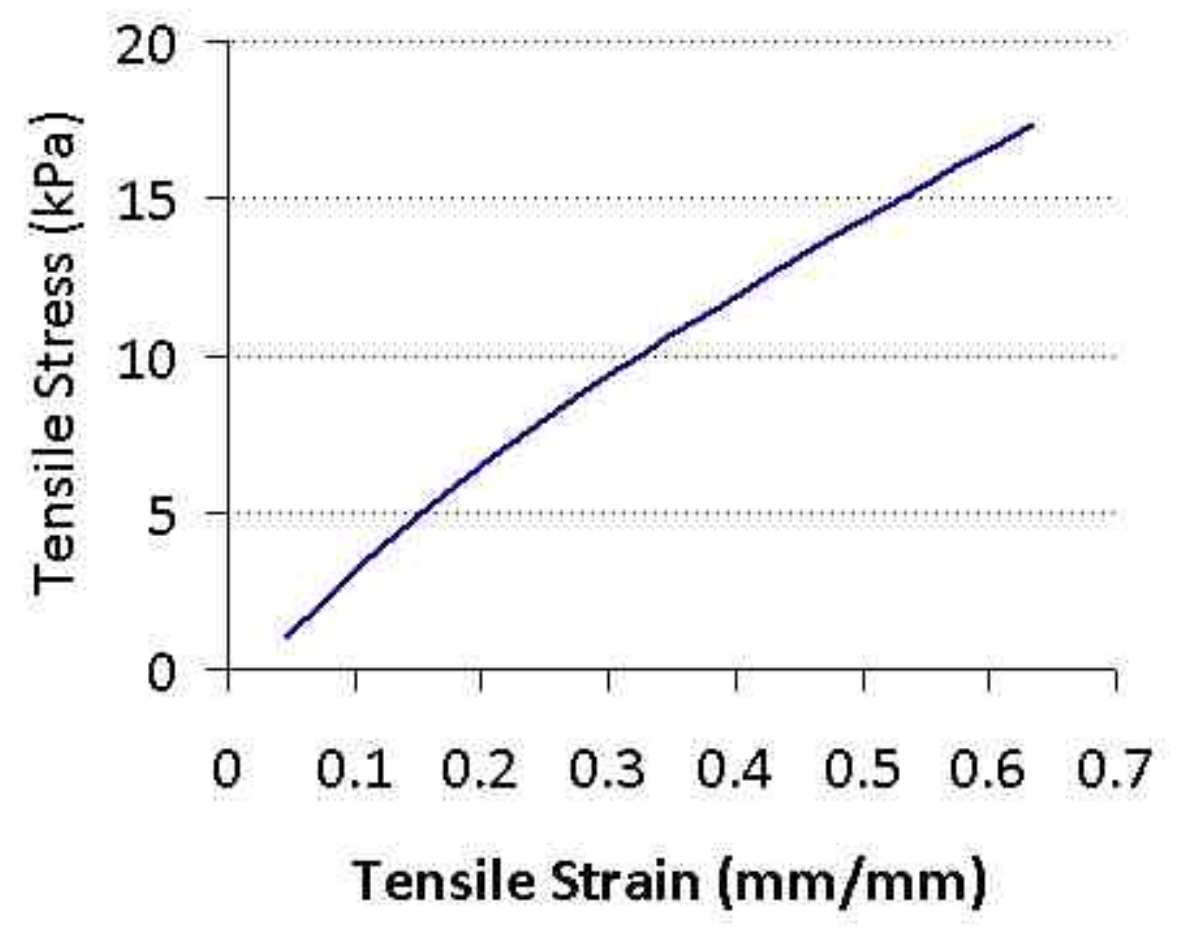

Figure 28. Stress-strain properties for normal silicone vocal fold models. As shown by the slope, these normal silicone vocal folds have a nearly linear stress-strain characteristic. 


\section{Stress vs. Strain for Fiber Models}

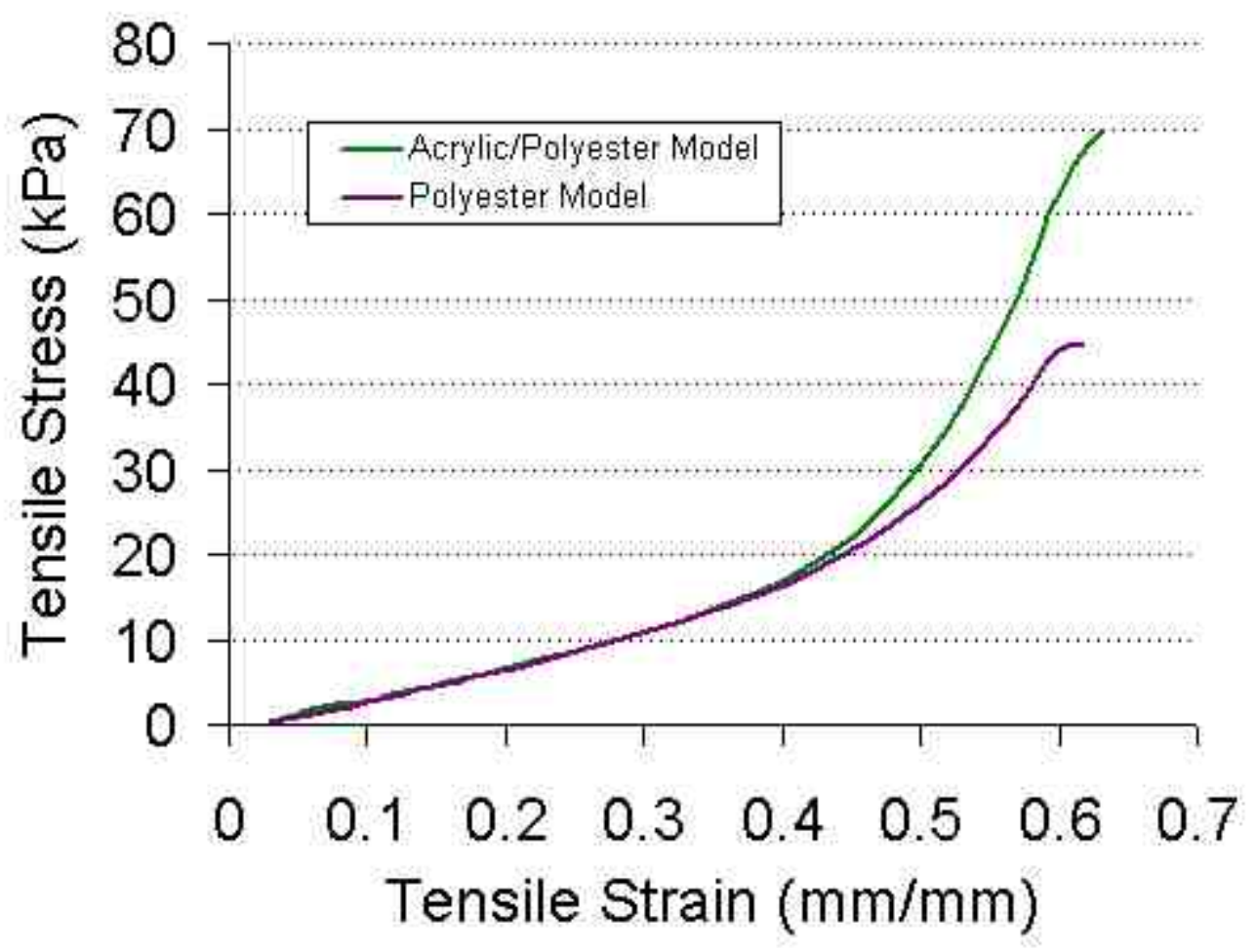

Figure 29. Stress-strain properties for fiber models. As can be seen, the use of polyester and acrylic fibers resulted in a nonlinear stress-strain characteristic. 


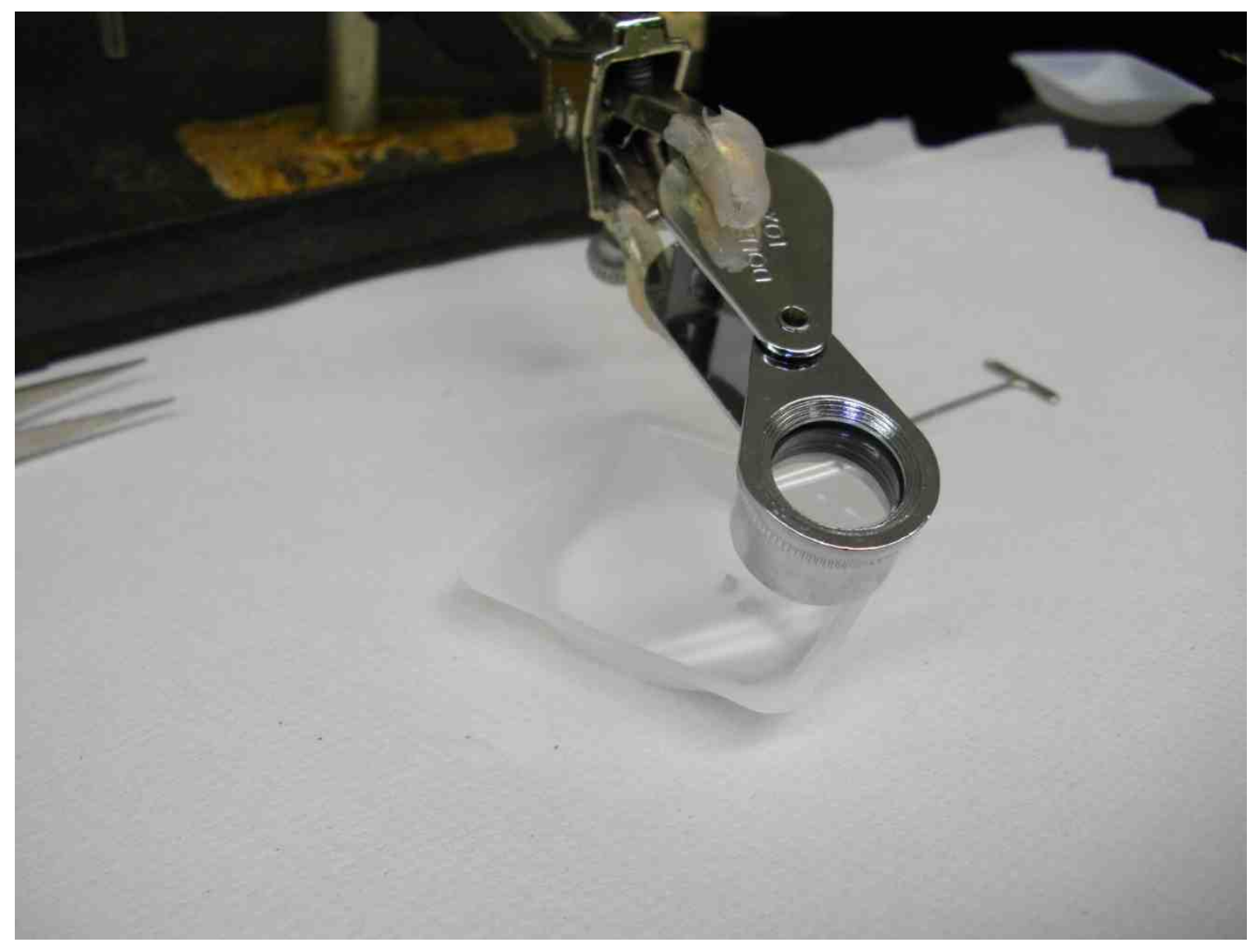

Figure 30. Set-up used to count acrylic fibers in each nonlinear fiber model. 10x magnification Selsi Loope (model No. 415) was used, as shown in this photo. 


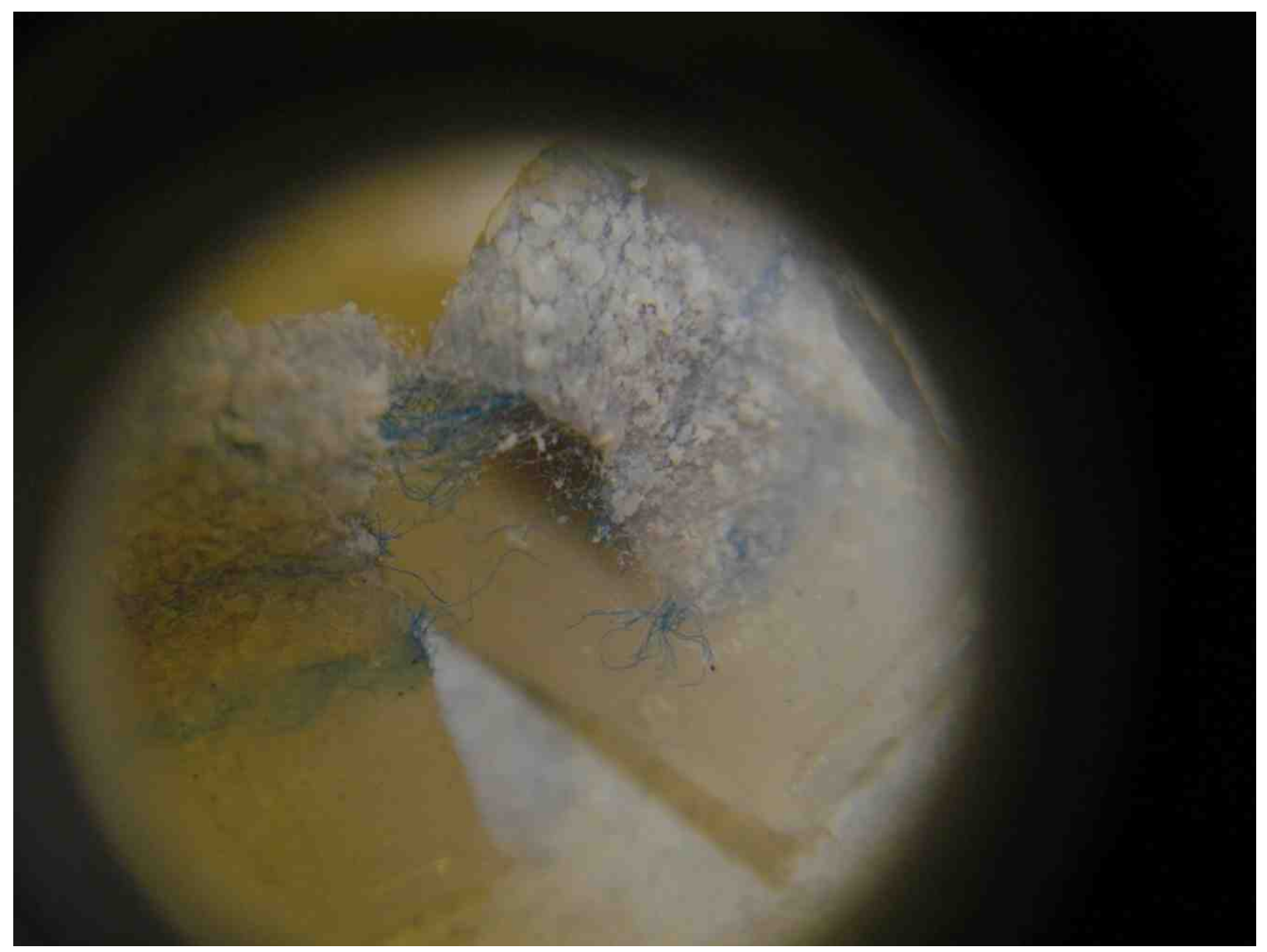

Figure 31. Image of the medial surfaces of an individual fiber vocal fold after being sliced in half with a razor blade but prior to removal of the 1-2 mm cover layer sample. 


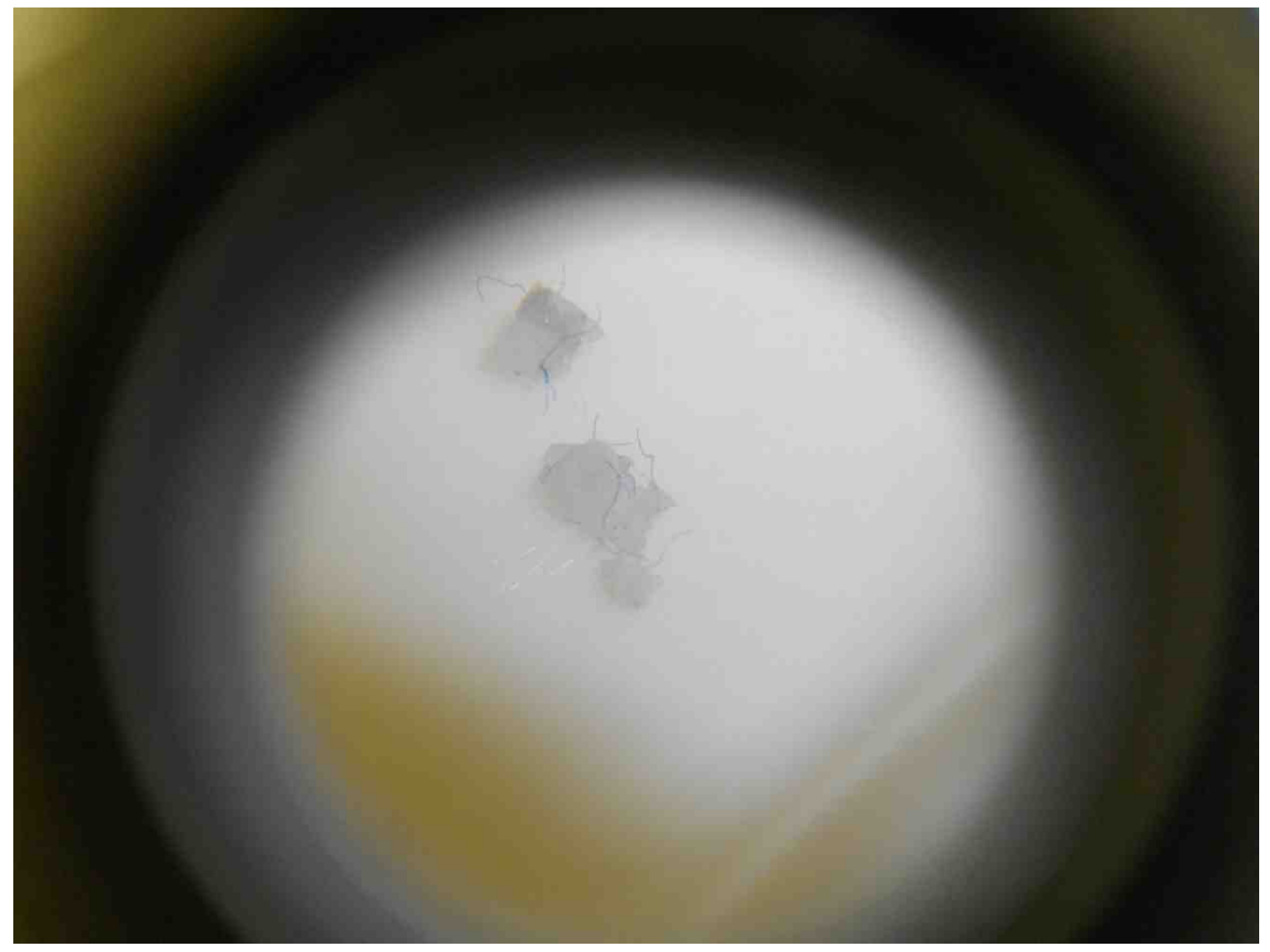

Figure 32. Photo through the 10x magnification Selsi Loope showing individual acrylic fibers (in this particular model, the fibers were blue in color). Each fiber was separated from the silicone and counted. 


\section{Fundamental Frequency}

As expected from the stress-strain results (see Figure 28), the three normal M5 models produced little variation in fundamental frequency as a function of vocal fold length (see Table 1 and Figure 33). As can be seen in Figure 33, Normal Model \#1 actually tended to decrease slightly in $\mathrm{F}_{0}$ as length increased, exhibiting a decrease of $2.7 \mathrm{~Hz}$ at the phonation onset threshold pressure $\left(\mathrm{P}_{\text {on }}\right)$ and of $2.2 \mathrm{~Hz}$ at $\mathrm{P}_{\text {on }}+0.20 \mathrm{kPa}$. Normal Model \#2, on the other hand, fluctuated up and down in $\mathrm{F}_{0}$ with the largest difference occurring between $+1 \mathrm{~mm}$ and $+4 \mathrm{~mm}$ extensions at $\mathrm{P}_{\text {on }}$ with a $4 \mathrm{~Hz}$ change. For the same model at $\mathrm{P}_{\text {on }}+0.20 \mathrm{kPa}$, the largest difference for $\mathrm{F}_{0}$ totaled only $3.3 \mathrm{~Hz}$ (from $+0 \mathrm{~mm}$ to $+1 \mathrm{~mm}$ extension). $+0 \mathrm{~mm}$ extension is considered the baseline or starting condition in which the vocal folds are in a relaxed, non-stretched state. In all models tested, the starting length was $18 \mathrm{~mm}$. With Normal Model \#3, the $\mathrm{F}_{0}$ again tended to fluctuate up and down with the largest difference in $\mathrm{F}_{0}$ occurring at $\mathrm{P}_{\text {on }}$ between $+0 \mathrm{~mm}$ and +2 mm extension, exhibiting a total shift of $6.1 \mathrm{~Hz}$. At $\mathrm{P}_{\text {on }}+0.20 \mathrm{kPa}$, the greatest difference in $\mathrm{F}_{0}$ occurred between $+1 \mathrm{~mm}$ and $+4 \mathrm{~mm}$ extensions for a $7.4 \mathrm{~Hz}$ difference.

The fiber models, on the other hand, followed a more predictable pattern of $\mathrm{F}_{0}$ change. Each model tended to increase in oscillation frequency as length increased. However, the extent of $\mathrm{F}_{0}$ change was inconsistent across the three models. Fiber Model \#1 exhibited a total $\mathrm{F}_{0}$ shift at $\mathrm{P}_{\text {on }}$ of $25.5 \mathrm{~Hz}$ with the largest difference occurring between $+0 \mathrm{~mm}$ and $+9 \mathrm{~mm}$ extension. At $\mathrm{P}_{\text {on }}+0.20 \mathrm{kPa}$, this same model demonstrated a $26.1 \mathrm{~Hz}$ change (see Table 2 and Figure 34 ).

Fiber Model \#2 followed this same predictable $\mathrm{F}_{0}$ increase as the vocal folds were stretched. However, its response was not quite as extensive as was the response of Fiber Model \#1. With this second model, change in $\mathrm{F}_{0}$ totaled $10.2 \mathrm{~Hz}$ at $\mathrm{P}_{\text {on }}$, with the largest difference 
Table 1

Fundamental Frequency $\left(F_{0}\right)$ at Onset Pressure $\left(\mathrm{P}_{\mathrm{on}}\right)$ and $\mathrm{P}_{\mathrm{on}}+0.20 \mathrm{kPa}$ for Normal Models \#1, 2 , and 3

\begin{tabular}{|c|c|c|c|c|c|c|c|c|}
\hline \multirow[t]{2}{*}{ Extension } & \multicolumn{2}{|c|}{$\begin{array}{c}\text { Normal \#1 } \\
\left(\mathrm{F}_{0} \text { in } \mathrm{Hz}\right)\end{array}$} & \multicolumn{2}{|c|}{$\begin{array}{c}\text { Normal \#2 } \\
\left(\mathrm{F}_{0} \text { in } \mathrm{Hz}\right)\end{array}$} & \multicolumn{2}{|c|}{$\begin{array}{c}\text { Normal \#3 } \\
\left(\mathrm{F}_{0} \text { in } \mathrm{Hz}\right) \\
\end{array}$} & \multicolumn{2}{|c|}{$\begin{array}{c}\text { Average } \\
\left(\mathrm{F}_{0} \text { in } \mathbf{H z}\right)\end{array}$} \\
\hline & at $\mathrm{P}_{\text {on }}$ & +0.20 & at $\mathrm{P}_{\text {on }}$ & +0.20 & at $\mathrm{P}_{\text {on }}$ & +0.20 & at $\mathrm{P}_{\text {on }}$ & +0.20 \\
\hline$+0 \mathrm{~mm}$ & 126.6 & 123.0 & 125.6 & 123.8 & 126.3 & 122.1 & 126.2 & 123.0 \\
\hline$+1 \mathrm{~mm}$ & 125.1 & 122.9 & 123.2 & 120.5 & 121.7 & 115.1 & 123.3 & 119.5 \\
\hline$+2 \mathrm{~mm}$ & 126.0 & 124.2 & 124.4 & 121.8 & 120.2 & 117.6 & 123.5 & 121.2 \\
\hline$+3 \mathrm{~mm}$ & 126.0 & 124.1 & 125.9 & 122.7 & 122.2 & 119.5 & 124.7 & 122.1 \\
\hline$+4 \mathrm{~mm}$ & 125.3 & 123.2 & 127.2 & 122.7 & 125.0 & 122.5 & 125.8 & 122.8 \\
\hline$+5 \mathrm{~mm}$ & 126.1 & 123.7 & 126.3 & 122.5 & 124.7 & 120.6 & 125.7 & 122.3 \\
\hline$+6 \mathrm{~mm}$ & 126.2 & 123.6 & 126.6 & 122.2 & 124.4 & 120.8 & 125.7 & 122.2 \\
\hline$+7 \mathrm{~mm}$ & 124.9 & 122.6 & 125.9 & 121.4 & 122.5 & 118.5 & 124.4 & 120.8 \\
\hline$+8 \mathrm{~mm}$ & 126.3 & 122.9 & 125.0 & 120.3 & 124.4 & 120.9 & 125.2 & 121.4 \\
\hline$+9 \mathrm{~mm}$ & 125.8 & 122.5 & 125.0 & 120.0 & 124.1 & 120.3 & 125.0 & 120.9 \\
\hline$+10 \mathrm{~mm}$ & 123.9 & 120.8 & 124.4 & 121.7 & 122.0 & 118.8 & 123.4 & 120.4 \\
\hline$(\operatorname{Max} \Delta)$ & $2.7 \mathrm{~Hz}$ & $2.2 \mathrm{~Hz}$ & $4.0 \mathrm{~Hz}$ & $3.3 \mathrm{~Hz}$ & $6.1 \mathrm{~Hz}$ & $7.4 \mathrm{~Hz}$ & $2.9 \mathrm{~Hz}$ & $3.5 \mathrm{~Hz}$ \\
\hline
\end{tabular}




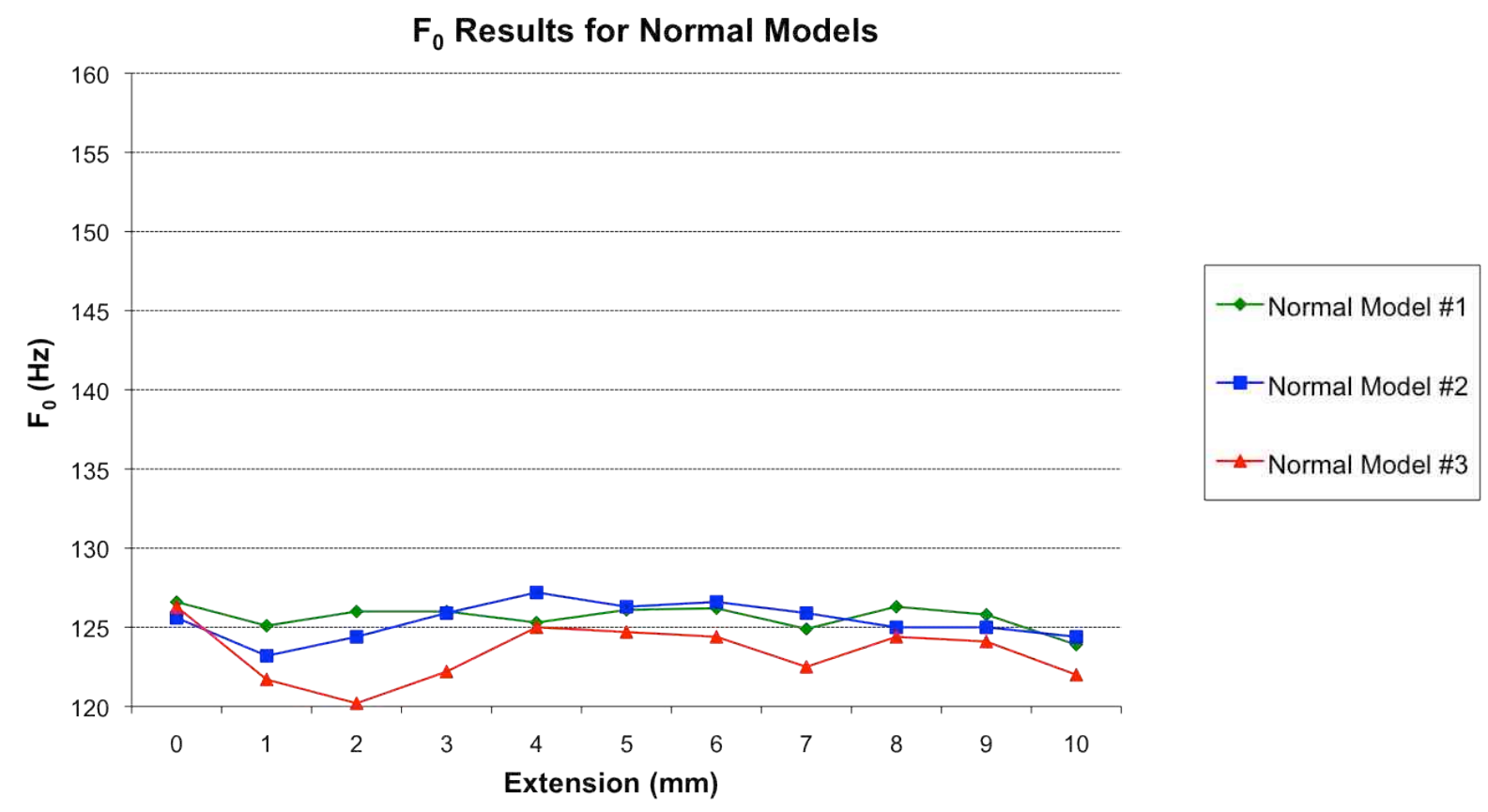

Figure 33. Fundamental frequency $\left(\mathrm{F}_{0}\right)$ vs. extension in $\mathrm{mm}$ for normal vocal fold models. 
Table 2

Fundamental Frequency $\left(F_{0}\right)$ at Onset Pressure $\left(\mathrm{P}_{\mathrm{on}}\right)$ and $\mathrm{P}_{\mathrm{on}}+0.20 \mathrm{kPa}$ for Fiber Models \#1, 2, and 3

\begin{tabular}{|c|c|c|c|c|c|c|c|c|}
\hline \multirow[t]{2}{*}{ Extension } & \multicolumn{2}{|c|}{$\begin{array}{c}\text { Fiber \#1 } \\
\left(\mathrm{F}_{0} \text { in } \mathrm{Hz}\right)\end{array}$} & \multicolumn{2}{|c|}{$\begin{array}{c}\text { Fiber \#2 } \\
\left(\mathrm{F}_{0} \text { in } \mathrm{Hz}\right)\end{array}$} & \multicolumn{2}{|c|}{$\begin{array}{c}\text { Fiber \#3 } \\
\left(\mathrm{F}_{0} \text { in } \mathrm{Hz}\right)\end{array}$} & \multicolumn{2}{|c|}{$\begin{array}{c}\text { Average } \\
\left(F_{0} \text { in } \mathbf{H z}\right)\end{array}$} \\
\hline & at $\mathrm{P}_{\text {on }}$ & +0.20 & at $\mathrm{P}_{\text {on }}$ & +0.20 & at $\mathrm{P}_{\text {on }}$ & +0.20 & at $\mathrm{P}_{\text {on }}$ & +0.20 \\
\hline$+\mathbf{0} \mathbf{~ m m}$ & 126.9 & 125.6 & 134.0 & 134.9 & 131.1 & 130.6 & 130.7 & 130.4 \\
\hline$+1 \mathrm{~mm}$ & 129.5 & 129.2 & 133.9 & 134.7 & 130.8 & 129.9 & 131.4 & 131.3 \\
\hline$+2 \mathrm{~mm}$ & 133.5 & 133.3 & 133.7 & 134.3 & 130.4 & 129.4 & 132.5 & 132.3 \\
\hline$+3 \mathrm{~mm}$ & 136.9 & 137.4 & 134.1 & 134.5 & 131.2 & 129.8 & 134.1 & 133.9 \\
\hline$+4 \mathrm{~mm}$ & 138.9 & 138.9 & 135.8 & 135.7 & 130.4 & 129.4 & 135.0 & 134.7 \\
\hline$+5 \mathrm{~mm}$ & 142.5 & 142.5 & 136.3 & 136.1 & 130.5 & 129.2 & 136.4 & 135.9 \\
\hline$+6 \mathrm{~mm}$ & 144.1 & 144.1 & 136.9 & 137.9 & 131.4 & 130.8 & 137.5 & 137.8 \\
\hline$+7 \mathrm{~mm}$ & 146.2 & 146.4 & 140.3 & 141.2 & 131.8 & 130.4 & 139.4 & 139.3 \\
\hline$+8 \mathrm{~mm}$ & 149.7 & 149.0 & 140.0 & 141.0 & 132.0 & 130.9 & 140.6 & 140.3 \\
\hline$+9 \mathrm{~mm}$ & 152.4 & 151.7 & 143.0 & 143.0 & 132.0 & 130.9 & 142.5 & 141.9 \\
\hline$+10 \mathrm{~mm}$ & 144.9 & 145.3 & 143.9 & 144.1 & 132.5 & 131.5 & 140.4 & 140.3 \\
\hline$(\operatorname{Max} \Delta)$ & $25.5 \mathrm{~Hz}$ & $26.1 \mathrm{~Hz}$ & $10.2 \mathrm{~Hz}$ & $9.8 \mathrm{~Hz}$ & $2.1 \mathrm{~Hz}$ & $2.3 \mathrm{~Hz}$ & $11.8 \mathrm{~Hz}$ & $11.5 \mathrm{~Hz}$ \\
\hline
\end{tabular}




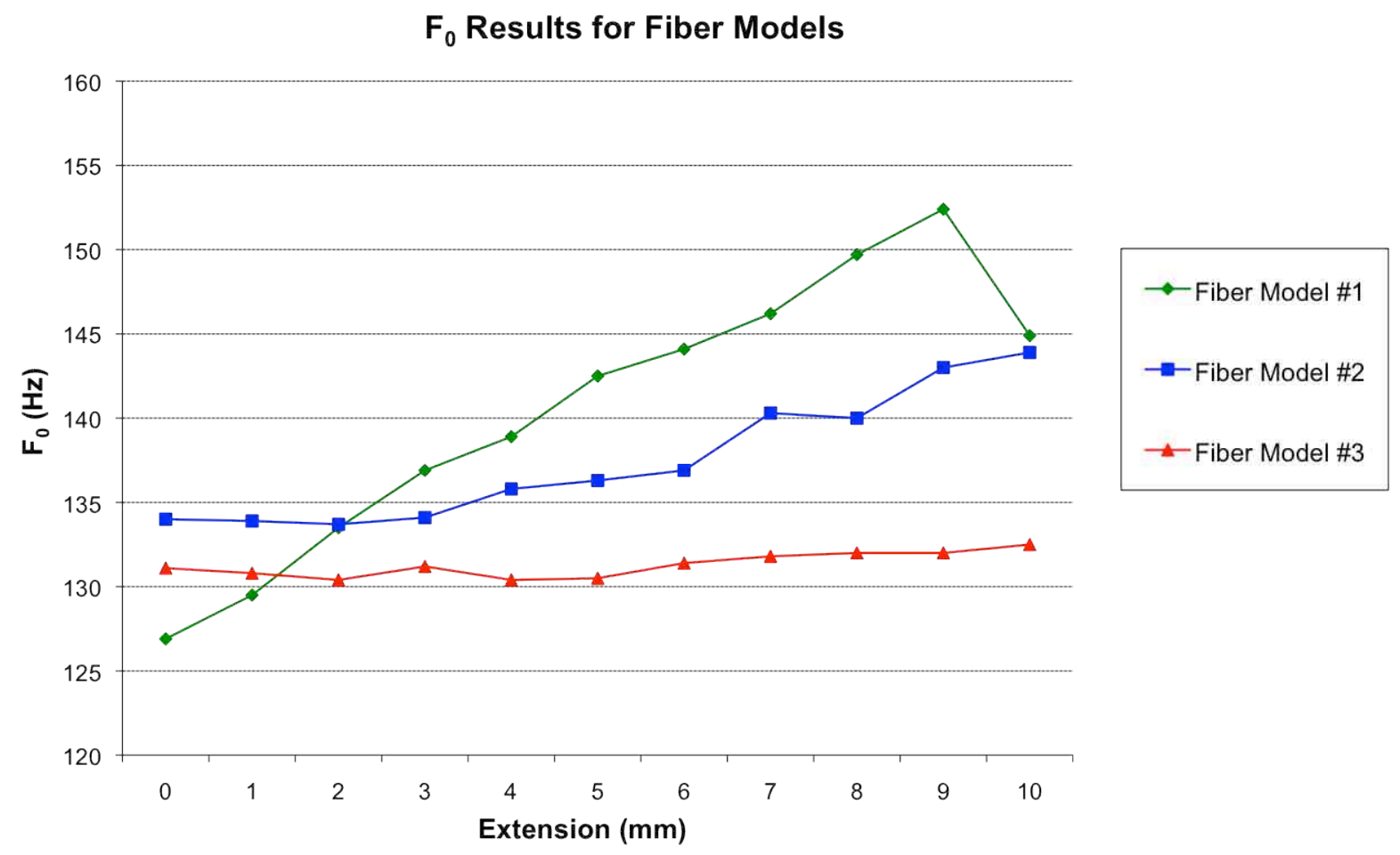

Figure 34. Fundamental frequency $\left(\mathrm{F}_{0}\right)$ vs. extension in $\mathrm{mm}$ for nonlinear vocal fold models with acrylic and polyester fibers embedded into the cover layer. 
occurring between $+2 \mathrm{~mm}$ and $+10 \mathrm{~mm}$ extensions. At $\mathrm{P}_{\text {on }}+0.20 \mathrm{kPa}$, the $\mathrm{F}_{0}$ change totaled 9.8 $\mathrm{Hz}$, with the largest difference again occurring at $+2 \mathrm{~mm}$ and $+10 \mathrm{~mm}$ extensions.

The final nonlinear model, Fiber Model \#3, provided the most modest results of all the fiber models. At $\mathrm{P}_{\text {on }}$, the maximum $\mathrm{F}_{0}$ change was only $2.1 \mathrm{~Hz}$, with the largest differences occurring between $+2 \mathrm{~mm}$ and $+10 \mathrm{~mm}$ extensions. This model also fluctuated more in its $\mathrm{F}_{0}$ changes with respect to length changes than the other two fiber models tested. At $\mathrm{P}_{\text {on }}+0.20 \mathrm{kPa}$, the $\mathrm{F}_{0}$ changed only $2.3 \mathrm{~Hz}$, with maximum differences occurring between $+5 \mathrm{~mm}$ and $+10 \mathrm{~mm}$ extensions.

\section{Phonation Onset Pressure ( $\left.\mathbf{P}_{\text {on }}\right)$}

For each vocal fold length tested, $\mathrm{P}_{\text {on }}$, or the pressure needed to initiate oscillation, was measured. In human vocal folds PTP and $\mathrm{P}_{\text {on }}$ increase with tension, which generally occurs as a result of an increase in vocal fold length (Solomon et al., 2007; Titze, 1992). This trend was not seen in any of the normal, linear M5 models. In fact, all three normal models demonstrated the opposite response, with a steady decrease in $\mathrm{P}_{\text {on }}$ as vocal fold length increased (see Figure 35). At $+0 \mathrm{~mm}$ extension, all three normal models had a $\mathrm{P}_{\text {on }}$ close to $0.80 \mathrm{kPa}$. At $+10 \mathrm{~mm}$ extension, on the other hand, all three had a $\mathrm{P}_{\text {on }}$ of closer to $0.30 \mathrm{kPa}$, a significant decrease from its initial $\mathrm{P}_{\text {on }}$ (see Table 3 and Figure 35).

The fiber models followed a less predictable pattern for changes in $\mathrm{P}_{\text {on }}$ with respect to vocal fold length (see Table 4 and Figure 36). In general, however, the $\mathrm{P}_{\text {on }}$ was slightly higher for the three fiber models than for the three normal M5 models. None of the fiber models reached as low as $0.30 \mathrm{kPa}$. The lowest $\mathrm{P}_{\text {on }}$ for any of the fiber models was $0.60 \mathrm{kPa}$, which occurred at 4 mm extension for Fiber Model \#2. The highest recorded $\mathrm{P}_{\mathrm{on}}$ for any of the fiber models was 
Table 3

Onset Pressures $\left(\mathrm{P}_{\mathrm{on}}\right)$ for Normal Models \#1, 2, and 3 at Each Extension

\begin{tabular}{|c|c|c|c|c|}
\hline Extension & $\begin{array}{c}\text { Normal \#1 } \\
\left(\mathrm{P}_{\text {on }} \text { in kPa) }\right.\end{array}$ & $\begin{array}{c}\text { Normal \#2 } \\
\left(\mathrm{P}_{\text {on }} \text { in kPa) }\right.\end{array}$ & $\begin{array}{c}\text { Normal \#3 } \\
\left(\mathrm{P}_{\text {on }} \text { in kPa) }\right.\end{array}$ & $\begin{array}{c}\text { Average } \\
\left(\mathrm{P}_{\text {on }} \text { in } \mathbf{k P a}\right)\end{array}$ \\
\hline$+\mathbf{0} \mathbf{m m}$ & 0.78 & 0.70 & 0.81 & 0.76 \\
\hline$+1 \mathrm{~mm}$ & 0.65 & 0.67 & 0.57 & 0.63 \\
\hline$+2 \mathrm{~mm}$ & 0.61 & 0.60 & 0.55 & 0.59 \\
\hline$+3 \mathrm{~mm}$ & 0.61 & 0.65 & 0.43 & 0.56 \\
\hline$+4 \mathrm{~mm}$ & 0.56 & 0.55 & 0.43 & 0.51 \\
\hline$+5 \mathrm{~mm}$ & 0.60 & 0.44 & 0.39 & 0.48 \\
\hline$+6 \mathrm{~mm}$ & 0.54 & 0.43 & 0.38 & 0.45 \\
\hline$+7 \mathrm{~mm}$ & 0.45 & 0.41 & 0.37 & 0.41 \\
\hline$+8 \mathrm{~mm}$ & 0.42 & 0.35 & 0.35 & 0.37 \\
\hline +9 $\mathrm{mm}$ & 0.34 & 0.38 & 0.33 & 0.35 \\
\hline$+10 \mathrm{~mm}$ & 0.37 & 0.30 & 0.28 & 0.32 \\
\hline$(\operatorname{Max} \Delta)$ & 0.44 & 0.40 & 0.53 & 0.44 \\
\hline
\end{tabular}


Onset Pressures for Normal Models

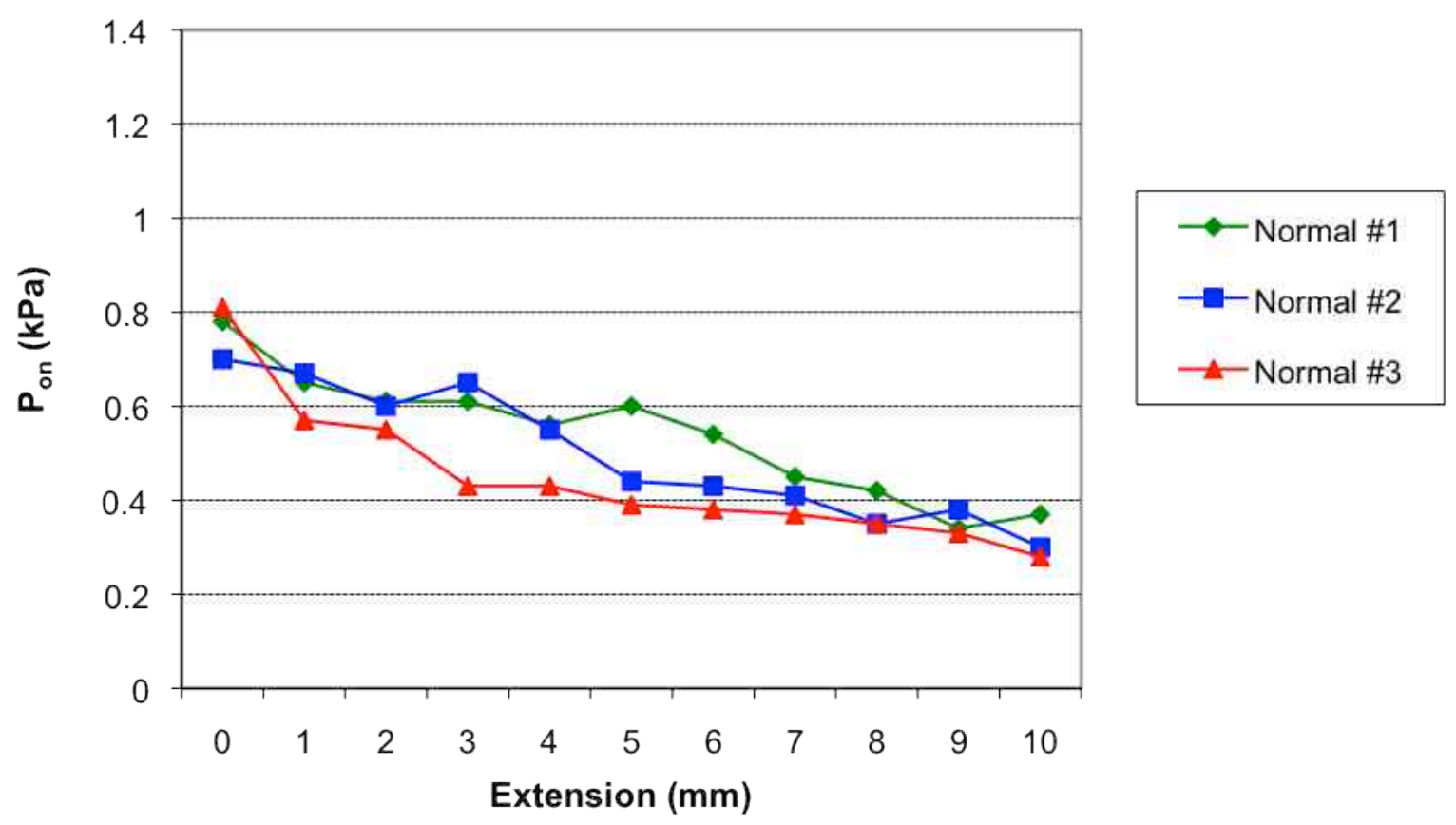

Figure 35. Onset pressure vs. extension for normal models. 
Table 4

Onset Pressures $\left(\mathrm{P}_{\mathrm{on}}\right)$ for Fiber Models \#1, 2, and 3 at Each Extension

\begin{tabular}{|c|c|c|c|c|}
\hline Extension & $\begin{array}{c}\text { Fiber \#1 } \\
\left(\mathrm{P}_{\text {on }} \text { in } \mathbf{k P a}\right)\end{array}$ & $\begin{array}{c}\text { Fiber \#2 } \\
\left(\mathrm{P}_{\text {on }} \text { in } \mathbf{k P a}\right)\end{array}$ & $\begin{array}{c}\text { Fiber \#3 } \\
\left(\mathrm{P}_{\text {on }} \text { in } \mathbf{k P a}\right)\end{array}$ & $\begin{array}{c}\text { Average } \\
\left(\mathrm{P}_{\text {on }} \text { in } \mathbf{k P a}\right)\end{array}$ \\
\hline$+\mathbf{0} \mathbf{m m}$ & 0.89 & 1.00 & 0.89 & 0.93 \\
\hline$+1 \mathrm{~mm}$ & 0.66 & 0.94 & 0.73 & 0.78 \\
\hline$+2 \mathrm{~mm}$ & 0.80 & 0.84 & 0.67 & 0.77 \\
\hline$+3 \mathrm{~mm}$ & 1.00 & 0.75 & 0.73 & 0.83 \\
\hline$+4 \mathrm{~mm}$ & 0.96 & 0.60 & 0.66 & 0.74 \\
\hline$+5 \mathrm{~mm}$ & 0.99 & 0.92 & 0.61 & 0.84 \\
\hline$+6 \mathrm{~mm}$ & 0.95 & 0.94 & 0.72 & 0.87 \\
\hline$+7 \mathrm{~mm}$ & 0.94 & 1.20 & 0.73 & 0.96 \\
\hline$+8 \mathrm{~mm}$ & 0.94 & 1.05 & 0.66 & 0.88 \\
\hline +9 $\mathrm{mm}$ & 1.02 & 1.13 & 0.73 & 0.96 \\
\hline$+10 \mathrm{~mm}$ & 0.78 & 1.03 & 0.88 & 0.90 \\
\hline$(\operatorname{Max} \Delta)$ & 0.36 & 0.60 & 0.28 & 0.22 \\
\hline
\end{tabular}




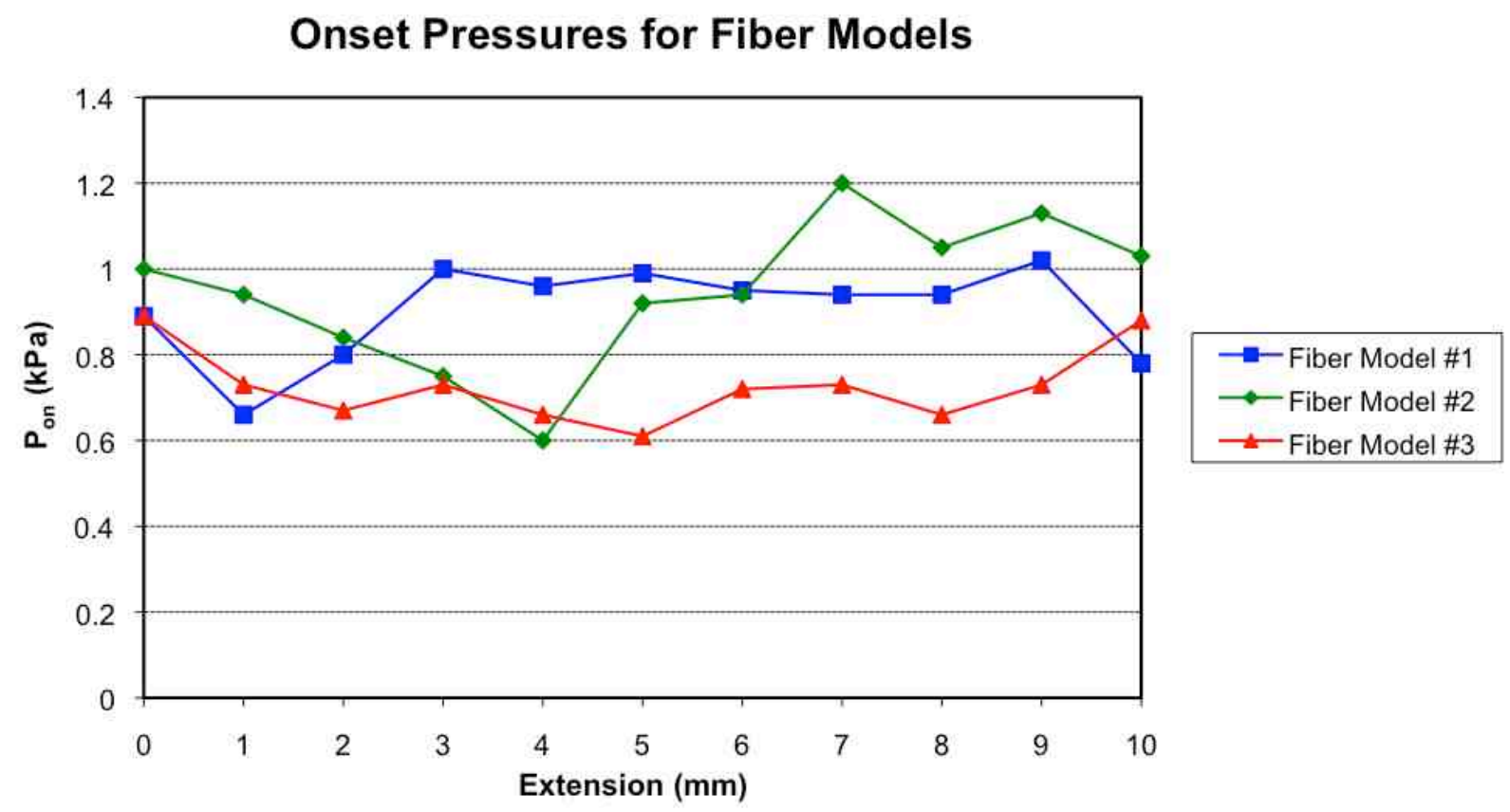

Figure 36. Onset pressure vs. extension for models with polyester and acrylic fibers embedded in the cover layer. 
$1.29 \mathrm{kPa}$ (which was recorded with Fiber Model \#2 during the relaxation phase when it was returned back to $+0 \mathrm{~mm}$ extension). For Fiber Model \#1, the mean $\mathrm{P}_{\text {on }}$ was $0.90 \mathrm{kPa}$, and the median $\mathrm{P}_{\text {on }}$ was $0.94 \mathrm{kPa}$. The mean $\mathrm{P}_{\text {on }}$ for Fiber Model \#2 was $0.95 \mathrm{kPa}$. The median $\mathrm{P}_{\text {on }}$ for Fiber Model \#2 was $0.94 \mathrm{kPa}$. For Fiber Model \#3, the mean $\mathrm{P}_{\text {on }}$ was $0.73 \mathrm{kPa}$, and the median $\mathrm{P}_{\text {on }}$ was $0.73 \mathrm{kPa}$. These phonation threshold pressure data also indicate a physical difference between Fiber Models \#1 and \#2 and Fiber Model \#3.

\section{Fiber Density}

After the frequency data were collected, it was determined that the number of acrylic fibers in each model may have varied somewhat and thus influenced the test results. Polyester fibers were more easily separated from the fabric and divided evenly prior to fiber layer construction, so this was believed to be fairly standard throughout all the nonlinear models used. Therefore, following data collection, the number of acrylic fibers embedded in each individual vocal fold (six in total, as each model contained two separate vocal folds) was determined. Results for each pair of vocal folds were averaged and then compared with the other two models to determine if this may have had a significant impact. Fiber Model \#3 was the most difficult for which to obtain fiber density results because the acrylic fibers used in this model were yellow and were sometimes difficult to distinguish from the polyester fibers, which were light purple and appeared white when embedded in the silicone. Specific acrylic fiber counts can be found in Table 5. Overall, no substantial difference was noted in the quantity of fibers contained in Fiber Models \#1 and 2. However, Fiber Model \#3 contained notably fewer fibers than the other two models. It is possible that this may have influenced the frequency results obtained and caused the inconsistency across the nonlinear models. 
Table 5

Number of Acrylic Fibers Present in Each Individual Vocal Fold. (Averages for each pair of vocal folds are included below these values. Individual folds are labeled "+" and "-.")

\begin{tabular}{lccccc}
\hline \multicolumn{3}{c}{ Fiber \#1 } & \multicolumn{2}{c}{ Fiber \#2 } & \multicolumn{2}{c}{ Fiber \#3 } \\
\hline+ & - & + & - & + & - \\
\hline 143 & 177 & 162 & 154 & 145 & 124 \\
\hline Average $=160$ & & Average $=158$ & Average $=134.5$ \\
\hline
\end{tabular}




\section{Changes in Frequency as a Result of Slight Changes in Subglottal Pressure}

One factor that was investigated in this study was the relationship between $\mathrm{F}_{0}$ and subglottal pressure. In previous studies, it has been shown that as subglottal pressure increases, $\mathrm{F}_{0}$ increases as well (Hsiao et al., 2001; Titze, 1989). In this study, two separate $\mathrm{F}_{0}$ measures were taken for comparison: one at the onset pressure and the other at $0.20 \mathrm{kPa}$ above onset pressure. Figures 37-42 illustrate these results. As can be seen in these graphs, $\mathrm{F}_{0}$ remained fairly constant for the fiber models. For the normal, silicone models, the $\mathrm{F}_{0}$ actually dropped fairly uniformly for each increase in subglottal pressure.

\section{Reliability Data}

To check the retest reliability of frequency and onset pressure results for both normal and fiber silicone vocal fold models, data were taken for each model during stretching in $1 \mathrm{~mm}$ increments and then during relaxation in $1 \mathrm{~mm}$ increments. Each test was then repeated 24 hours later and results were compared.

As can be seen in Figures 43-48, both normal and fiber vocal fold models displayed hysteresis, or a sort of memory in which the effect of a force lags behind its cause due to the properties of the system. This is evidenced by the banana-shaped curve made by stretching and relaxation data for each model. This hysteresis is also present in the human vocal folds, although its effects seemed to be longer-lasting in the silicone vocal folds than would be expected in human vocal folds. This hysteresis is still seen to a smaller degree 24 hours after initial testing during the reliability retest (Plant et al., 2004).

The retest results revealed that the silicone provided fairly replicable results for the normal vocal fold models. For the fiber vocal fold models, the retest results followed a similar pattern for fundamental frequency response and onset pressure to the original testing; however, 


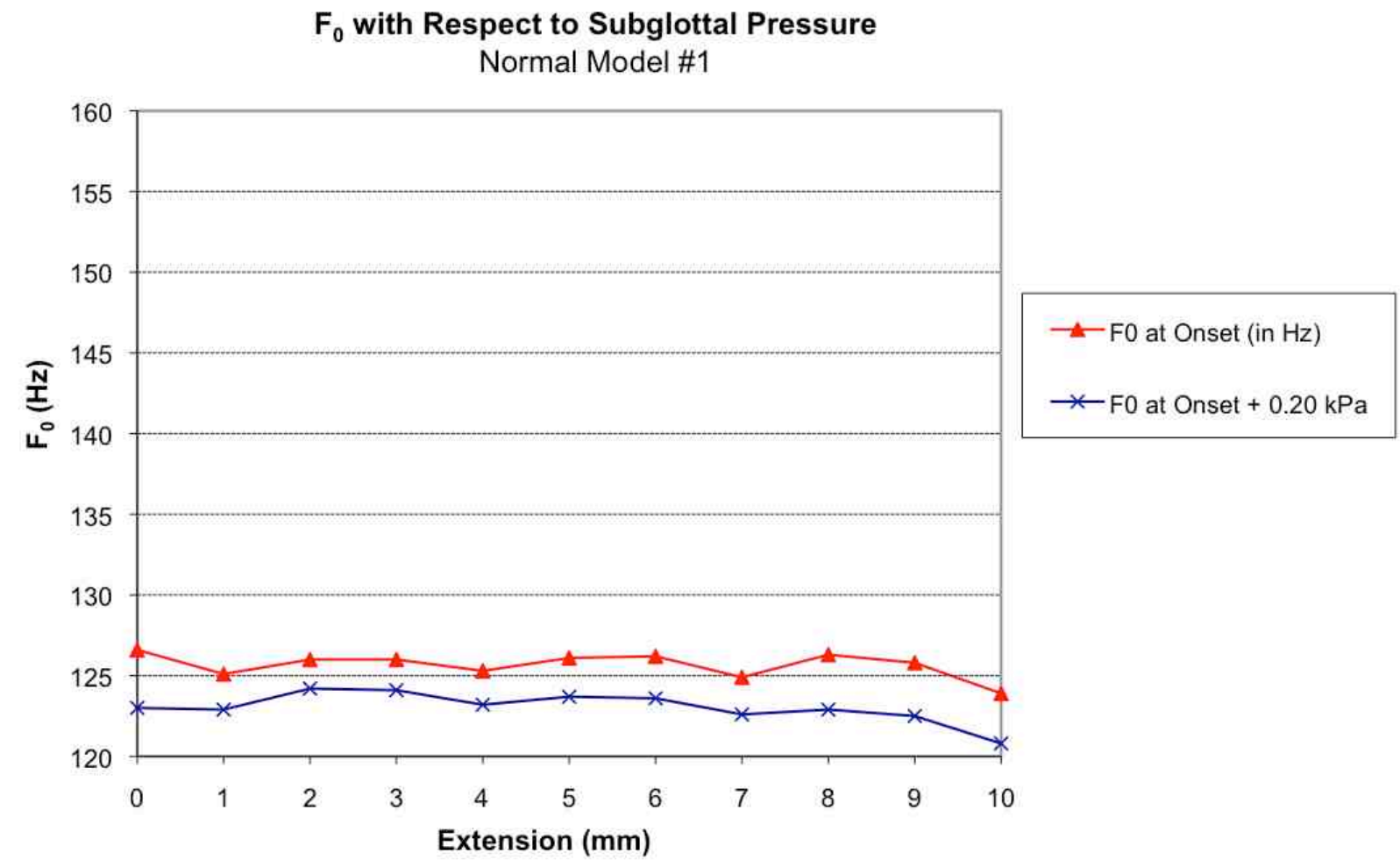

Figure 37. $\mathrm{F}_{0}$ response for Normal Model \#1 at onset pressure and at $0.20 \mathrm{kPa}$ above onset. 


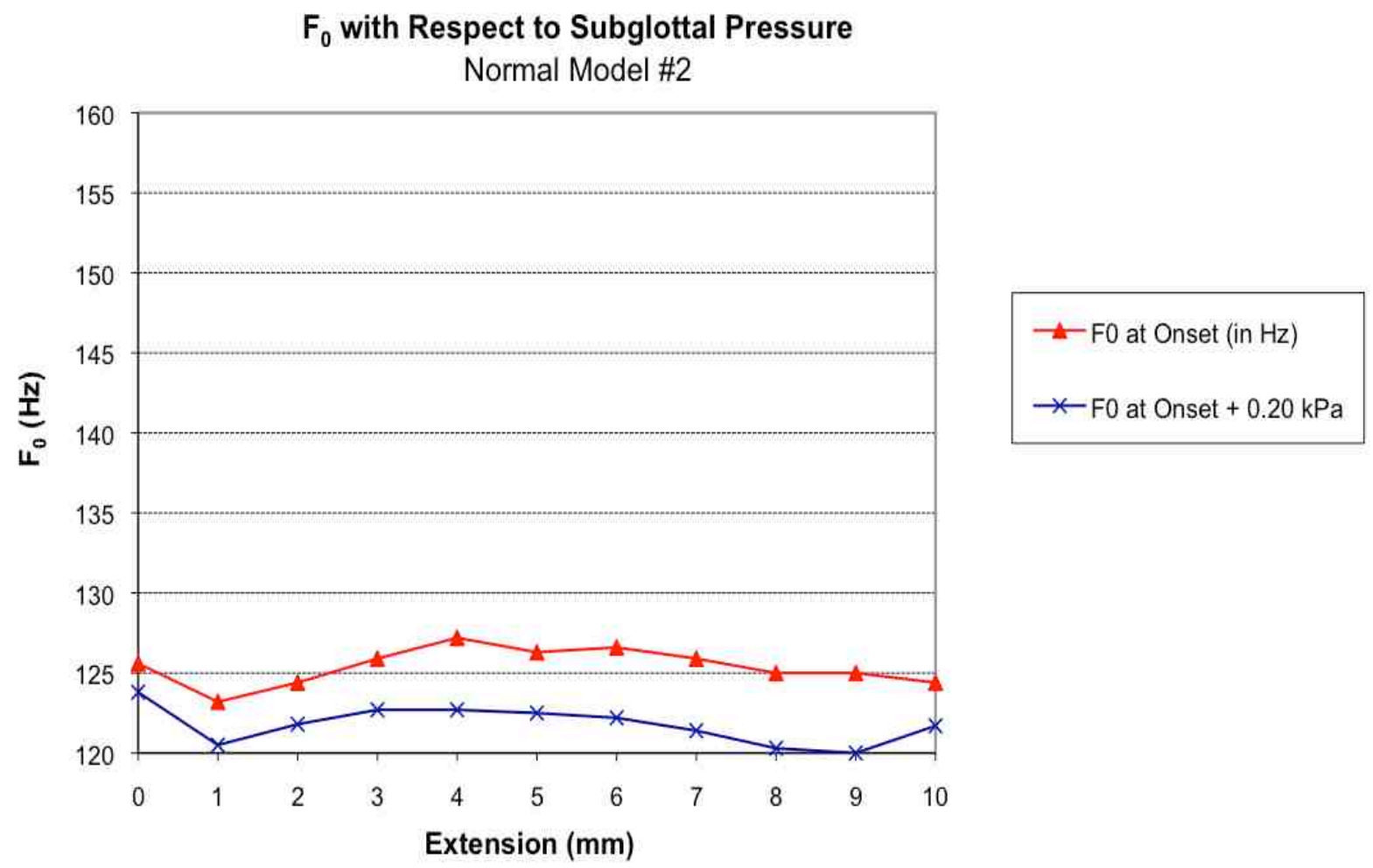

Figure $38 . \mathrm{F}_{0}$ response for Normal Model \#2 at onset pressure and at $0.20 \mathrm{kPa}$ above onset. 


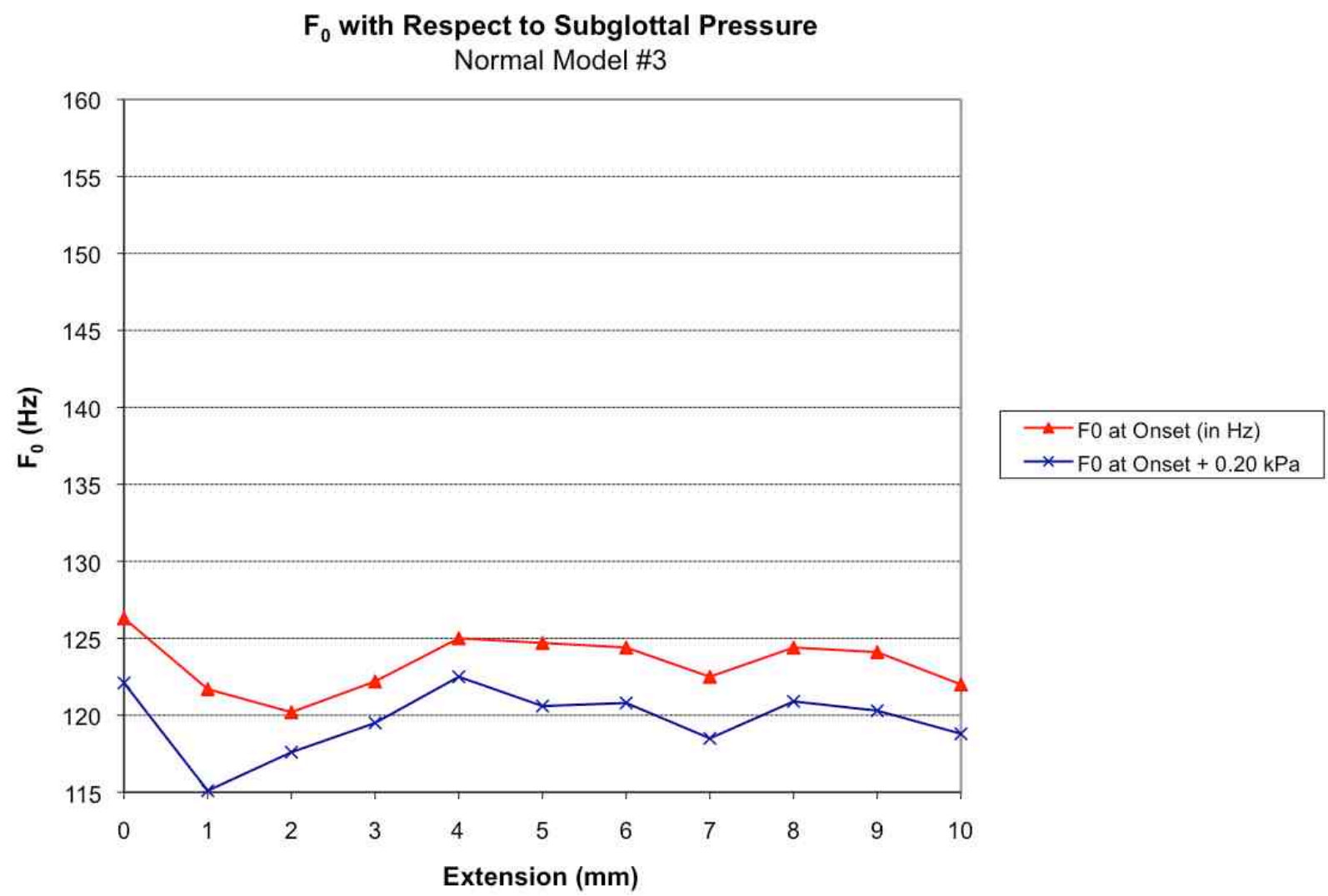

Figure 39. $\mathrm{F}_{0}$ response for Normal Model \#3 at onset pressure and at $0.20 \mathrm{kPa}$ above onset. 


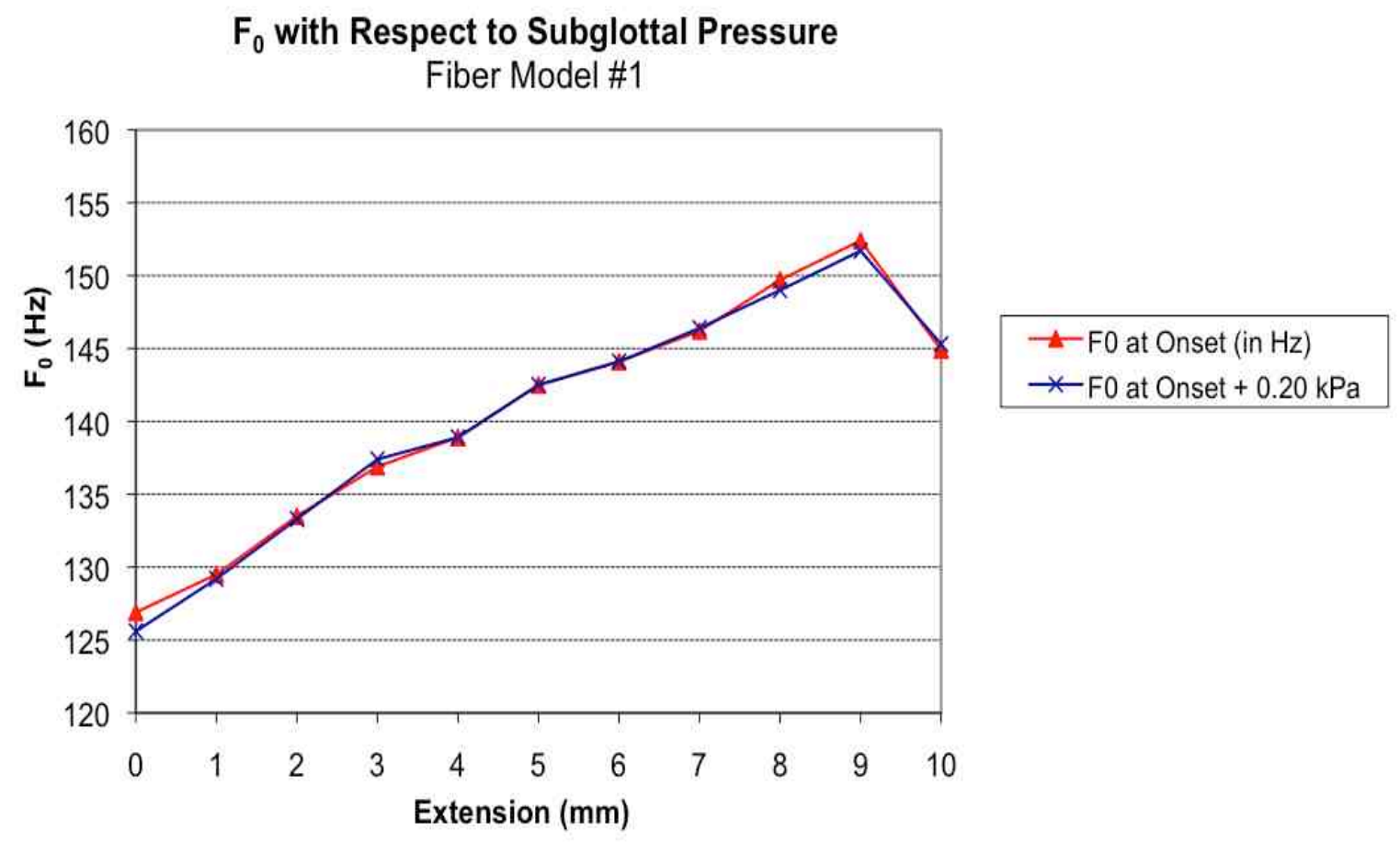

Figure 40. $\mathrm{F}_{0}$ response for Fiber Model \#1 at onset pressure and at $0.20 \mathrm{kPa}$ above onset. 


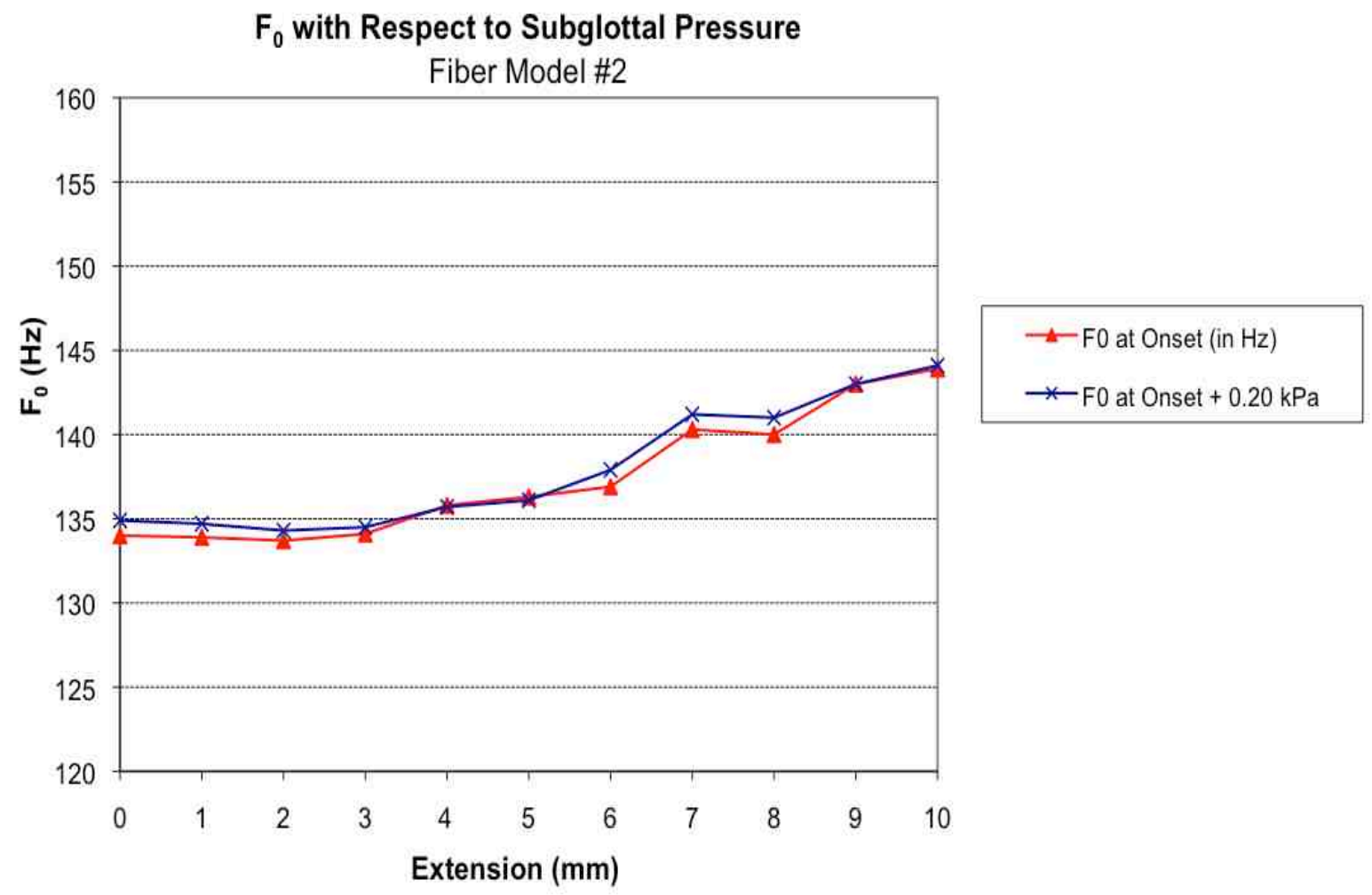

Figure 41. $\mathrm{F}_{0}$ response for Fiber Model \#2 at onset pressure and at $0.20 \mathrm{kPa}$ above onset. 


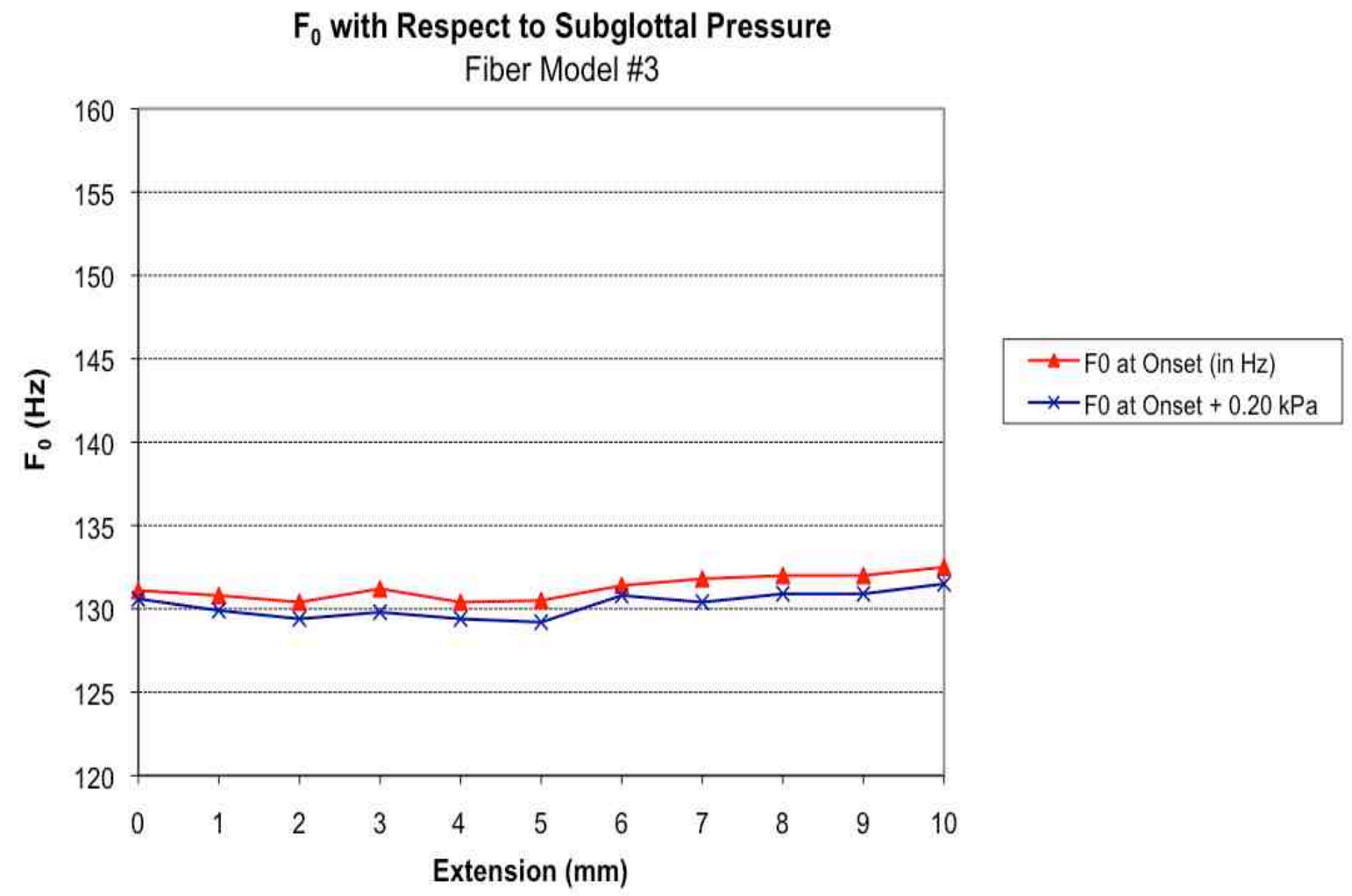

Figure 42. $\mathrm{F}_{0}$ response for Fiber Model \#3 at onset pressure and at $0.20 \mathrm{kPa}$ above onset. 


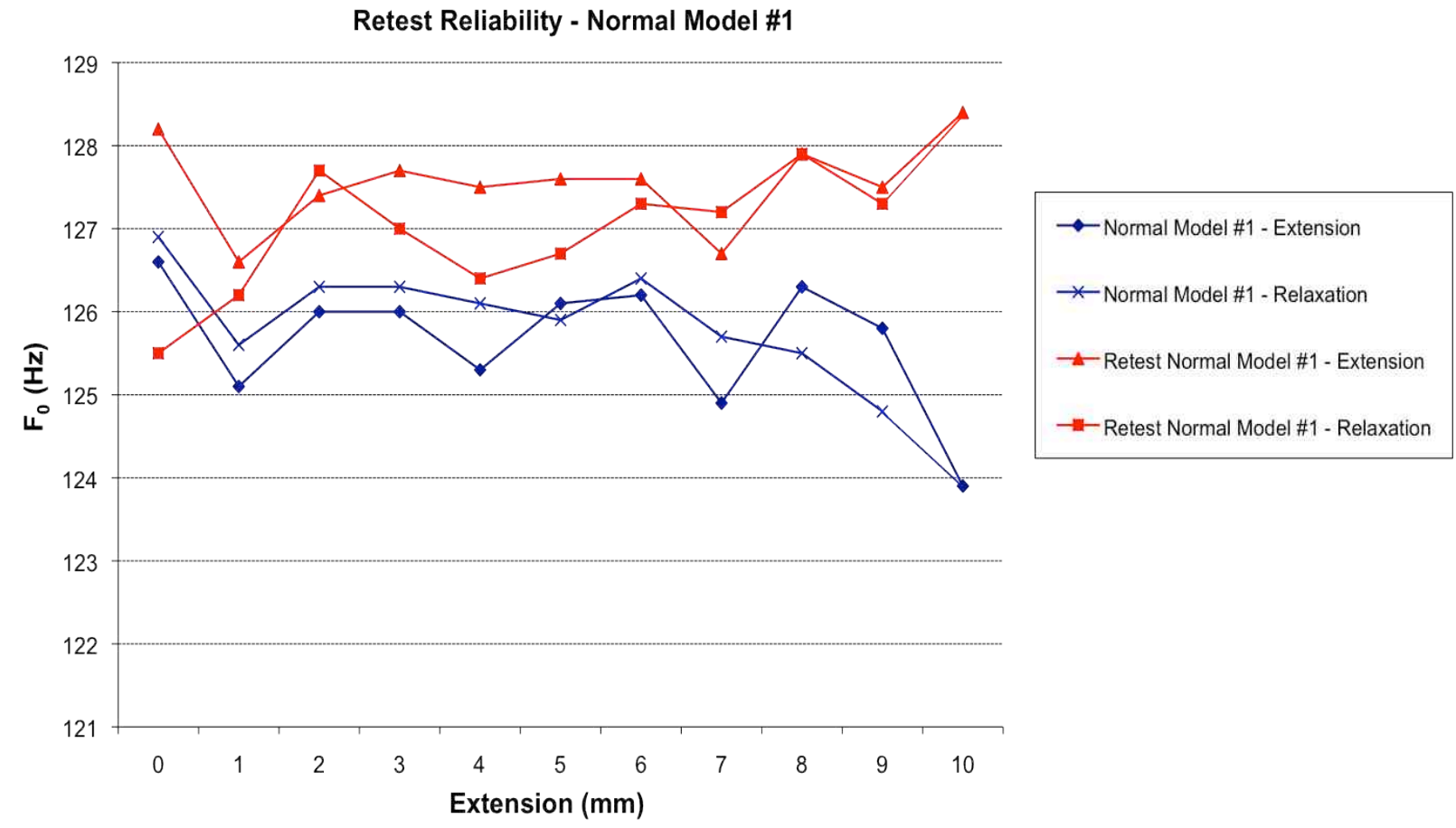

Figure 43. Frequency response for Normal Model \#1. The blue line represents the original set of data collected for extension and relaxation. The red line shows the same extension and relaxation data taken 24 hours later. 


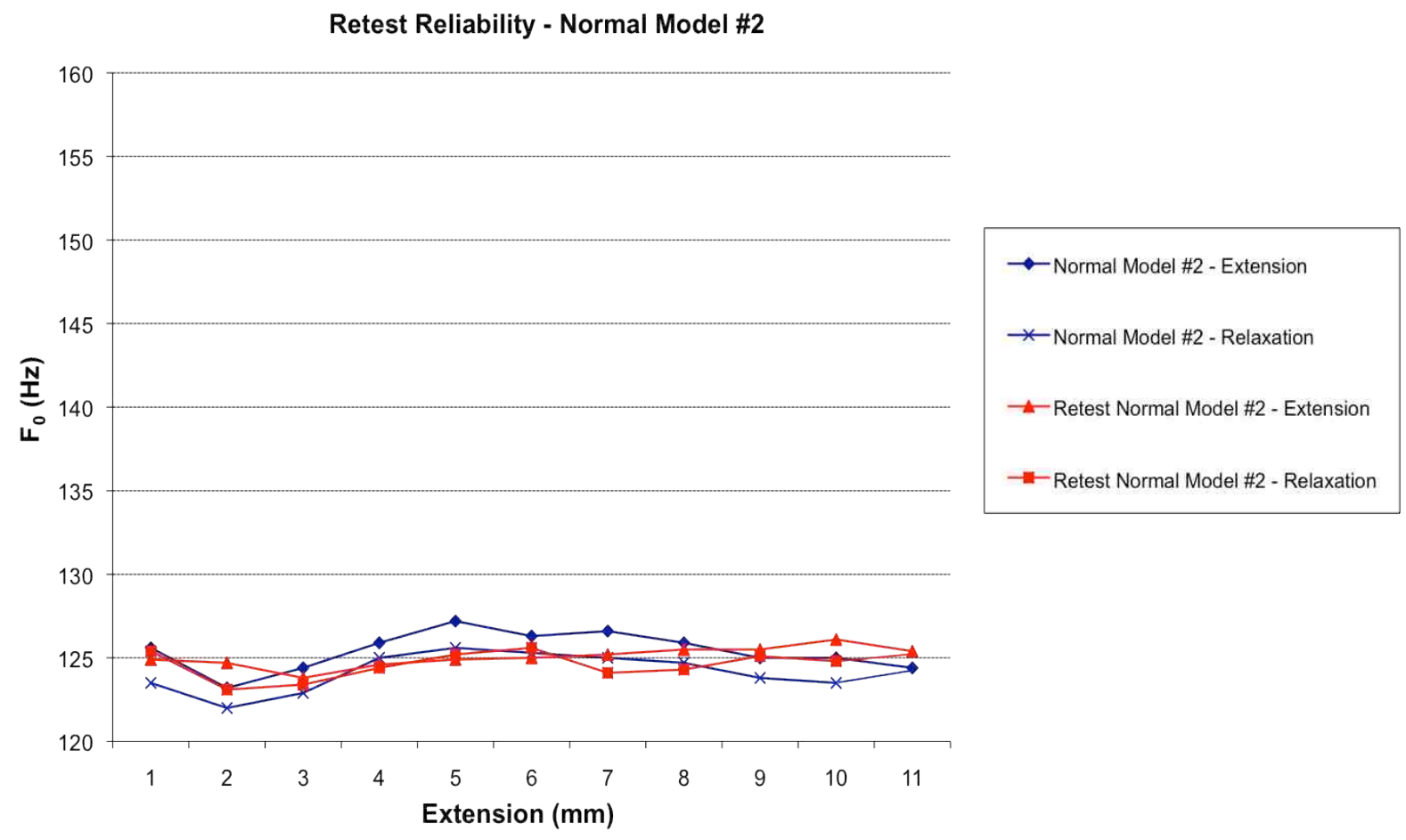

Figure 44. Frequency response for Normal Model \#2. The blue line represents the original set of data collected for extension and relaxation. The red line shows the same extension and relaxation data taken 24 hours later. 


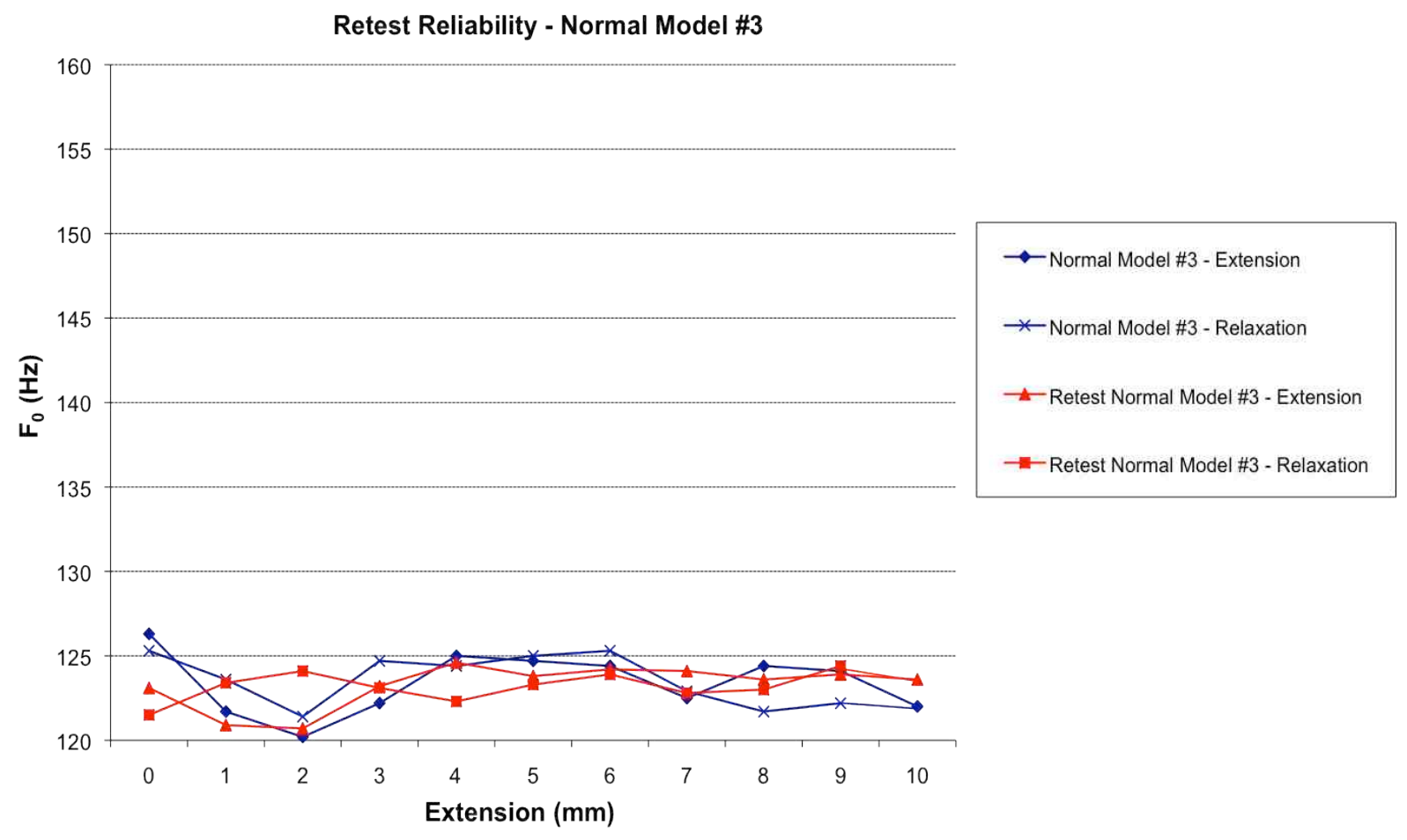

Figure 45. Frequency response for Normal Model \#3. The blue line represents the original set of data collected for extension and relaxation. The red line shows the same extension and relaxation data taken 24 hours later. 


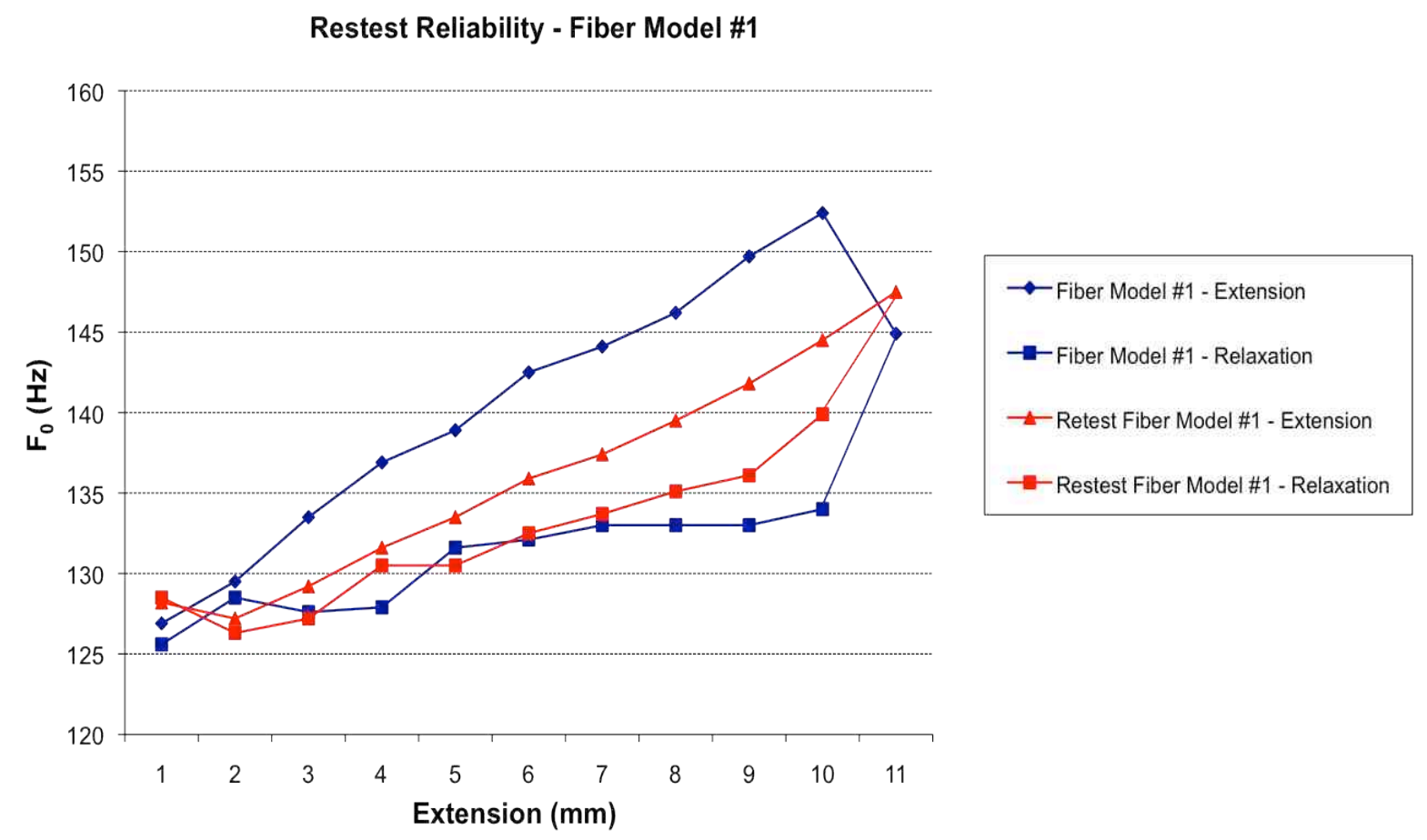

Figure 46. Frequency response for Fiber Model \#1. The blue line represents the original set of data collected for extension and relaxation. The red line shows the same extension and relaxation data taken 24 hours later. 


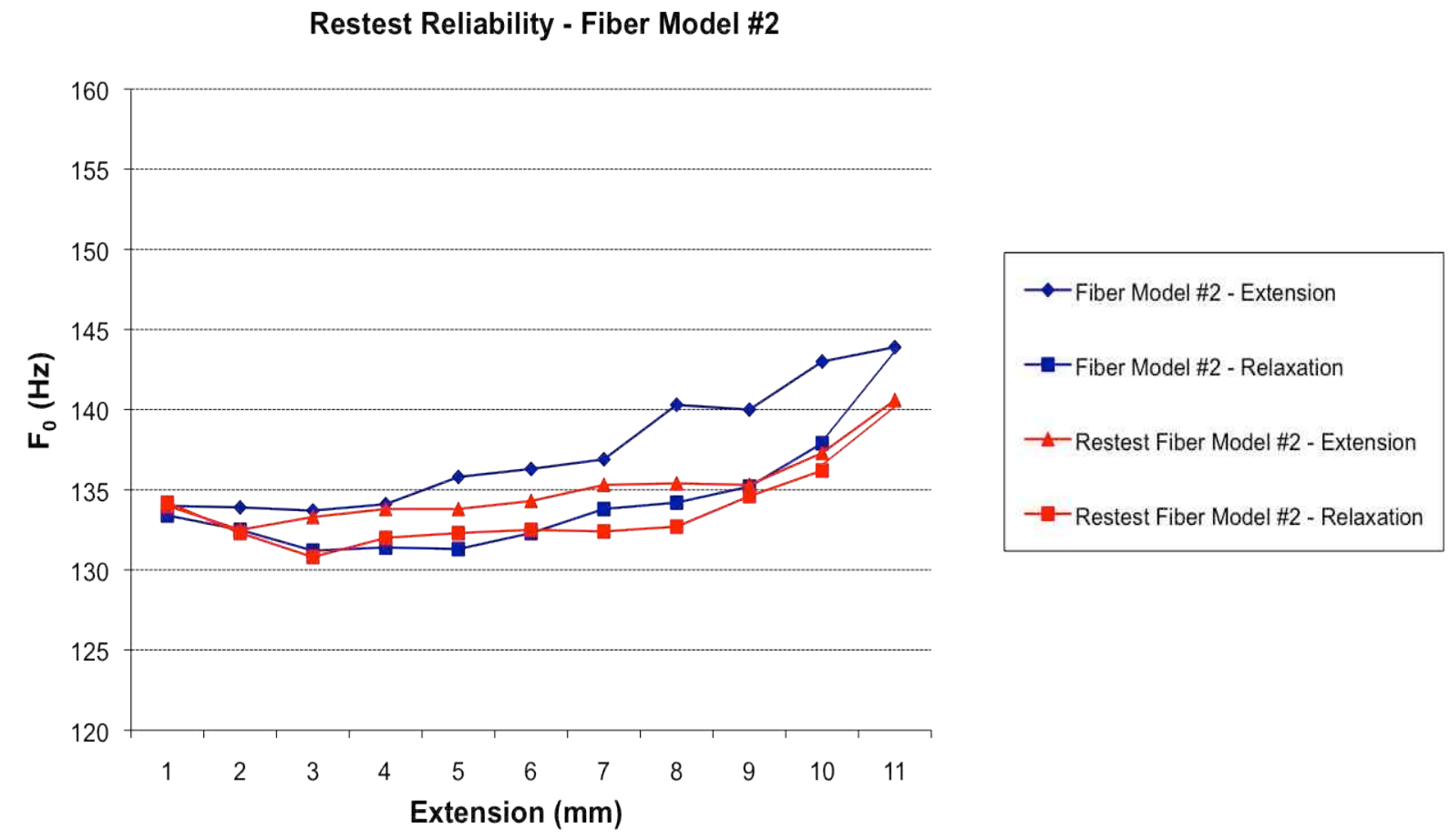

Figure 47. Frequency response for Fiber Model \#2. The blue line represents the original set of data collected for extension and relaxation. The red line shows the same extension and relaxation data taken 24 hours later. 


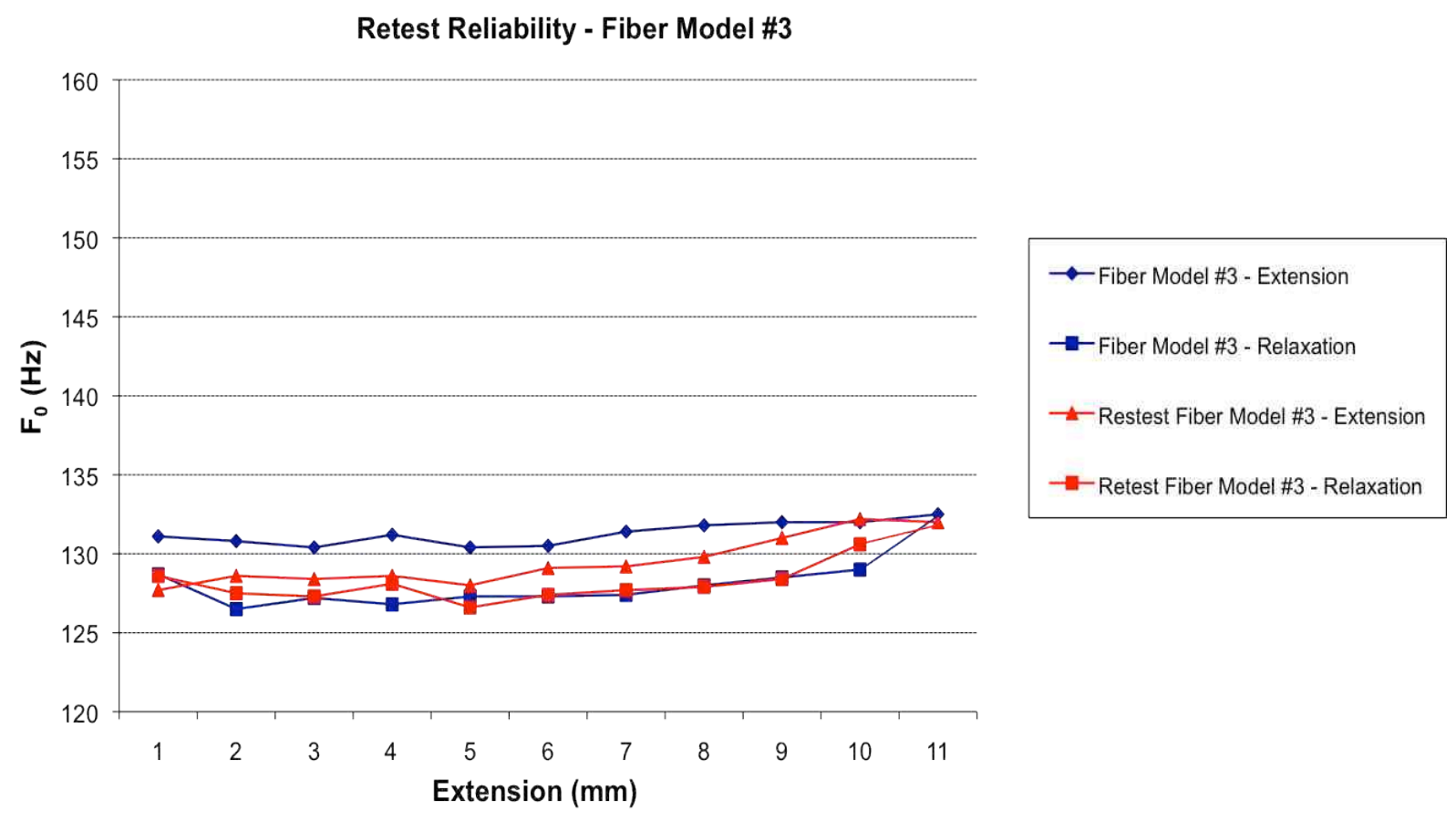

Figure 48. Frequency response for Fiber Model \#3. The blue line represents the original set of data collected for extension and relaxation. The red line shows the same extension and relaxation data taken twenty-four hours later. 
the frequency response was not quite as significant during the retest as it was during the original set of testing.

\section{Discussion}

As described and illustrated above, there were many differences between the responses of the linear and nonlinear models used in this study. The difference in fundamental frequency response was predicted due the effect of linear vs. nonlinear stress-strain properties on vocal fold tension, and thus the frequency of vibration. These predicted differences were observed during this study, with very little change in $\mathrm{F}_{0}$ with increases in length for the normal silicone models and with significant increases in $\mathrm{F}_{0}$ with increases in length for two out of the three fiber models tested. These frequency results for nonlinear vocal folds were much more representative of true human vocal fold response than those obtained with linear vocal fold models. Few studies have quantified the effect of the vocal folds' nonlinear tissue properties on frequency response while excluding the effect of the thyroarytenoid muscle. However, it has been noted in previous studies that vocal fold elongation does correspond to increasing frequency (Gray et al., 2000; Hollien, 1960; Hollien \& Moore, 1960). This was not seen in the linear vocal fold models, but was seen to some extent with nonlinear models.

In addition, the $\mathrm{P}_{\text {on }}$ for differing vocal fold lengths were greatly impacted by linear vs. nonlinear properties. The normal, linear vocal folds demonstrated a progressive decrease in onset pressure for increasing lengths while the nonlinear vocal fold models showed a steadier and somewhat higher average onset pressure for all lengths tested. Previous studies suggest that, in the human vocal folds, PTP increases with increasing $F_{0}$ (Solomon et al., 2007). It is unclear why this pattern was not seen in the silicone models, especially in the nonlinear models. However, the steadier and higher $\mathrm{P}_{\text {on }}$ seen in the nonlinear models may be due to increased 
stiffness caused by the presence of fibers within the cover layer, even without extension of the tensioning plates or increased vocal fold length.

Both linear and nonlinear vocal folds demonstrated evidence of hysteresis during the relaxation data collection. This hysteresis effect has likewise been observed with human vocal fold tissues and excised larynges (Chan, Fu, Young, \& Tirunagari, 2007; Gray et al., 2000). In this regard, both linear and nonlinear models accurately represented the human voice.

Retest results demonstrated a more reliable and repeatable frequency response from the linear silicone models than the fiber models. This is most likely due to the fact that the fibers embedded in the nonlinear models did not hold up well under the $10 \mathrm{~mm}$ stretch. It is possible that the fibers began to pull out of the glue or even break after a single set of testing.

One rather unexpected result was that the frequency responses of the nonlinear vocal folds were not consistent across the three models tested. There are several possible explanations for this. One is that each model may have contained more or fewer fibers than the others, since it was difficult to control the exact number of strands contained in each, especially with the acrylic fibers. This became apparent upon examination in that Fiber Model \#3 contained visibly fewer fibers than Fiber Models \#1 and 2.

Another factor that may have come into play relates to how well the glue was able to cure and hold together under the stretching forces. Several models used during preliminary testing came unglued due to a poorly manufactured tube of glue and/or to the presence of air bubbles in the glue, which were often introduced during the gluing process. This occasional poor adhesion sometimes caused the fibers themselves, or even the actual vocal folds, to come unglued from the plates, resulting in reduced tension and a poor frequency response. Many of these problems 
were resolved prior to data collection, but it is possible that some of these factors may have come into play during testing as well.

In addition, the amount of pre-strain placed on the fibers during fiber layer construction was not closely monitored. This also may have influenced the amount of tension present in each set of vocal folds used for testing.

Onset pressure readings were also difficult to monitor. Many factors could have influenced these readings as well. One such factor has to do with the design of the four-plate tensioning system. Because of difficulties maintaining glottal closure with a two-plate tensioning system, a four-plate tensioning system was used in this study, as previously described. This allowed for glottal closure to be maintained, even at higher levels of extension. However, it was difficult to monitor how closely the vocal folds were in contact each time the vocal folds were re-adducted, which was done at almost every $1 \mathrm{~mm}$ interval. It is possible then that some pressure readings were taken with the vocal folds pressed tightly together while others were taken with the vocal folds barely touching at midline.

It is also interesting to note that the vibration pattern appeared somewhat different between linear and nonlinear models. As can be seen in Figures 26 and 27, normal models appeared to have a more significant inferior-superior motion than the nonlinear models. This has been one drawback of linear, silicone vocal fold models to date since human vocal folds demonstrate a stronger surface or mucosal wave and less inferior-superior motion. Nonlinear models did appear to have a reduced inferior-superior motion and a greater lateral motion based on the high-speed images obtained during testing. This variable was not investigated further or quantified during this study, but it appears from the images obtained that the nonlinear properties 
of the vocal folds may have had a significant effect on vibration pattern and inferior-superior motion of the vocal folds.

Further research is currently needed to more accurately monitor and control the variables discussed so that a clearer comparison can be made between vocal folds with linear and nonlinear stress-strain properties, especially with respect to $\mathrm{F}_{0}$ response and $\mathrm{P}_{\text {on }}$ or PTP. Research also needs to be done to quantify the effects of active tensioning within the human vocal folds, taking into account antagonistic thyroarytenoid and cricothyroid muscle activation, and its impact on $\mathrm{F}_{0}$ response and PTP.

This present study gives a good foundation for future voice research using nonlinear silicone vocal fold models and gives evidence that the vocal folds' nonlinear tissue properties play a crucial, though not exclusive, role in $\mathrm{F}_{0}$ control of the human voice. 


\section{References}

Baer, T. (1981). Observation of vocal fold vibration: Measurement of excised larynges. In K. N. Stevens \& M. Hirano (Eds.), Vocal fold physiology (pp. 119-133). Tokyo: University of Tokyo Press.

Case, J. L. (2002). Clinical management of voice disorders (4th ed.). Austin, TX: ProEd.

Chan, R. W., Fu, M., Young, L., \& Tirunagari, N. (2007). Relative contributions of collagen and elastin to elasticity of the vocal fold under tension. Annals of Biomedical Engineering, 35(8), 1471-1483. doi: 10.1007/s10439-007-9314-х

Chan, R. W., Titze, I. R., \& Titze, M. R. (1997). Further studies of phonation threshold pressure in a physical model of the vocal fold mucosa. The Journal of the Acoustical Society of America, 101(6), 3722-3727. doi: 10.1121/1.418331

Cleveland, T., \& Sundberg, J. (1988). Acoustic analysis of three male voices of different quality. Paper presented at the Stockholm Music Acoustics Conference, Stockholm: Royal Swedish Academy of Music.

Dollinger, M., \& Berry, D. A. (2006). Computation of the three-dimensional medial surface dynamics of the vocal folds. Journal of Biomechanics, 39(2), 369-374. doi: 10.1016/j.jbiomech.2004.11.026

Drechsel, J. S., \& Thomson, S. L. (2008). Influence of supraglottal structures on the glottal jet exiting a two-layer synthetic, self-oscillating vocal fold model. The Journal of the Acoustical Society of America, 123(6), 4434-4445. doi: 10.1121/1.2897040

Finkelhor, B. K., Titze, I. R., \& Durham, P. L. (1988). The effect of viscosity changes in the vocal folds on range of oscillation. Journal of Voice, 1(4), 320-325. doi: 10.1016/S08921997(88)80005-5 
Gramming, P. (1988). The phonetogram: An experimental and clinical study. Dissertation, University of Lund, Malmö, Sweden.

Gray, S. D., Alipour, F., Titze, I. R., \& Hammond, T. H. (2000). Biomechanical and histologic observations of vocal fold fibrous proteins. Annals of Otology, Rhinology, \& Laryngology, 109(1), 77-85.

Gray, S. D., Hirano, M., \& Sato, K. (1993). Molecular and cellular structure of vocal fold tissue. In I. R. Titze (Ed.), Vocal fold physiology: frontiers in basic science (pp. 1-36). San Diego, CA: Singular Publishing Group.

Hirano, M., \& Kakita, Y. (1985). Cover-body theory of vocal fold vibration. In R. G. Daniloff (Ed.), Speech science: recent advances (pp. 1-46). San Diego, CA: College-Hill Press.

Hirano, M., Kurita, S., \& Nakashima, T. (1981). Structure of the vocal folds. In K. N. Stevens \& M. Hirano (Eds.), Vocal fold physiology (pp. 33-43). Tokyo: University of Tokyo Press.

Hollien, H. (1960). Vocal pitch variation related to changes in vocal fold length. Journal of Speech and Hearing Research, 3(2), 150-156.

Hollien, H., \& Moore, G. P. (1960). Measurements of the vocal folds during changes in pitch. Journal of Speech and Hearing Research, 3(2), 157-165.

Hsiao, T. Y., Liu, C. M., Luschei, E. S., \& Titze, I. R. (2001). The effect of cricothyroid muscle action on the relation between subglottal pressure and fundamental frequency in an in vivo canine model. Journal of Voice, 15(2), 187-193. doi: 10.1016/S08921997(01)00020-0

Jiang, J. J., Chang, C. I., Raviv, J. R., Gupta, S., Banzali, F. M., \& Hanson, D. G. (2000). Quantitative study of mucosal wave via videokymography in canine larynges. The Laryngoscope, 1000(9), 1567-1573. doi: 10.1097/00005537-200009000-00032 
Jiang, J. J., \& Titze, I. R. (1993). A methadological study of hemilaryngeal phonation. The Laryngoscope, 103, 872-882. doi: 10.1288/00005537-199308000-00008

Lieberman, P. (1968). Vocal chord motion in man. Annals of the New York Academy of Science, 155(1), 28-38. doi: 10.1111/j.1749-6632.1968.tb56746.x

Lofqvist, A., Baer, T., McGarr, N. S., \& Story, R. S. (1989). The cricothyroid muscle in voicing control. The Journal of the Acoustical Society of America, 85(3), 1314-1321. doi: $10.1121 / 1.397462$

Martin, F. N., \& Clark, J. G. (2006). Introduction to audiology (9th ed.). Boston: Pearson Education.

Pickup, B. A., \& Thomson, S. L. (2009). Influence of asymmetric stiffness on the structural and aerodynamic response of synthetic vocal fold models. Journal of Biomechanics, 42, 2219-2225.

Plant, R. L., Freed, G. L., \& Plant, R. E. (2004). Direct measurement of onset and offset phonation threshold pressure in normal subjects. The Journal of the Acoustical Society of America, 116(6), 3640-3646. doi: 10.1121/1.1812309

Riede, T., Tokuda, I. T., Munger, J. B., \& Thomson, S. L. (2008). Mammalian laryngeal air sacs add variability to the vocal tract impedence: Physical and computational modeling. The Journal of the Acoustical Society of America, 124(1), 634-647. doi: 10.1121/1.2924125

Rubin, H. J. (1960a). Further observations on the neurochronaxic theory of voice production. Archives of Otolaryngology, 72.

Rubin, H. J. (1960b). The neurochronaxic theory of voice production--A refutation. Archives of Otolaryngology, 71. 
Saito, S., Fukuda, H., Isogai, Y., \& Ono, H. (1981). X-ray stroboscopy. In K. N. Stevens \& M. Hirano (Eds.), Vocal fold physiology (pp. 95-106). Tokyo: University of Tokyo Press.

Scherer, R. C., Shinwari, D., De Witt, K. J., Zhang, C., Kucinschi, B. R., \& Afjeh, A. A. (2001). Intraglottal pressure profiles for a symmetric and oblique glottis with a divergence angle of 10 degrees. The Journal of the Acoustical Society of America, 109(4), 1616-1630. doi: $10.1121 / 1.1333420$

Scherer, R. C., Titze, I. R., \& Curtis, J. F. (1983). Pressure-flow relationships in two models of the larynx having rectangular glottal shapes. The Journal of the Acoustical Society of America, 73(2), 668-676. doi: 10.1121/1.388959

Seikel, J., King, D. W., \& Drumright, D. G. (2005). Anatomy \& physiology for speech, language, and hearing (3rd ed.). Clifton Park, NY: Thomson Delmar Learning.

Solomon, N. P., Ramanathan, P., \& Makashay, M. J. (2007). Phonation threshold pressure across pitch and range: Preliminary test of a model. Journal of Voice, 21(5), 541-550. doi: 10.1016/j.jvoice.2006.04.002

Strong, W. J., \& Plitnik, G. R. (1992). Music Speech Audio. Provo, U.T.: Soundprint.

Thomson, S. L., Mongeau, L., \& Frankel, S. H. (2005). Aerodynamic transfer of energy to the vocal folds. The Journal of the Acoustical Society of America, $118(3 \mathrm{Pt}$ 1), 1689-1700. doi: $10.1121 / 1.2000787$

Titze, I. R. (1980). Comments on the myoelastic-aerodynamic theory of phonation. Journal of Speech and Hearing Research, 23, 495-510.

Titze, I. R. (1989). On the relation between subglottal pressure and fundamental frequency in phonation. The Journal of the Acoustical Society of America, 85(2), 901-906. doi: $10.1121 / 1.397562$ 
Titze, I. R. (1992). Phonation threshold pressure: a missing link in glottal aerodynamics. The Journal of the Acoustical Society of America, 91(5), 2926-2935. doi: 10.1121/1.402928

Titze, I. R. (1994). Principles of voice production. Englewood Cliffs, N.J.: Prentice Hall.

Titze, I. R., Schmidt, S. S., \& Titze, M. R. (1995). Phonation threshold pressure in a physical model of the vocal fold mucosa. The Journal of the Acoustical Society of America, 97(5 Pt 1), 3080-3084. doi: 10.1121/1.411870

van den Berg, J. (1968). Sound production in isolated human larynges. Annals of the New York Academy of Science, 155(1), 18-27. doi: 10.1111/j.1749-6632.1968.tb56745.x

Verdolini-Marston, K., Titze, I. R., \& Druker, D. G. (1990). Changes in phonation threshold pressure with induced conditions of hydration. Journal of Voice, 4(2), 142-151. doi: 10.1016/S0892-1997(05)80139-0

Zemlin, W. R. (1998). Speech and hearing science: Anatomy and physiology (4th ed.). Boston Allyn and Bacon.

Zhang, Z. (2009). Characteristics of phonation onset in a two-layer vocal fold model. Journal of the Acoustical Society of America, 125(2), 1091-1102. doi: 10.1121/1.3050285

Zhang, Z., Neubauer, J., \& Berry, D. A. (2006a). Aerodynamically and acoustically driven modes of vibration in a physical model of the vocal folds. The Journal of the Acoustical Society of America, 120(5 Pt 1), 2841-2849. doi: 10.1121/1.2354025

Zhang, Z., Neubauer, J., \& Berry, D. A. (2006b). The influence of subglottal acoustics on laboratory models of phonation. The Journal of the Acoustical Society of America, 120(3), 1558-1569. doi: 10.1121/1.2225682 